\title{
Revisión / Review \\ Broad-spectrum survey of medicinal plants as a potential source of anticancer agents
}

[Estudio de amplio espectro de plantas medicinales como fuente potencial de agentes contra el cáncer]

\author{
K. Saranya ${ }^{1}$, V. Manivasagan ${ }^{1}$, K. Gopi ${ }^{1} \&$ K. Karthik ${ }^{2}$ \\ ${ }^{1}$ Department of Biotechnology, Adhiyamaan College of Engineering (Autonomous), Hosur 635109, Tamil Nadu, India \\ ${ }^{2}$ Departments of Biotechnology, Nadar Mahajana Sangam S. Vellaichamy Nadar College (Autonomous), Madurai 625019, Tamil Nadu, India
}

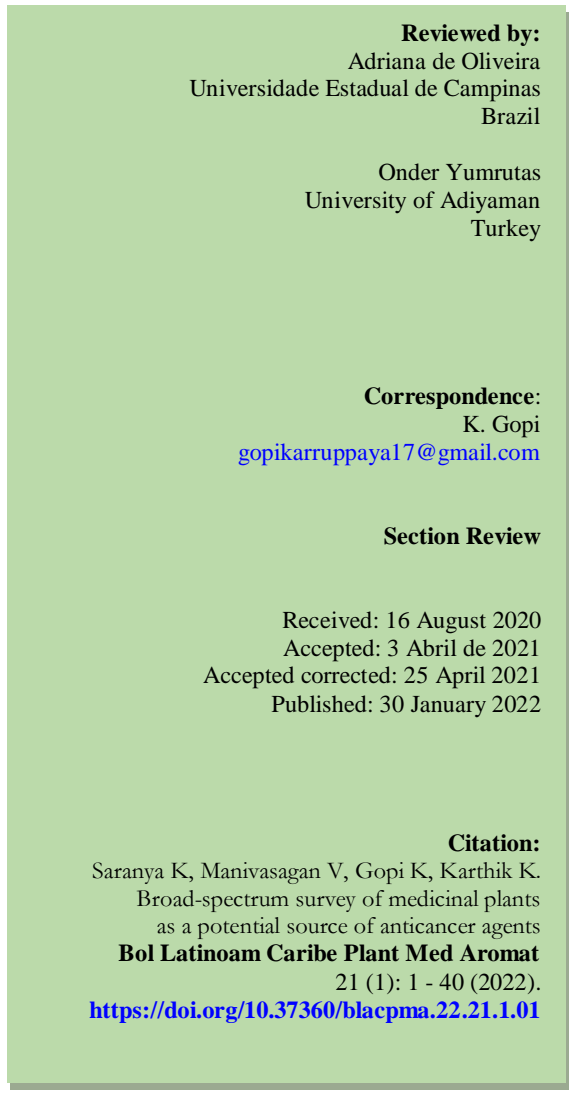

\begin{abstract}
Cancer is an abnormal and uncontrolled growth of cells that spreads through cell division. There are different types of medicines available to treat cancers, but no drug is found to be fully effective and safe for humans. The major problem involved in the cancer treatments is the toxicity of the established drug and their side effects. Medicinal plants are used as folk medicines in Asian and African populations for thousands of years. $60 \%$ of the drugs for treating cancer are derived from plants. More than 3000 plants have anticancer activity. The present review aims at the study of a broad spectrum survey of plants having anticancer components for different type of cancers. This article consists of 364 medicinal plants and their different parts as potential Source of Anticancer Agents.
\end{abstract}

Keywords: Cancer; Medicinal plants; Anticancer activity; Phytochemicals; Cell lines.

Resumen: El cáncer es un crecimiento anormal y descontrolado de células que se disemina a través de la división celular. Hay diferentes tipos de medicamentos disponibles para tratar el cáncer, pero no se ha encontrado ningún medicamento que sea completamente efectivo y seguro para los seres humanos. El principal problema involucrado en los tratamientos del cáncer es la toxicidad del fármaco establecido y sus efectos secundarios. Las plantas medicinales se utilizan como medicinas populares en poblaciones asiáticas y africanas durante miles de años. El $60 \%$ de los medicamentos para el tratamiento del cáncer se derivan de plantas. Más de 3000 plantas tienen actividad anticancerígena. La presente revisión tiene como objetivo el estudio de un estudio de amplio espectro de plantas que tienen componentes anticancerígenos para diferentes tipos de cánceres. Este artículo consta de 364 plantas medicinales y sus diferentes partes como fuente potencial de agentes anticancerígenos.

Palabras clave: Cáncer; Plantas medicinales; Actividad anticancerígena; Fitoquímicos; Líneas celulares. 


\section{INTRODUCTION}

Cancer is the abnormal and uncontrolled growth of cells that spreads through cell division. Cancer cells spread to other tissues through body fluids and destroy normal cells present in the other parts of the body. These cells are generated due to the imbalance of the body and by correcting this imbalance; the cancer can be treated (Prakash et al., 2013). Cancer begins with mutations in DNA, which instructs the cells how to grow and divide. Normal cells in the human body have the ability to repair the mutations in their DNA, but the mutation which is not repaired and causing the cells to grow becomes cancerous (Krishnamurthi, 2000). Every year, millions of people are diagnosed with cancer. Cancer is the second most cause of death in the world, and 9.6 million deaths in 2018. About 1 in 6 deaths in the world occur due to cancer. According to the American Cancer Society, deaths arising from cancer constitute $2-3 \%$ of the annual deaths recorded worldwide. Thus, cancer kills about 3500 million people annually all over the world (WHO, 2018).

Lung cancer is the most common cause of cancer in the world with 2,093,876 new cases and $1,761,007$ deaths. Breast cancer is the most common type of cancer in women with 2,088,849 new cases and 626,679 deaths. Prostate cancer is the second most common cause of cancer in the world with 1,276,106 new cases and 358,989 deaths (Siegel et al., 2018). The different type of cancer that affecting the humans and most common effects of all the type of cancers affect the digestive tract. It is very difficult to find the specific cause of cancer. However, tobacco use, alcohol consumption, environmental pollutants, infectious agents, high body mass index (BMI), low fruit and vegetable intake, lack of physical activity, and lifestyles are some commonly known reasons responsible for this disease. Environmental factor that contributes to the cancer deaths includes radiation, infection, heredity, stress and environmental pollutants; Tobacco use is the most important risk factor for cancer and is responsible for approximately $22 \%$ of cancer deaths and smoking causes $90 \%$ of lung cancer (GBD, 2016). It also causes kidney, stomach, pancreas, larynx, and bladder cancer. Physical inactivity, obesity and diet relate to $30-35 \%$ of cancer deaths (Kuper et al., 2002). This article provides a comprehensive analysis of plant derived anticancer compounds and their anticancer therapeutic properties of various types of in vitro and in vivo models.

\section{Anticancer medicinal plants}

Medicinal plants place an important role in basis and traditional medicine systems, and it provided an effective and curable remedy for mankind. Medicinal plants have been used as folk medicines in Asian, Chinese and African populations for thousands of years. Herbal medicines have been used and are still used in developing countries as the primary source of medical treatment. Plants have been used in the medicine for their natural antiseptic properties and important drug sources (Garg et al., 2007). Phytochemicals and their derived medicinal components are present in different parts of the plant like flower, flower stigmas, pericarp, sprouts, fruits, seeds, roots, rhizomes, stem, leaf, embryo, bark and it contains phytochemical components like Terpenoids, Flavonoids, Phenols, Saponins, Tannins, Alkaloids, Proteins, and Amino acids, Resins, Oils, Carbohydrates, Steroids and Glycosides, biomolecules and other primary and secondary metabolites. They play significant roles in either inhibiting cancer cell or activating proteins to suppress the growth (Tariq et al., 2017). According to the WHO, more than $80 \%$ of the population in the developing countries is depending on traditional medicine for the treatment of cancer (Merina et al., 2012). According to statistics, $60 \%$ of the drugs used in cancer treatments are derived from plants. The effort of researchers to find anticancer components from plants was launched by the US National Cancer Institute (NCI) in 1957. Today, many of the most useful and curative anticancer drugs are derived from the natural plant products. Since the initiation of NCI program, more than 35,000 plant species had investigated and resulted in the discovery of anticancer drugs. Anticancer compounds have been identified and extracted from medicinal plants for their anticancer properties include Allicin, Apigenin, Berberine, Catechin gallate, Celastrol, Curcumin, Epigallocatechin gallate, Fisetin, Flavopiridol, Gambogicacid, Genistein, Plumbagin, Quercetin, Resveratrol, Silibinin, Taxol, Vinblastine, Vincristine, Combretastatins, Paclitaxel, Camptothecin, Homoharringtonine. Plant derived anticancer agents are highly effective in the treatment of cancer cells. Due to this, there is a high demand of these plants for the production of therapeutically important compounds. There are different types of medicinal plants all over the world, which are being used traditionally for cancer prevention and treatment. Some phytochemicals that are important active constituents of plants have shown in future

Boletín Latinoamericano y del Caribe de Plantas Medicinales y Aromáticas / 2 
cancer management. The medicinal plants and their anticancer activities are mentioned in Table No. 1.

\section{Development of anticancer agents, from plants}

Medicinal plants are the important source of anticancer agents based upon the active phytochemical components present in the plants. Several medicinal plants used as a folk medicine in many countries (Jamshidi-Kia et al., 2018). The main reason for the medicinal plants having the many pharmacological activities, it has a specific active component against the disease. Based on the pharmacological activities the active components are purged from the medicinal plants.

The purification of active phytochemical components forms medicinal plants having the many step chemical and biological process. Flower, flower stigmas, pericarp, sprouts, fruits, seeds, roots, rhizomes, stem, leaf, embryo and bark are the important part of the medicinal plants having anticancer properties. Extraction process was collecting the plant components in the different fractions using solvents. Most of the plant extraction process was using the Soxhlet extraction. Phytochemical analysis was process was identifying the phytochemical components present in the crude plant extract. The structural identification of active phytochemical components and bioactivity of the plant extract fractions using various analytical techniques such as TLC, HPLC, FTIR, Mass spectroscopy and NMR. These analytical techniques were analyzing the quantity and quality of components. Chromatography techniques used for purification of active components based upon the polarity of solvent and active component. Superdex, Sephadex, Silica and many other suitable matrixes can be used for fractionation of active components. Purified phytochemical components examined for preclinical study under in-vitro cancer cell lines and in-vivo animal models for pharmacokinetics, pharmacodynamics, metabolism, Biosafety and side effects. Detailed scheme of selection of medicinal plant, extractions, phytochemical analysis, compound identification, synthesis, preclinical studies and clinical trials of anticancer agent is shown in Figure No. 1.

Figure No. 1

Detailed scheme of selection of medicinal plant, extractions, phytochemical analysis, compound identification, synthesis, preclinical studies and clinical trials of anticancer agent

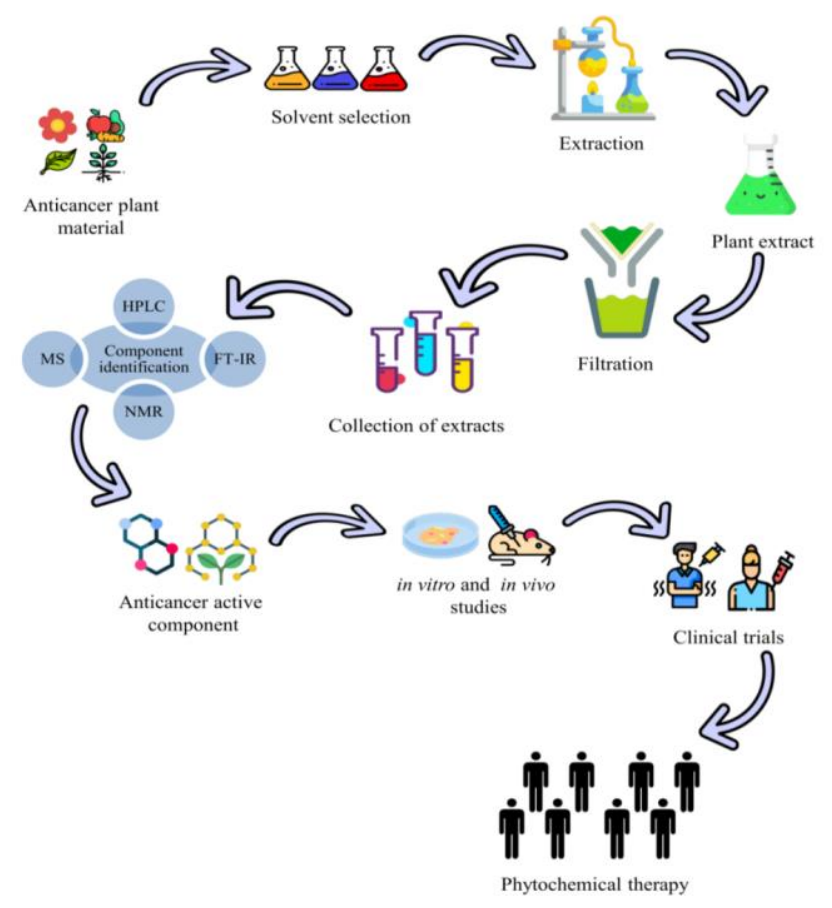

Icons made by Freepik from www.flaticon.com

Boletín Latinoamericano y del Caribe de Plantas Medicinales y Aromáticas / 3 
Table No. 1

The medicinal plants and their anticancer activities

\begin{tabular}{|c|c|c|c|c|c|}
\hline $\begin{array}{l}\text { S.N } \\
\text { o. }\end{array}$ & Plant name & $\begin{array}{l}\text { Plant part } \\
\text { used }\end{array}$ & Anti cancer agents & $\begin{array}{l}\text { Specific cancer } \\
\text { suppressed }\end{array}$ & Reference $s$ \\
\hline 1. & Acacia Cyclops & Pods & Monoterpenoid & breast cancer & Jelassi et al., 2014 \\
\hline 2. & Acacia salicina & Leaves & Flavonoids & leukemia & Chatti et al., 2009 \\
\hline 3. & Achillea cretica & Shoot & Lactone & $\begin{array}{l}\text { breast, ovarian, } \\
\text { colon cancer }\end{array}$ & Hichri et al., 2018 \\
\hline 4. & Acorus calamus & Rhizome & $\alpha$-asarone, $\beta$-asarone & gioblastoma & Das et al., 2019 \\
\hline 5. & Actaea racemosa & Roots & Actein & $\begin{array}{l}\text { liver and breast } \\
\text { cancer }\end{array}$ & Rice et al.,2007 \\
\hline 6. & Actinidia chinensis & Fruit, root & $\begin{array}{l}\text { Polysaccharide known } \\
\text { as ACPS-R }\end{array}$ & $\begin{array}{l}\text { colon cancer, breast } \\
\text { cancer }\end{array}$ & He et al., 2019 \\
\hline 7. & $\begin{array}{l}\text { Aegiceras } \\
\text { corniculatum }\end{array}$ & All parts & Benzoquinones & $\begin{array}{l}\text { gastric, liver cancer, } \\
\text { myeloid leukaemia }\end{array}$ & Li et al., 2020 \\
\hline 8. & Aegle marmelos & Bark & Skimmianine, Lupeol & liver cancer & Mukhija et al., 2015 \\
\hline 9. & Agapanthus africanus & Root & Isoliquiritigenin & breast cancer & $\begin{array}{l}\text { Srinivas \& Afolayan, } \\
2007\end{array}$ \\
\hline 10. & Agave Americana & Leaves & $\begin{array}{l}\text { Steroidal saponin, } \\
\text { alkaloid, coumarin, } \\
\text { isoflavonoid }\end{array}$ & breast cancer & Anajwala et al., 2010 \\
\hline 11. & Ageratum conizoides & Leaves & Kaempferol & $\begin{array}{l}\text { colon, breast, } \\
\text { prostate Cancer, } \\
\text { leukemia }\end{array}$ & Adebayo et al., 2010 \\
\hline 12. & Aglaila foveolata & $\begin{array}{l}\text { Fruits and } \\
\text { twigs }\end{array}$ & Silvestrol & murine leukemia & Kim et al., 2007a \\
\hline 13. & Aglaila sylvestre & Fruit, twings & Silvesterol & $\begin{array}{l}\text { breast cancer, liver } \\
\text { cancer }\end{array}$ & Hwang et al., 2004 \\
\hline 14. & Agrimonia pilosa & Herbs & $\begin{array}{l}\text { Agrimonolide, } \\
\text { flavonoid, triterpene, } \\
\text { tannin and coumarin }\end{array}$ & $\begin{array}{l}\text { cervical cancer, } \\
\text { rhabdomyosarcoma }\end{array}$ & Koshiura et al., 1985 \\
\hline 15. & Agropyron repens & Rhizomes & $\begin{array}{l}\text { Polysaccharide and } \\
\text { mucilage }\end{array}$ & cervical cancer & Sharma et al., 2011 \\
\hline 16. & Ailanthus Altissima & Bark & $\begin{array}{l}\text { Triterpene, tannin, } \\
\text { saponin and quercetin- } \\
\text { 3-glucoside }\end{array}$ & breast cancer & Anderson et al., 1983 \\
\hline 17. & Akebia quinata & Friut & Flavonoid and saponin & liver cancer & Tascilar et al., 2006 \\
\hline 18. & Alium cepa & Flowers & Polyphenols & human cancer cells & Lee et $a l ., 2014$ \\
\hline 19. & Allium sativum & Leaves & $\begin{array}{l}\text { Allylmercaptocysteine } \\
\text { Allicin, allicin alliin, } \\
\text { alliinase }\end{array}$ & $\begin{array}{l}\text { lymphoma, cervix } \\
\text { cancer }\end{array}$ & Karmakar et al., 2011 \\
\hline 20. & Allium wallichii & All parts & $\begin{array}{l}\text { Steroids, terpenoids, } \\
\text { Flavonoids }\end{array}$ & $\begin{array}{l}\text { leukemia, } \\
\text { glioblastoma and } \\
\text { colon cancer }\end{array}$ & Bhandari et al., 2017 \\
\hline 21. & Aloe barbadensis & Leaves & Alexin B, emodin & $\begin{array}{l}\text { leukaemia, stomach } \\
\text { cancer }\end{array}$ & Shalabi et al., 2015 \\
\hline 22. & Aloe ferox & Leaves & $\begin{array}{l}\text { Aloe-emodin, Emodin, } \\
\text { Aloin }\end{array}$ & $\begin{array}{l}\text { carcinoma, } \\
\text { hepatoma cells, skin } \\
\text { cancer }\end{array}$ & Jia et al., 2008 \\
\hline 23. & Aloe vera & Leaves & Alexin B, emodin & leukaemia, stomach & Shalabi et al., 2015 \\
\hline
\end{tabular}

Boletín Latinoamericano y del Caribe de Plantas Medicinales y Aromáticas / 4 


\begin{tabular}{|c|c|c|c|c|c|}
\hline & & & & cancer & \\
\hline 24. & Alpinia galangal & Rhizomes & $\begin{array}{l}\text { Kaempferide, } \\
\text { Pinocembrin }\end{array}$ & $\begin{array}{l}\text { breast cancer, lung } \\
\text { cancer }\end{array}$ & $\begin{array}{l}\text { Samarghandian et al., } \\
2014\end{array}$ \\
\hline 25. & Alstonia scholaris & Root, bark & $\begin{array}{l}\text { O- } \\
\text { methylmacralstonine, } \\
\text { talcarpine, } \\
\text { villalstonine, } \\
\text { pleiocarpamine }\end{array}$ & lung cancer & Monika \&Singh, 2015 \\
\hline 26. & Amoora rohituka & Stem bark & Amooranin & $\begin{array}{l}\text { lymphocytic } \\
\text { leukaemia }\end{array}$ & Chan et al., 2011 \\
\hline 27. & Ananas comosus & Fruit, stem & Bromelain & breast cancer & Chang et al., 2019 \\
\hline 28. & $\begin{array}{l}\text { Andrographis } \\
\text { paniculata }\end{array}$ & Leaves & Andrographolide & liver cancer & Ji et al., 2007 \\
\hline 29. & $\begin{array}{l}\text { Anemarrbena } \\
\text { asphodeloides }\end{array}$ & Root & Benzophenones & $\begin{array}{l}\text { hepatocellular } \\
\text { carcinoma }\end{array}$ & Shoemaker et al., 2005 \\
\hline 30. & Angelica sinensis & Root & N-butylidenephthalide & stomach cancer & Liao et al., 2018 \\
\hline 31. & Annona crassiflora & Leaves & $\begin{array}{l}\text { Caffeic acid, sinapic } \\
\text { acid, rutin }\end{array}$ & $\begin{array}{l}\text { glioma, renal, ovary } \\
\text { cancer }\end{array}$ & Formagio et al., 2015 \\
\hline 32. & Annona coriacea & Seeds & $\begin{array}{l}\text { Ferulic acid, sinapic } \\
\text { acid }\end{array}$ & $\begin{array}{l}\text { glioma, lymphoid } \\
\text { melanoma, lung, } \\
\text { renal, ovary cancer }\end{array}$ & Formagio et al., 2015 \\
\hline 33. & Annona squamosa & Seed & Bullatacin & liver cancer & Biba et al., 2013 \\
\hline 34. & Anthriscus sylvestris & Root & $\begin{array}{l}\text { Podophyllotoxin, } \\
\text { Sylvestris }\end{array}$ & human leukaemia & Jeong et al., 2007 \\
\hline 35. & $\begin{array}{l}\text { Aphanamixis } \\
\text { polystachya }\end{array}$ & Bark & Amooranin & $\begin{array}{l}\text { spleen and liver } \\
\text { cancer }\end{array}$ & $\begin{array}{l}\text { Jagetia \& Venkatesha, } \\
2012\end{array}$ \\
\hline 36. & Apium graveolens & Seed & Apigenin & prostate cancer & $\begin{array}{l}\text { Subhadra Devi et al., } \\
2011\end{array}$ \\
\hline 37. & Arachis hypogaea & Peanut-skin & procyanidin $\mathrm{A} 1$ & leukemia & Al-Snafi , 2014 \\
\hline 38. & Arctium lappa & $\begin{array}{l}\text { Root, bark, } \\
\text { seed }\end{array}$ & Lappaol F & breast cancer & Sun et al., 2014 \\
\hline 39. & Arcangelisia flava & Root, stem & $\begin{array}{l}\text { Protoberberine and 20- } \\
\text { hydroxyecdysone }\end{array}$ & breast cancer & Pratama et al., 2018 \\
\hline 40. & Argemone gracilenta & All parts & $\begin{array}{l}\text { Argemonine and } \\
\text { Berberine }\end{array}$ & $\begin{array}{l}\text { B-cell lymphoma, } \\
\text { leukaemia }\end{array}$ & $\begin{array}{l}\text { Leyva-Peralta et al., } \\
2015\end{array}$ \\
\hline 41. & Argemone mexicana & Leaves & Pancorine, Argenaxine & $\begin{array}{l}\text { gall bladder and } \\
\text { breast cancer }\end{array}$ & $\begin{array}{l}\text { Brahmachari et al., } \\
2013\end{array}$ \\
\hline 42. & Aristolochia contorta & $\begin{array}{l}\text { Root and } \\
\text { fruit }\end{array}$ & $\begin{array}{l}\text { Lysicamine, } \\
\text { oxaaporphine, } \\
\text { aristolochic acid } \\
\end{array}$ & stomach cancer & Akindele et al., 2014 \\
\hline 43. & Aronia melanocarpa & Leaves & Polyphenol & leukemia & Thi \&Hwang, 2018 \\
\hline 44. & Artemisia annиa & All parts & Artemisinin & $\begin{array}{l}\text { liver, breast and } \\
\text { pancreatic cancer }\end{array}$ & Efferth, 2017 \\
\hline 45. & Artemisia argyi & All parts & Isoscopoletin & $\begin{array}{l}\text { lung and colon } \\
\text { cancer }\end{array}$ & McGovern et al., 2010 \\
\hline 46. & Artemisia maritima & All parts & Santonin & $\begin{array}{l}\text { kidney and colon } \\
\text { cancer }\end{array}$ & Qadir et al., 2019 \\
\hline 47. & Artemisia vulgaris & $\begin{array}{l}\text { Flower, } \\
\text { Leaves }\end{array}$ & Borneol & $\begin{array}{l}\text { breast and kidney } \\
\text { cancer }\end{array}$ & Gordanian et al., 2014 \\
\hline
\end{tabular}




\begin{tabular}{|c|c|c|c|c|c|}
\hline 48. & Artocarpus obtusus & Bark & Xanthones & $\begin{array}{l}\text { leukemia, breast } \\
\text { cancer }\end{array}$ & Hashim et al., 2012 \\
\hline 49. & Asclepias curassavica & Leaves & Asclepin, cardenolides & liver cancer & Li et al., 2009 \\
\hline 50. & $\begin{array}{l}\text { Asparagus } \\
\text { cochinchinensis }\end{array}$ & Root & $\begin{array}{l}\text { Spirosteroids, } \\
\text { asparacosins A }\end{array}$ & $\begin{array}{l}\text { hepatocellular } \\
\text { carcinoma }\end{array}$ & Park et al., 2011 \\
\hline 51. & Asparagus officinalis & Leaves & asparagamine $\mathrm{A}$ & lung, colon cancer & $\begin{array}{ll}\text { Bousserouel et al., } \\
2013\end{array}$ \\
\hline 52. & Asparagus racemosus & Root & Shatavarins & $\begin{array}{l}\text { breast, colon, kidney } \\
\text { carcinoma }\end{array}$ & Mitra et al., 2012 \\
\hline 53. & Aster tataricus & All parts & $\begin{array}{l}\text { Triterpene, } \\
\text { monoterpene and } \\
\text { epifriedelanol }\end{array}$ & $\begin{array}{l}\text { head and neck } \\
\text { cancer }\end{array}$ & Wang et al., 2017 \\
\hline 54. & Astragalus gummijera & Leaves & Endotoxin & lung cancer & Wu et al., 2017 \\
\hline 55. & $\begin{array}{l}\text { Astragalus } \\
\text { membranaceus }\end{array}$ & Leaves, root & Swainsonine & $\begin{array}{l}\text { brain tumors, } \\
\text { stomach cancer }\end{array}$ & $\begin{array}{l}\text { William \& } \\
2007\end{array}$ \\
\hline 56. & Azadirachata indica & All parts & $\begin{array}{l}\text { Azadirachtin, } \\
\text { Nimbolide, Gedunin, } \\
\text { Quercetin }\end{array}$ & $\begin{array}{l}\text { cervical, ovarian, } \\
\text { breast cancer }\end{array}$ & Moga et al., 2018 \\
\hline 57. & Bacopa monnieri & Whole plant & $\begin{array}{l}\text { Cucurbitacins, } \\
\text { betulinic acid }\end{array}$ & breast cancer & Mallick et al., 2015a \\
\hline 58. & Bauhinia racemosa & $\begin{array}{l}\text { Bark, } \\
\text { Flowers }\end{array}$ & Kaempferol, quercetin & $\begin{array}{l}\text { Ehrlich ascites } \\
\text { carcinoma }\end{array}$ & Gupta et al., 2004a \\
\hline 59. & Bauhinia variegate & Bark & $\begin{array}{l}\text { Kaempferol } \\
\text { galactoside }\end{array}$ & $\begin{array}{l}\text { breast, lung and } \\
\text { liver cancer }\end{array}$ & Sharma et al., 2019 \\
\hline 60. & Berberis amurensis & Fruit & Berbamine & breast cancer & Ghafourian et al., 2017 \\
\hline 61. & Berberis vulgaris & Roots, bark & Berberine & $\begin{array}{l}\text { breast, liver, colon } \\
\text { cancers }\end{array}$ & Ghafourian et al., 2017 \\
\hline 62. & Betula alba & Bark & Betulinic acid & $\begin{array}{l}\text { thyroid, breast, lung } \\
\text { and colon } \\
\text { carcinoma, }\end{array}$ & Rzeski et al., 2006 \\
\hline 63. & Betula Sp. & Leaves & Betulinic acid & $\begin{array}{l}\text { human melanoma } \\
\text { and leukaemia }\end{array}$ & $\begin{array}{l}\text { Cragg \&Newman, } \\
2005\end{array}$ \\
\hline 64. & Betula utilis & Bark & Betulinic acid, Betulin & Melanomas & Król et al., 2015 \\
\hline 65. & Biophytum sensitivum & Fruits & Amentoflavone & $\begin{array}{l}\text { Dalton's lymphoma } \\
\text { ascites, Ehrlich } \\
\text { ascites carcinoma }\end{array}$ & Oh et al., 2013 \\
\hline 66. & Bleekeria vitensis & Leaves & Elliptinium & $\begin{array}{l}\text { myelogenous } \\
\text { leukaemia and } \\
\text { breast cancer }\end{array}$ & Lauritano et al., 2016 \\
\hline 67. & Blumea balsamifera & Whole plant & Dihydroflavonol & $\begin{array}{l}\text { hepatocellular } \\
\text { carcinoma }\end{array}$ & Pang et al., 2014a \\
\hline 68. & Blumea lanceolaria & Leaves & $\begin{array}{l}\text { Borneol, } \\
\text { caryophyllene }\end{array}$ & lymphoma & Norikura et al., 2008 \\
\hline 69. & Boerhavia diffusa & Root & Punarnavine & $\begin{array}{l}\text { malignant melanoma } \\
\text { cancer }\end{array}$ & Mishra et al., 2014 \\
\hline 70. & Boswellia serrata & Gum & Boswellic acid & prostate cancer & Garg \& Deep, 2015 \\
\hline 71. & Brassica oleraceae & red cabbage & Sulforaphane & epithelial carcinoma & Devi \&Thangam, 2012 \\
\hline 72. & $\begin{array}{l}\text { Broussonetia } \\
\text { Papyrifera } \\
\end{array}$ & $\begin{array}{l}\text { Fruits, } \\
\text { Leaves, bark }\end{array}$ & $\begin{array}{l}\text { 2S-abyssinone } \\
\text { Verubulin }\end{array}$ & $\begin{array}{l}\text { glioblastoma, brain } \\
\text { cancer }\end{array}$ & Pang et al., 2014b \\
\hline 73. & Brucca javanica & Seed & Quassinoids & lymphoblastic & Zhao et al., 2014 \\
\hline
\end{tabular}




\begin{tabular}{|c|c|c|c|c|c|}
\hline & & & & leukemia & \\
\hline 74. & Brucea antidysenterica & Leaves, seed & Bruceantin & skin cancer & $\begin{array}{l}\text { Cragg \& Newman, } \\
2005\end{array}$ \\
\hline 75. & Bryophyllum pinnatum & Leaves & Bryophyllin A & cervical cancer & Mahata et al., 2012 \\
\hline 76. & Bryonia dioica & Root & Myricetin & breast cancer & Benarba et al., 2019 \\
\hline 77. & $\begin{array}{l}\text { Bulpleurum } \\
\text { scorzoneraefolium }\end{array}$ & Root & Saikosaponins & $\begin{array}{l}\text { pancreatic, breast, } \\
\text { cervical cancer }\end{array}$ & Law et al., 2014 \\
\hline 78. & Bursera microphylla & Bark, leaves & Burseran & $\begin{array}{l}\text { epidermoid } \\
\text { carcinoma }\end{array}$ & $\begin{array}{lll}\text { Marcotullio et al., } \\
2018\end{array}$ \\
\hline 79. & Butea monosperma & Flower & Butrin & liver cancer & Choedon et al., 2010 \\
\hline 80. & Buxus hildebrandtii & Leaves & $\begin{array}{l}\text { cyclomicrobuxamine, } \\
\text { buxamine-A, } \\
\text { moenjodaramine }\end{array}$ & $\begin{array}{l}\text { lung, urinary bladder } \\
\text { carcinoma,breast } \\
\text { cancer }\end{array}$ & Mothana et al., 2007 \\
\hline 81. & Cajanus cajan & Root & Cajanol & breast cancer & Pal et al., 2011 \\
\hline 82. & Calotropis gigantea & Flowers & $\begin{array}{l}\text { Anhydrosophoradiol- } \\
\text { 3-acetate }\end{array}$ & $\begin{array}{l}\text { Ehrlich's ascites } \\
\text { carcinoma }\end{array}$ & Habib \& Karim, 2013 \\
\hline 83. & Calotropis procera & Latex & $\begin{array}{l}\text { Calactin, calotropin, } \\
\text { asceplin }\end{array}$ & brest cancer & Bhat et al., 2014 \\
\hline 84. & Calvatia caelata & Fruit & Laccases, Calcaelin & liver, breast cancer & $\mathrm{Ng}$ et al., 2003 \\
\hline 85. & Camellia sinensis & Leaves & $\begin{array}{l}\text { Epigallocatechin } \\
\text { gallate }\end{array}$ & $\begin{array}{l}\text { brain, prostate, } \\
\text { cervical and bladder } \\
\text { cancer }\end{array}$ & Das et al., 2010 \\
\hline 86. & $\begin{array}{l}\text { Camptotheca } \\
\text { acuminate }\end{array}$ & Fruits & Camptotheein & $\begin{array}{l}\text { endometrial cancer, } \\
\text { lung cancer }\end{array}$ & $\begin{array}{l}\text { López-Meyer et al., } \\
1994\end{array}$ \\
\hline 87. & Cannabis Sativa & Leaves & Cannabinoid & $\begin{array}{l}\text { lung, pancreas, } \\
\text { breast, prostate and } \\
\text { colorectal cancer }\end{array}$ & Appendino et al., 2011 \\
\hline 88. & Capsicum annuum & Fruit & Luteolin & colorectal cancer & Osman et al., 2015 \\
\hline 89. & Careya arborea & Leaves & $\begin{array}{l}\text { Quercetin, rutin, } \\
\text { catechin }\end{array}$ & $\begin{array}{l}\text { lung cancer, } \\
\text { leukaemia }\end{array}$ & Panda et al., 2017 \\
\hline 90. & Carissa spinarum & Fruit & $\begin{array}{l}\text { Alkaloids, saponins, } \\
\text { tannins, flavonoids }\end{array}$ & $\begin{array}{l}\text { nasopharyngeal } \\
\text { carcinoma }\end{array}$ & Sahreen et al., 2013 \\
\hline 91. & Cassia auriculata & Leaves & $\begin{array}{l}\text { Procyanidins, 3-O- } \\
\text { beta-D- } \\
\text { xylopyranosides } \\
\end{array}$ & $\begin{array}{l}\text { breast and larynx } \\
\text { cancer }\end{array}$ & Meena et al., 2019 \\
\hline 92. & Cassia fistula & Fruit & $\begin{array}{l}\text { Inositol and 2- } \\
\text { pyrrolidone }\end{array}$ & $\begin{array}{l}\text { cervical cancer and } \\
\text { breast cancer }\end{array}$ & Ali, 2014 \\
\hline 93. & Cassia senna & $\begin{array}{l}\text { Flower, } \\
\text { Leaves }\end{array}$ & $\begin{array}{l}\text { Quercimeritrin } \\
\text { scutellarein and rutin }\end{array}$ & $\begin{array}{l}\text { breast cancer, } \\
\text { prostate cancer }\end{array}$ & $\begin{array}{lll}\text { Gurukumar et } & a l . \\
2010 & & \\
\end{array}$ \\
\hline 94. & Catharanthus roseus & Leaves & $\begin{array}{l}\text { Vinblastine, } \\
\text { Vincristine }\end{array}$ & $\begin{array}{l}\text { breast, ovary, cervix, } \\
\text { lung cancer }\end{array}$ & Almagro et al., 2015 \\
\hline 95. & Catunaregum spinosa & Leaves & Doxorubicin & breast cancer & Sandoval et al., 2016 \\
\hline 96. & Centaurea montana & Seed & Montamine & colon cancer & Shoeb et al., 2006 \\
\hline 97. & Centaurea schischkinii & Seed & Schischkinnin & $\begin{array}{l}\text { colon cancer, rectal } \\
\text { cancer }\end{array}$ & Shoeb et al., 2005 \\
\hline 98. & Centella asiatica & Leaves & Asiatic acid & $\begin{array}{l}\text { melanoma, breast, } \\
\text { glioblastoma cancer }\end{array}$ & Baby et al., 1995 \\
\hline 99. & $\begin{array}{l}\text { Cephalotaxus } \\
\text { hainanensis }\end{array}$ & $\begin{array}{l}\text { Bark and } \\
\text { Leaves } \\
\end{array}$ & $\begin{array}{l}\text { Harringtonine and } \\
\text { homoharringtonine }\end{array}$ & leukemia & Han , 1994 \\
\hline 100. & Cephalotaxus & All parts & Homoharringtonine, & myelodysplastic & Feldman et al., 1996 \\
\hline
\end{tabular}




\begin{tabular}{|c|c|c|c|c|c|}
\hline & harringtonia & & cephalotaxine & $\begin{array}{l}\text { syndrome, chronic } \\
\text { myeloid leukemia }\end{array}$ & \\
\hline 101. & Chelidonium jajus & Herbs & $\begin{array}{l}\text { Sanguinarine and } \\
\text { chelerythrine, } \\
\text { chelidonine }\end{array}$ & $\begin{array}{l}\text { pancreas cancer, } \\
\text { colon cancer, breast } \\
\text { cancer }\end{array}$ & Capistrano et al., 2015 \\
\hline 102. & $\begin{array}{l}\text { Chelidonium majus } \\
\text { var. asiaticum }\end{array}$ & Herbs & $\begin{array}{l}\text { Sanguinarine, } \\
\text { chelerythrine, } \\
\text { berberine }\end{array}$ & $\begin{array}{l}\text { breast, lung, liver, } \\
\text { colon cancer }\end{array}$ & Lee et al., 2005 \\
\hline 103. & Chimaphila umbellata & All parts & $\begin{array}{l}\text { Ericolin, arbutin, urson } \\
\text { and tannin }\end{array}$ & breast cancer & Galván et al., 2008 \\
\hline 104. & $\begin{array}{l}\text { Chrysanthemum } \\
\text { morifolum }\end{array}$ & Flowers & Heliantriol & gastric cancer & Ukiya et al., 2002 \\
\hline 105. & Cicer arietinum & Seed & $\begin{array}{l}\text { Bowman-Birk-type } \\
\text { Protease }\end{array}$ & $\begin{array}{l}\text { breast and prostate } \\
\text { cancer }\end{array}$ & Magee et al., 2012 \\
\hline 106. & Cichorium intybus & Leaves & $\begin{array}{l}\text { Kaempferol, lutedin, } \\
\text { epigenins and } \\
\text { quercetin }\end{array}$ & $\begin{array}{l}\text { breast and prostate } \\
\text { cancer }\end{array}$ & Kandil et al., 2019 \\
\hline 107. & Cissus quadrangularis & Leaves & $\begin{array}{l}\text { Resveratrol, gallic } \\
\text { acid, quercetin, }\end{array}$ & breast cancer & Suresh et al., 2019 \\
\hline 108. & Citrullus colocynthis & Leaves & Cucurbitacin & breast cancer & Zheng et al., 2020 \\
\hline 109. & Citrus maxima & Citrus peel & $\begin{array}{l}\text { Hesperidin, } \\
\text { neohesperidin and } \\
\text { naringin }\end{array}$ & $\begin{array}{l}\text { colon, prostate, lung } \\
\text { and liver }\end{array}$ & KunduSen et al., 2011 \\
\hline 110. & Citrus medica & All parts & $\begin{array}{l}\text { limonin, nomilin, } \\
\text { ichangin }\end{array}$ & breast cancer & Cirmi et al., 2017 \\
\hline 111. & Clausena lansium & Seed & Clausenalansamid A,B & gastric, liver cancer & Maneerat et al., 2011 \\
\hline 112. & Cleistanthus collinus & Bark & $\begin{array}{l}\text { Cleistanthin, } \\
\text { Collinusin }\end{array}$ & $\begin{array}{l}\text { colon cancer, breast } \\
\text { cancer, lung cancer }\end{array}$ & $\begin{array}{l}\text { Pradheepkumar \& } \\
\text { Shanmugam,1999 } \\
\end{array}$ \\
\hline 113. & Clematis manshrica & $\begin{array}{l}\text { Flower, } \\
\text { Leaves }\end{array}$ & $\begin{array}{l}\text { 1,4-benzoquinone,5- } \\
\text { oethyl- } \\
\text { embelin, 15-carbon } \\
\text { isoprenoid }\end{array}$ & $\begin{array}{l}\text { liver cancer and } \\
\text { blood cancer }\end{array}$ & Zhao et al., 2005 \\
\hline 114. & $\begin{array}{l}\text { Clerodendrum } \\
\text { serratum }\end{array}$ & Leaves & $\begin{array}{l}\text { Cryptojaponol, } \\
\text { fortunin E }\end{array}$ & $\begin{array}{l}\text { myeloid leukemia, } \\
\text { hepatocellular } \\
\text { carcinoma }\end{array}$ & Zalke et al., 2010 \\
\hline 115. & $\begin{array}{l}\text { Clerodendrum } \\
\text { viscosum }\end{array}$ & Leaves & $\begin{array}{l}\text { Tannic acid, quercetin, } \\
\text { gallic acid, and rutin }\end{array}$ & $\begin{array}{l}\text { breast, brain, lung } \\
\text { cancer }\end{array}$ & Shendge et al., 2017 \\
\hline 116. & Coccinia grandis & Leaves & Protease inhibitors & colon cancer & $\begin{array}{l}\text { Satheesh \& Murugan, } \\
2011\end{array}$ \\
\hline 117. & Codonopsis pilosula & Leaves & Exopolysaccharides & $\begin{array}{l}\text { hepatocellular } \\
\text { carcinoma }\end{array}$ & Zhang et al., 2019 \\
\hline 118. & Coix lachrymal jobi & Seed & $\begin{array}{l}\text { Trans-ferulyl } \\
\text { stigmasterol }\end{array}$ & colorectal cancer & Manosroi et al., 2016 \\
\hline 119. & Colchicum Autumnale & Leaves & Colchicine & $\begin{array}{l}\text { Hodgkin's } \\
\text { lymphoma, chronic } \\
\text { granulocytic } \\
\text { leukaemia }\end{array}$ & Lin et al., 2015 \\
\hline 120. & Colchicum luteum & Corm,seed & $\begin{array}{l}\text { Colchicine, } \\
\text { demecolcine }\end{array}$ & $\begin{array}{l}\text { stomach cancer, } \\
\text { hypopharyngeal } \\
\text { cancer }\end{array}$ & Kumar et al., 2017 \\
\hline
\end{tabular}

Boletín Latinoamericano y del Caribe de Plantas Medicinales y Aromáticas / 8 


\begin{tabular}{|c|c|c|c|c|c|}
\hline 121. & Coleus forskholli & Root & Forskolin & gastric carcinoma & Kanne et al., 2015 \\
\hline 122. & Combretum caffrum & $\begin{array}{l}\text { Bark, and } \\
\text { fruit }\end{array}$ & Combretastatins & $\begin{array}{l}\text { colon and leukemia } \\
\text { and lung cancer }\end{array}$ & Lauritano et al., 2016 \\
\hline 123. & Commiphora myrrha & Myrrh & 2-Cyclohexen-1-one & $\begin{array}{l}\text { breast, } \\
\text { hepatocellular, } \\
\text { carcinomas, } \\
\text { cervical, skin cancer }\end{array}$ & Chen et al., 2013 \\
\hline 124. & Conyza Canadensis & Root & $\begin{array}{l}\text { Conyzapyranone } \mathrm{A} \\
\text { and } \mathrm{B}\end{array}$ & $\begin{array}{l}\text { epidermoid } \\
\text { carcinoma }\end{array}$ & $\begin{array}{l}\text { Csupor-Löffler et al., } \\
2011\end{array}$ \\
\hline 125. & Cratoxylum formosum & Root & $\begin{array}{l}\text { Formoxanthone, } \\
\text { xanthone } \\
\text { macluraxanthone } \\
\end{array}$ & $\begin{array}{l}\text { breast, oral, cervical, } \\
\text { colon cancer }\end{array}$ & Boonsri et al., 2006 \\
\hline 126. & Crinum asiaticum & Bulb & $\begin{array}{l}\text { Crinamine, } \\
\text { criasiaticidine A }\end{array}$ & cervical cancer & Min et al., 2001 \\
\hline 127. & Crocus sativus & Flower & $\begin{array}{l}\text { Crocin, picrocrocin, } \\
\text { crocetin, and safranal }\end{array}$ & $\begin{array}{l}\text { sarcoma and oral } \\
\text { cancer }\end{array}$ & Bakshi et al., 2009 \\
\hline 128. & Croton lechleri & $\begin{array}{l}\text { Leaves } \\
\text { resin }\end{array}$ & $\begin{array}{l}\text { Taspine, } \\
\text { ethnomedicine }\end{array}$ & $\begin{array}{l}\text { colorectal cancer, } \\
\text { prostate cancer }\end{array}$ & Montopoli et al., 2012 \\
\hline 129. & Croton macrobotrys & Leaves & Corydine, salutaridine & $\begin{array}{l}\text { leukemia and lung } \\
\text { cancer }\end{array}$ & Motta et al., 2011 \\
\hline 130. & Curcuma longa & $\begin{array}{l}\text { Dried } \\
\text { rhizome }\end{array}$ & Curcumin & $\begin{array}{l}\text { colon } \\
\text { adenocarcinoma }\end{array}$ & Ooko et al., 2017 \\
\hline 131. & Curcuma zedoaria & All parts & $\alpha$-Curcumene & overian cancer & Shin \& Lee, 2013 \\
\hline 132. & Daphne genkwa & Flower & $\begin{array}{l}\text { Yuanhualine, } \\
\text { yuanhuahine and } \\
\text { yuanhuagine } \\
\end{array}$ & lung cancer & Du et al., 2016 \\
\hline 133. & Daphne mezereum & All parts & Mezerein & leukemia & $\begin{array}{l}\text { Kupchan \& Baxter, } \\
1975\end{array}$ \\
\hline 134. & Datura metal & All parts & Withonilides & breast cancer & Kumaran et al., 2014 \\
\hline 135. & Daucus carota & Carrot juice & Falcarinol and lutein & lymphoid leukaemia & Shebaby et al., 2014 \\
\hline 136. & Debregeasia saeneb & Stem & Tannins & internal tumors & Tariq et al., 2017 \\
\hline 137. & Dillenia pentagyna & Bark, leaves & $\begin{array}{l}\text { Betulinic acid, } \\
\text { glutathione }\end{array}$ & $\begin{array}{l}\text { ascites Dalton's } \\
\text { lymphoma }\end{array}$ & $\begin{array}{l}\text { Rosangkima \& Prasad, } \\
2004\end{array}$ \\
\hline 138. & Dioscorea collettii & Rhizomes & Dioscin & $\begin{array}{l}\text { liver and human } \\
\text { gastric cancer }\end{array}$ & $\mathrm{Hu} \& \mathrm{Yao}, 2003$ \\
\hline 139. & $\begin{array}{l}\text { Diospyros } \\
\text { chamaethamnus }\end{array}$ & Root & $\begin{array}{l}\text { Anthraquinones, } \\
\text { coumarins }\end{array}$ & $\begin{array}{l}\text { renal and breast } \\
\text { cancer }\end{array}$ & $\begin{array}{l}\text { Dushimemaria et al., } \\
2017\end{array}$ \\
\hline 140. & Diphylleia grayi & Root, stem & $\begin{array}{l}\text { Diphyllin, } \\
\text { deoxypodophyllotoxin }\end{array}$ & prostate cancer & Hu et al., 2016 \\
\hline 141. & Dracena cinnabari & Resin & $\begin{array}{l}\text { Dracophan, } \\
\text { ametacyclophan, } \\
\text { Cinnabaron } \\
\end{array}$ & oral carcinogenesis & Al-Afifi et al., 2018 \\
\hline 142. & $\begin{array}{l}\text { Dryopteris } \\
\text { crassirhizoma }\end{array}$ & Rhizomes & $\begin{array}{l}\text { Filicinic, filicic acids, } \\
\text { aspidinol and aspidin }\end{array}$ & $\begin{array}{l}\text { squamous cell } \\
\text { carcinoma }\end{array}$ & Peng et al., 2009 \\
\hline 143. & Duchesnea indica & All parts & Polysaccharide & ovarian, liver cancer & Xiang et al., 2019 \\
\hline 144. & Dysosma versipllis & Root & Podophyllotoxin & cancer & Yu et al., 1991 \\
\hline 145. & $\begin{array}{l}\text { Dysoxylum } \\
\text { binectariferum }\end{array}$ & Stem & Rohitukine & leukemia & Safia et al., 2015 \\
\hline 146. & Echinacea angustifolia & Root & $\begin{array}{l}\text { Arabinogalactan, } \\
\text { doxorubicin }\end{array}$ & $\begin{array}{l}\text { cervical cancer, } \\
\text { breast cancer }\end{array}$ & Huntimer et al., 2006 \\
\hline
\end{tabular}




\begin{tabular}{|c|c|c|c|c|c|}
\hline 147. & Echinophora cinerea & All parts & $\begin{array}{l}\text { Quercetin and } \\
\text { kaempferol }\end{array}$ & $\begin{array}{l}\text { bladder carcinoma, } \\
\text { leukemia }\end{array}$ & Hosseini et al., 2017 \\
\hline 148. & Echinops setifer & All parts & Echinopsine & skin cancer & Shaikh et al., 2014 \\
\hline 149. & Elusine coracana & Seed & $\begin{array}{l}\text { Ragi bifunctional } \\
\text { inhibitor }\end{array}$ & $\begin{array}{l}\text { myeloid leukemia } \\
\text { cell and K562 cell } \\
\text { line }\end{array}$ & Srikanth \& Chen, 2016 \\
\hline 150. & Embelia ribes & Fruit & Embelin & $\begin{array}{l}\text { liver, pancreas, } \\
\text { colon cancer }\end{array}$ & Ko et al., 2018 \\
\hline 151. & Emblica officinalis & Fruit & $\begin{array}{l}\text { Coumaric and ferulic } \\
\text { acids }\end{array}$ & $\begin{array}{l}\text { breast, liver, } \\
\text { leukemia }\end{array}$ & Jose et al., 2001 \\
\hline 152. & $\begin{array}{l}\text { Enterolobium } \\
\text { Contortisiliquum }\end{array}$ & Seed & Trypsin inhibitor & $\begin{array}{l}\text { gastric and breast } \\
\text { cancer }\end{array}$ & Nakahata et al., 2011 \\
\hline 153. & $\begin{array}{l}\text { Erythronium } \\
\text { americanum }\end{array}$ & All parts & $\begin{array}{l}\alpha \text {-methyl- } \\
\text { enebutyrolactone }\end{array}$ & breast cancer & $\begin{array}{l}\text { Cavallito \& Haskell, } \\
1946\end{array}$ \\
\hline 154. & Erythroxylum pervillei & Root & Pervilleines & carcinoma & Restrepo et al., 2019 \\
\hline 155. & Euonymus alatus & All parts & $\begin{array}{l}\text { Triterpene, euolatin, } \\
\text { steroid and } \\
\text { sesquiterpene alkaloid }\end{array}$ & breast cancer & Zhai et al., 2016 \\
\hline 156. & $\begin{array}{l}\text { Eupatorium } \\
\text { cannabinum }\end{array}$ & All parts & Sesquiterpene, lactone & colon cancer & Grigore et al., 2018 \\
\hline 157. & Euphorbia peplus & Leaves & 3-Ingenyl angelate & skin cancer & Ogbourne et al., 2004 \\
\hline 158. & $\begin{array}{l}\text { Euphorbia } \\
\text { semiperfoliata }\end{array}$ & $\begin{array}{l}\text { Leaves } \\
\text { stem }\end{array}$ & Jatrophane & pancreatic cancer & Bruni et al., 2004 \\
\hline 159. & $\begin{array}{l}\text { Fagopyrum } \\
\text { esculentum }\end{array}$ & Seed & Amygdalin, rutin & $\begin{array}{l}\text { T-acute } \\
\text { lymphoblastic } \\
\text { leukemia }\end{array}$ & Kim et al., 2007b \\
\hline 160. & Ferula angulata & $\begin{array}{l}\text { Leaves and } \\
\text { flower }\end{array}$ & $\begin{array}{l}\text { Vinblastine and } \\
\text { vincristine }\end{array}$ & gastric cancer & Heidari et al., 2014 \\
\hline 161. & Flacourtia jangomos & $\begin{array}{l}\text { Fruit and } \\
\text { flower }\end{array}$ & Limonoid & carcinoma & George et al., 2017 \\
\hline 162. & Fragaria vesca & $\begin{array}{l}\text { Leaves and } \\
\text { fruit }\end{array}$ & $\begin{array}{l}\text { Flavonoid, tannin, } \\
\text { borneol and ellagic } \\
\text { acid }\end{array}$ & lung cancer & Erwiyani et al., 2016 \\
\hline 163. & Fritillaria thunbergii & All parts & Alkaloid and peimine & $\begin{array}{l}\text { lung cancer, liver } \\
\text { cancer, breast cancer }\end{array}$ & Li et al., 2019a \\
\hline 164. & Galium aparine & All parts & $\begin{array}{l}\text { Iridoid, polyphenolic } \\
\text { acid, tannin, sitosterol }\end{array}$ & leukemia & Shi et al., 2016 \\
\hline 165. & Ginkgo biloba & Leaves & Bilobalide & colon cancer & Li et al., 2019b \\
\hline 166. & Gleditsia sinessis & Thorns & Flavanocoumarin & breast cancer & Yu et al., 2017a \\
\hline 167. & Gloriosa superba & Seed & Colchicines & $\begin{array}{l}\text { lung, colon,breast, } \\
\text { pancreatic cancer }\end{array}$ & Balkrishna et al., 2019 \\
\hline 168. & Glycine $\max$ & Seed & $\begin{array}{l}\text { Soybean trypsin } \\
\text { inhibitor }\end{array}$ & $\begin{array}{l}\text { human ovarian } \\
\text { cancer }\end{array}$ & Lima et al., 2017 \\
\hline 169. & Glycyrrhiza glabra & Root & Glycyrrhizin & $\begin{array}{l}\text { breast, } \\
\text { gastrointestinal } \\
\text { cancer }\end{array}$ & Nazmi et al., 2018 \\
\hline 170. & Glycyrrhiza uralensis & Root & Isoliquiritigenin & lung cancer & Ayeka et al., 2016 \\
\hline 171. & $\begin{array}{l}\text { Gossypium } \\
\text { barbadense }\end{array}$ & Seed, leaves & Gossypol & $\begin{array}{l}\text { ovarian cancer, } \\
\text { breast cancer, } \\
\text { leukemia }\end{array}$ & Stipanovic et al., 2009 \\
\hline
\end{tabular}

Boletín Latinoamericano y del Caribe de Plantas Medicinales y Aromáticas / 10 


\begin{tabular}{|c|c|c|c|c|c|}
\hline 172. & Gossypium hirsutum & All parts & Gossypol & colorectal cancer & Stipanovic et al., 2009 \\
\hline 173. & Grsium bracteosum & All parts & Podophyllotoxin & $\begin{array}{l}\text { lung cancer, Kaposis } \\
\text { sarcoma, lymphoma }\end{array}$ & Zi et al., 2018 \\
\hline 174. & $\begin{array}{l}\text { Guibourtia } \\
\text { coleosperma }\end{array}$ & Root & $\begin{array}{l}\text { Anthraquinones, } \\
\text { coumarins }\end{array}$ & $\begin{array}{l}\text { breast and cervical } \\
\text { cancer }\end{array}$ & $\begin{array}{l}\text { Dushimemaria et al., } \\
2017\end{array}$ \\
\hline 175. & Gunnera perpensa & Root & $\begin{array}{l}\text { Z-venusol ,3-methyl 2- } \\
\text { butenyl }\end{array}$ & breast cancer & Mathibe et al., 2016 \\
\hline 176. & $\begin{array}{l}\text { Gynostemma } \\
\text { pentaphyllum }\end{array}$ & Aerial parts & Panoxadiol & $\begin{array}{l}\text { leukemia ,colon } \\
\text { cancer, prostate } \\
\text { carcinoma }\end{array}$ & Li et al., 2016 \\
\hline 177. & Gyrophora esculenta & Lichen & $\beta$-d-glucan & sarcoma 180 & Shibata et al., 1968 \\
\hline 178. & Herba epimedii & Leaves & $\begin{array}{l}\text { Icariin, icaritin, } \\
\text { icarisideII }\end{array}$ & $\begin{array}{l}\text { prostate, lung, } \\
\text { kidney and gastric } \\
\text { cancer }\end{array}$ & Yong et al., 2017 \\
\hline 179. & Hydrastis canadensis & All parts & $\begin{array}{l}\text { Hydrastine, berberine, } \\
\text { lactone berberastine, } \\
\text { candaline }\end{array}$ & $\begin{array}{l}\text { cervical, breast, } \\
\text { prostate cancer }\end{array}$ & Karmakar et al., 2010 \\
\hline 180. & Hypericum perforatum & Aerial parts & Hypericin & $\begin{array}{l}\text { skin cancer, prostate } \\
\text { cancer, breast } \\
\text { cancer, }\end{array}$ & Mirmalek et al., 2016 \\
\hline 181. & Hypoxis argentea & Corms & Mononyasine $\mathrm{A}$ and $\mathrm{B}$. & $\begin{array}{l}\text { colorectal and breast } \\
\text { cancer }\end{array}$ & Ncube et al., 2013 \\
\hline 182. & Hypoxis colchicifolia & $\begin{array}{l}\text { Leaves } \\
\text { root }\end{array}$ & Hypoxoside, rooperol & $\begin{array}{l}\text { breast cancer, colon } \\
\text { cancer, leukemia }\end{array}$ & Ncube et al., 2013 \\
\hline 183. & $\begin{array}{l}\text { Indigofera } \\
\text { aspalathoides }\end{array}$ & Leaves & Colchicine & $\begin{array}{l}\text { hepatocellular } \\
\text { carcinoma }\end{array}$ & $\begin{array}{l}\text { Krishnasamy et al., } \\
2016\end{array}$ \\
\hline 184. & Indigofera tinctoria & $\begin{array}{l}\text { Root, stem, } \\
\text { leaves }\end{array}$ & Indirubins & $\begin{array}{l}\text { lung cancer, } \\
\text { epidermoid cancer }\end{array}$ & $\begin{array}{l}\text { Renukadevi \& Sultana, } \\
2011\end{array}$ \\
\hline 185. & Ipomoeca batatas & Root & $\begin{array}{l}\text { Trypsin inhibitor } \\
\text { protein }\end{array}$ & $\begin{array}{l}\text { promyelocytic } \\
\text { leukemia cells }\end{array}$ & Sugata et al., 2015 \\
\hline 186. & Iridaceaelatea pallasii & All parts & $\begin{array}{l}\text { Irisquinone, } \\
\text { Kaempferol }\end{array}$ & $\begin{array}{l}\text { pancreatic, lung, } \\
\text { ovarian, breast } \\
\text { cancer }\end{array}$ & Gupta et al., 2017 \\
\hline 187. & Iris kumaoensis & Rhizomes & Benzoquinones & $\begin{array}{l}\text { gastric, live cancer, } \\
\text { myeloid leukaemia }\end{array}$ & Mahmood et al., 2002 \\
\hline 188. & Jatropha curcas & Leaves, root & Curcusone $\mathrm{A}$ and $\mathrm{B}$ & $\begin{array}{l}\text { mouse lymphoma, } \\
\text { human cervix cancer }\end{array}$ & Aiyelaagbe et al., 2011 \\
\hline 189. & Junchus effuses & All parts & $\begin{array}{l}\text { Tridecanone, effusol, } \\
\text { juncanol, } \\
\text { phenylpropanoid, } \\
\text { dehydroeffusol }\end{array}$ & leukemia & Gao et al., 2014 \\
\hline 190. & Justicia procumbens & All parts & Justicidin, diphyllin & $\begin{array}{l}\text { colorectal cancer, } \\
\text { bladder cancer }\end{array}$ & Liu et al., 2018a \\
\hline 191. & $\begin{array}{l}\text { Kaempferia } \\
\text { angustifolia }\end{array}$ & Rhizomes & $\begin{array}{l}\text { Flavokawain A, } \\
\text { Kaempfolienol and } \\
\text { zeylenol }\end{array}$ & breast, colon cancer & Tang et al., 2014 \\
\hline 192. & Kaempferia galangal & Rhizomes & $\begin{array}{l}\text { kaempulchraol, ethyl } \\
\text { trans p- } \\
\text { methoxycinnamate }\end{array}$ & $\begin{array}{l}\text { lung cancer, human } \\
\text { cholangiocarcinoma }\end{array}$ & Elshamy et al., 2019 \\
\hline 193. & Kaempferia pulchra & Rhizomes & kolavelool, $2 \beta-$ & pancreatic and & Elshamy et al., 2019 \\
\hline
\end{tabular}

Boletín Latinoamericano y del Caribe de Plantas Medicinales y Aromáticas / 11 


\begin{tabular}{|c|c|c|c|c|c|}
\hline & & & hydroxykolavelool & cervix cancers & \\
\hline 194. & Kaempferia rotunda & Rhizomes & $\begin{array}{l}\text { methyl- } \beta-\mathrm{D} \text { - } \\
\text { galactopyranoside }\end{array}$ & $\begin{array}{l}\text { Ehrlich ascites } \\
\text { carcinoma }\end{array}$ & Elshamy et al., 2019 \\
\hline 195. & Khaya senegalensis & Stem bark & $\begin{array}{l}3 \alpha, 7 \alpha- \\
\text { dideacetylkhivorin } \\
\text { and 1-O- } \\
\text { acetylkhayanolide B }\end{array}$ & $\begin{array}{l}\text { breast cancer, } \\
\text { colorectal cancer }\end{array}$ & Zhang et al., 2007 \\
\hline 196. & Knowltonia capensis & Leaves & $\begin{array}{l}\text { Ranunculin and } \\
\text { protoanemonin }\end{array}$ & leukemia & Powrie, 1975 \\
\hline 197. & $\begin{array}{l}\text { Lagerstroemia } \\
\text { speciosa }\end{array}$ & Leaves & Benzo(a)pyrene & lung cancer & Mousa et al., 2019 \\
\hline 198. & Lanata camara & All parts & $\begin{array}{l}\text { Camerine, } \\
\text { isocamerine, } \\
\text { micranine, } \\
\text { lantanine, } \\
\text { lantadene }\end{array}$ & $\begin{array}{l}\text { lung cancer, liver } \\
\text { cancer }\end{array}$ & Ghosh et al., 2010 \\
\hline 199. & Larrea mexicana & Leaves & Chaparral & $\begin{array}{l}\text { leukaemia and } \\
\text { melanoma }\end{array}$ & $\begin{array}{l}\text { Morán-Santibañez et } \\
\text { al., } 2019\end{array}$ \\
\hline 200. & Larrea tridentate & All parts & Cyclolignans & breast cancer & $\begin{array}{l}\text { Morán-Santibañez et } \\
\text { al., } 2019\end{array}$ \\
\hline 201. & Leea indica & Leaves & Gallic acid & $\begin{array}{l}\text { Ehrlich ascites } \\
\text { carcinoma }\end{array}$ & Ghagane et al., 2017 \\
\hline 202. & Lens culinaris & Seed & Lectin & colon cancer & Chan et al., 2015 \\
\hline 203. & Lentinus edodes & All parts & Lentinan & sarcoma-180 in mice & $\begin{array}{l}\text { Vetchinkina } \text { et al., } \\
2016\end{array}$ \\
\hline 204. & Ligustrum lucidum & Fruit & $\begin{array}{l}\text { Oleanolic acid and } \\
\text { ursolic acid }\end{array}$ & $\begin{array}{l}\text { lung and pancreatic } \\
\text { carcinoma, breast } \\
\text { and prostate }\end{array}$ & Xia et al., 2011 \\
\hline 205. & Limonia acidissima & Fruit & Stigmasterol & breast cancer & Dhakar et al., 2019 \\
\hline 206. & Linium album & All parts & $\begin{array}{l}\text { Etopside, teniposide, } \\
\text { etophose, } \\
\text { podophylotoxin }\end{array}$ & gastric cancer & Asl et al., 2018 \\
\hline 207. & Linum persicum & Aerial parts & Aryltetralin & $\begin{array}{l}\text { myeloid leukemia } \\
\text { and lung carcinoma }\end{array}$ & Javidnia et al., 2010 \\
\hline 208. & Linum usitatissimum & $\begin{array}{l}\text { Leaves, } \\
\text { flowers }\end{array}$ & $\begin{array}{l}\text { Cynogenetic } \\
\text { glycosides }\end{array}$ & breast cancer & $\begin{array}{l}\text { Sakarkar \& } \\
\text { Deshmukh, } 2011 \\
\end{array}$ \\
\hline 209. & $\begin{array}{l}\text { Liriodendron } \\
\text { Tulipifera }\end{array}$ & Stem & $\begin{array}{l}\text { Costunolide, } \\
\text { tulipinolide, } \\
\text { liriodenine, }\end{array}$ & $\begin{array}{l}\text { KB (oral cancer), } \\
\text { HT29 cell line }\end{array}$ & Kang et al., 2014 \\
\hline 210. & Lonicera japonica & All parts & $\begin{array}{l}\text { Luteoin, Kaempferol, } \\
\text { biflavonoids }\end{array}$ & lung cancer & Park et al., 2017 \\
\hline 211. & Lupinus angustifolius & Root & Lupin & breast cancer & Stapel et al., 2015 \\
\hline 212. & Lupinus arcticus & Seed & Lupin & $\begin{array}{l}\text { lymphoblastic } \\
\text { leukemia }\end{array}$ & Deeg et al., 2012 \\
\hline 213. & Lupinus luteus & Flowers & $\begin{array}{l}\text { Genistein-8-C- } \\
\text { glucoside, genistein }\end{array}$ & ovarian carcinoma & Antosiak et al., 2017 \\
\hline 214. & $\begin{array}{l}\text { Macrotyloma } \\
\text { uniflorum }\end{array}$ & Leaves & $\begin{array}{l}\text { Phytic acid, phenolic } \\
\text { acid }\end{array}$ & human osteosarcoma & Prasad \&Singh, 2015 \\
\hline 215. & Mamordica charantia & All parts & $\begin{array}{l}\alpha \text {-momorcharin and } \beta \text { - } \\
\text { momorcharin }\end{array}$ & $\begin{array}{l}\text { breast, colon and } \\
\text { pancreatic cancer }\end{array}$ & Fang et al., 2019 \\
\hline
\end{tabular}

Boletín Latinoamericano y del Caribe de Plantas Medicinales y Aromáticas / 12 


\begin{tabular}{|c|c|c|c|c|c|}
\hline 216. & Mappia foetida & Bark & Camptothecin & $\begin{array}{l}\text { leukemia, breast } \\
\text { cancer }\end{array}$ & Wall \& Wani, 1996 \\
\hline 217. & $\begin{array}{l}\text { Matricaria } \\
\text { chamomilla }\end{array}$ & All parts & Apigenin & colorectal cancer & $\begin{array}{l}\text { Al-Dabbagh et al., } \\
2019\end{array}$ \\
\hline 218. & Macleaya cordata & Root & Chelerythrine & breast cancer & Almeida et al., 2017 \\
\hline 219. & Medicago scutellata & Seed & Trypsin inhibitor & $\begin{array}{l}\text { human breast and } \\
\text { cervical cancer }\end{array}$ & Lanza et al., 2004 \\
\hline 220. & Mimosa pudica & All parts & L-Mimosine & $\begin{array}{l}\text { erythroleukemic, } \\
\text { lung } \\
\text { adenocarcinoma }\end{array}$ & Jose et al., 2016 \\
\hline 221. & Momordica charantia & $\begin{array}{l}\text { Leaves, } \\
\text { roots }\end{array}$ & Charantin & $\begin{array}{l}\text { colon cancer and } \\
\text { breast cancer }\end{array}$ & Fang et al., 2019 \\
\hline 222. & Morinda citrifolia & Root & Damnacanthal & $\begin{array}{l}\text { lung cancer, } \\
\text { sarcomas }\end{array}$ & Brown, 2012 \\
\hline 223. & Moringa oleifera & Leaves & Niazinine A & blood cancer & Al-Asmari et al., 2015 \\
\hline 224. & Nelumbo nucifera & Flowers & Neferine & colon cancer & Zhao et al., 2017 \\
\hline 225. & Newbouldia laevis & Root & $\begin{array}{l}\text { 2-acetylfuro-1,4- } \\
\text { Naphthoquinone }\end{array}$ & $\begin{array}{l}\text { pancreatic cancer, } \\
\text { leukemia cancer }\end{array}$ & Eyong et al., 2005 \\
\hline 226. & Nicotiana tabacum & Leaves & $\begin{array}{l}\alpha-2,7,11- \\
\text { cyprotermine-4,6-diol }\end{array}$ & $\begin{array}{l}\text { hepatocellular } \\
\text { carcinoma }\end{array}$ & Yuan et al., 2019 \\
\hline 227. & Nigella sativa & Seed & Thymoquinone & $\begin{array}{l}\text { lymphocytic } \\
\text { leukemia and liver } \\
\text { cancer }\end{array}$ & $\begin{array}{l}\text { Majdalawieh \& } \\
\text { Fayyad, } 2016\end{array}$ \\
\hline 228. & $\begin{array}{l}\text { Nothapodytes } \\
\text { nimmoniana }\end{array}$ & Bark & Camptothecin & $\begin{array}{l}\text { colorectal and } \\
\text { ovarian cancers }\end{array}$ & Mithun et al., 2017 \\
\hline 229. & Ochrosia elliptica & All parts & $\begin{array}{l}\text { Ellipticine, 9-methoxy } \\
\text { ellipticine }\end{array}$ & $\begin{array}{l}\text { breast cancer, } \\
\text { carcinoma cells }\end{array}$ & Chen et al., 2017 \\
\hline 230. & Ocimum sanctum & Leaves & $\begin{array}{l}\text { Eugenol, orientin, } \\
\text { vicenin, Luteolin }\end{array}$ & $\begin{array}{l}\text { skin, liver, lung, } \\
\text { breast cancer }\end{array}$ & $\begin{array}{l}\text { Karthikeyan et al., } \\
1999\end{array}$ \\
\hline 231. & Oldenlandia diffusa & $\begin{array}{l}\text { Stem, bark, } \\
\text { leaves, fruit } \\
\text { peel }\end{array}$ & Ursolic acid & $\begin{array}{l}\text { lungs, ovary, uterus, } \\
\text { stomach, liver, colon } \\
\text { cancer }\end{array}$ & Gupta et al., 2004b \\
\hline 232. & Olea europaea & $\begin{array}{l}\text { Leaves and } \\
\text { oil }\end{array}$ & $\begin{array}{l}\text { Oleic acid and } \\
\text { oleuropein }\end{array}$ & $\begin{array}{l}\text { skin cancer, } \\
\text { leukemia }\end{array}$ & de Marino et al., 2014 \\
\hline 233. & Ononis spinosa & Root & Formononetin & $\begin{array}{l}\text { breast, colon, } \\
\text { prostate, bladder, } \\
\text { lung and cervical } \\
\text { cancer }\end{array}$ & Jiang et al., 2019 \\
\hline 234. & Operculina turpethum & Root & $\begin{array}{l}\text { Glutathione, ascorbic } \\
\text { acid and alpha } \\
\text { tocopherol }\end{array}$ & breast cancer & Gupta \& Ved, 2017 \\
\hline 235. & Oroxylum indicum & Bark & $\begin{array}{l}\text { Chrysine, baicalein } \\
\text { and oroxylin-A }\end{array}$ & human leukemia & Dev et al., 2010 \\
\hline 236. & Oryza sativa & Seed & $\begin{array}{l}\text { Oryzanol, tocotrienol } \\
\text { and tocopherol }\end{array}$ & $\begin{array}{l}\text { fibrosarcoma, breast } \\
\text { cancer }\end{array}$ & Pintha et al., 2014 \\
\hline 237. & Paeonia suffruticosa & Seed & Oligostilbenes & $\begin{array}{l}\text { lung, breast and } \\
\text { bone cancer }\end{array}$ & Gao \& He, 2017 \\
\hline 238. & Panax ginseng & Root, leaves & $\begin{array}{l}\text { Panaxadiol, } \\
\text { panaxatriol }\end{array}$ & $\begin{array}{l}\text { breast, ovary, lung, } \\
\text { prostate and colon } \\
\text { cancer }\end{array}$ & Du et al., 2013 \\
\hline
\end{tabular}

Boletín Latinoamericano y del Caribe de Plantas Medicinales y Aromáticas / 13 


\begin{tabular}{|c|c|c|c|c|c|}
\hline 239. & Panax notoginseng & Root & $\begin{array}{l}\text { 5-fluorouracil, } \\
\text { panaxadiol and } \\
\text { irinotecan }\end{array}$ & colon cancer & Wang et al., 2007a \\
\hline 240. & Panax pseudoginseng & Root & $\begin{array}{l}\text { Fluorouracil, } \\
\text { Protopanaxadiol }\end{array}$ & colon cancer & Wang et al., 2015 \\
\hline 241. & Panx quinquefolium & Root & $\begin{array}{l}\text { Ginsenoside, } \\
\text { sesquiterpene }\end{array}$ & $\begin{array}{l}\text { ovarian, breast, } \\
\text { colon, liver cancer }\end{array}$ & Wang et al., 2008 \\
\hline 242. & Paris polyphilla & Herbs & Polyphyllin & $\begin{array}{l}\text { prostate cancer, lung } \\
\text { cancer }\end{array}$ & Zhang et al., 2018a \\
\hline 243. & Passiflora caerulea & Flower & Chrysin & colorectal cancer & León et al., 2015 \\
\hline 244. & Patrinia heterophylla & Root & $\begin{array}{l}\text { Paclitaxel, etoposide, } \\
\text { and irinotecan }\end{array}$ & $\begin{array}{l}\text { gastric, cervical, } \\
\text { colon, breast cancer }\end{array}$ & Sheng et al., 2019 \\
\hline 245. & $\begin{array}{l}\text { Patrinia } \\
\text { scabiosaefolia }\end{array}$ & Essential oil & $\begin{array}{l}\text { Caryophyllene oxide, } \\
\text { caryophyllene, } \\
\text { calarene }\end{array}$ & $\begin{array}{l}\text { colon, liver, gastric } \\
\text { cancer }\end{array}$ & Lin et al., 2018 \\
\hline 246. & Peganum harmala & Root & Harmine & breast cancer & Ayoob et al., 2017 \\
\hline 247. & $\begin{array}{l}\text { Peristrophe } \\
\text { bicalyculata }\end{array}$ & All parts & $\begin{array}{l}\text { Caryophyllene, } \\
\text { zingiberene }\end{array}$ & breast cancer & $\begin{array}{l}\text { Ogunwande et al., } \\
2010\end{array}$ \\
\hline 248. & Pestemon deustus & All parts & Liriodendrin & $\begin{array}{l}\text { colon, lung, skin and } \\
\text { stomach cancer }\end{array}$ & Jolad et al., 1980 \\
\hline 249. & Pfaffia paniculata & Root & $\begin{array}{l}\text { Pfaffic acid and } \\
\text { pfaffosides }\end{array}$ & breast cancer & $\begin{array}{l}\text { Levitsky \& } \\
\text { Dembitsky, } 2015\end{array}$ \\
\hline 250. & Phaleria macrocarpa & Fruit & Gallic acid & $\begin{array}{l}\text { colon, cervical, } \\
\text { breast cancer }\end{array}$ & Hendra et al., 2011 \\
\hline 251. & Phaseolus acutifolius & Seed & $\begin{array}{l}\text { Tepary bean protease } \\
\text { Inhibitor }\end{array}$ & $\begin{array}{l}\text { leukemia L1210 and } \\
\text { lymphoma MBL2 }\end{array}$ & Sun et al., 2010 \\
\hline 252. & Phaseolus vulgaris & Seed & $\begin{array}{l}\text { Epicatechin, } \\
\text { myricetin, } \\
\text { formononetin, } \\
\text { kaempferol }\end{array}$ & $\begin{array}{l}\text { colorectal and breast } \\
\text { cancer }\end{array}$ & Ombra et al., 2016 \\
\hline 253. & Picrorrhizia kurroa & Root & $\begin{array}{l}\text { Picrosides, } \\
\text { cucurbitacins, } \\
\text { apocynin }\end{array}$ & $\begin{array}{l}\text { breast and cervix } \\
\text { cancer }\end{array}$ & Mallick et al., 2015b \\
\hline 254. & Pisum sativum & Pea & $\begin{array}{l}\text { Apigenin, daidzein, } \\
\text { genistein, and } \\
\text { kaempferol }\end{array}$ & $\begin{array}{l}\text { human colorectal } \\
\text { and colon cancer }\end{array}$ & $\begin{array}{l}\text { Rungruangmaitree \& } \\
\text { Jiraungkoorskul, } 2017\end{array}$ \\
\hline 255. & $\begin{array}{l}\text { Platycodon } \\
\text { grandiflorum }\end{array}$ & Root & Platycodin D & $\begin{array}{l}\text { colorectal, lung, } \\
\text { breast cancer }\end{array}$ & Jeon et al., 2019 \\
\hline 256. & Pleurotus sajor-caju & All parts & Polysaccharides & $\begin{array}{l}\text { leukemia and liver } \\
\text { cancer }\end{array}$ & Finimundy et al., 2013 \\
\hline 257. & Plumbago zeylanica & Leaves & Plumbagin & $\begin{array}{l}\text { liver, pancreatic, } \\
\text { leukemia, breast } \\
\text { cancer }\end{array}$ & Chen et al., 2009 \\
\hline 258. & Podophyllum emodii & Leaves & Podophyllotoxin & $\begin{array}{l}\text { lung cancer, brain } \\
\text { tumors, } \\
\text { lymphoblastic } \\
\text { leukemia }\end{array}$ & Liang et al., 2016 \\
\hline 259. & $\begin{array}{l}\text { Podophyllum } \\
\text { hexandrum }\end{array}$ & Leaves & Podophyllotoxin & $\begin{array}{l}\text { breast, ovary, lung, } \\
\text { liver, bladder cancer }\end{array}$ & Kumar et al., 2015 \\
\hline 260. & Podophyllum peltatum & Leaves & Podophyllotoxin & lung carcinoma & Eyberger et al., 2006 \\
\hline
\end{tabular}

Boletín Latinoamericano y del Caribe de Plantas Medicinales y Aromáticas / 14 


\begin{tabular}{|c|c|c|c|c|c|}
\hline 261. & $\begin{array}{l}\text { Polygonum } \\
\text { cuspidatum }\end{array}$ & All parts & $\begin{array}{l}\text { Resveratrol, polydatin, } \\
\text { emodin, chrysophanic } \\
\text { acid }\end{array}$ & $\begin{array}{l}\text { colorectal, skin, } \\
\text { liver cancer }\end{array}$ & Wu et al., 2018 \\
\hline 262. & $\begin{array}{l}\text { Polygonum } \\
\text { multiflorum }\end{array}$ & All parts & $\begin{array}{l}\text { Saponin, flavonoid } \\
\text { and vitamin A }\end{array}$ & breast cancer & Liu et al., 2018b \\
\hline 263. & Potentilla chinensis & All parts & Gallic acid and tannin & osteosarcoma cancer & Wan et al., 2016 \\
\hline 264. & Potentilla fulgens & Root & $\begin{array}{l}\text { Kaempferol, ellagic } \\
\text { acid }\end{array}$ & $\begin{array}{l}\text { breast, stomach, } \\
\text { gastric cancer }\end{array}$ & Radhika et al., 2012 \\
\hline 265. & Prunella vulgaris & All parts & $\begin{array}{l}\text { Oleanolic acid, ursolic } \\
\text { acid }\end{array}$ & breast, lung cancer & Hwang et al., 2013 \\
\hline 266. & Psoralea corylifolia & Seed & $\begin{array}{l}\text { Psoralidin, bavachinin, } \\
\text { psoralen }\end{array}$ & $\begin{array}{l}\text { stomach and } \\
\text { prostate cancer }\end{array}$ & Wang et al., 2011 \\
\hline 267. & Pteris multifida & Root & Pterokaurane & $\begin{array}{l}\text { colorectal, lung } \\
\text { cancer }\end{array}$ & Kim et al., 2017 \\
\hline 268. & Pueraria lobata & Root & Puerarin & colon cancer & Zhang et al., 2018b \\
\hline 269. & Pycnanthus angolensis & Root & Pycnanthulignene & $\begin{array}{l}\text { carcinoma,colon } \\
\text { cancer }\end{array}$ & Nono et al., 2010 \\
\hline 270. & Pygeum africanum & Bark & Phytosterol, triterpene & prostate cancer & Shenouda et al., 2007 \\
\hline 271. & Pyrus malus & Fruit & Quercetin, procyanidin & liver, breast cancer & He \& Liu, 2007 \\
\hline 272. & Raphanus sativus & Root & Glucosinolates & liver cancer & Hanlon et al., 2007 \\
\hline 273. & Rheum palmatum & Root & $\begin{array}{l}\text { Emodin and aloe- } \\
\text { emodin }\end{array}$ & breast cancer & Nho et al., 2015 \\
\hline 274. & Rhinacanthus nasuta & Leaves, root & $\begin{array}{l}\text { Rhinacanthin-C, } \\
\text { rhinacanthone }\end{array}$ & $\begin{array}{l}\text { cervical and liver } \\
\text { cancers }\end{array}$ & Boueroy et al., 2018 \\
\hline 275. & Rhus chinensis & Leaves, seed & $\begin{array}{l}\text { Pentagalloylglucose } \\
\text { and gallic acid }\end{array}$ & $\begin{array}{l}\text { breast, leukemia, } \\
\text { melanoma and liver } \\
\text { cancer }\end{array}$ & Djakpo \& Yao, 2010 \\
\hline 276. & Rhus succedanea & Sap & $\begin{array}{l}\text { Heptadecenylhydroqui } \\
\text { none }\end{array}$ & $\begin{array}{l}\text { colon, liver, cervical } \\
\text { cancer }\end{array}$ & Wu et al., 2002 \\
\hline 277. & Rosmarinus officinalis & Aerial parts & $\begin{array}{l}\text { Carnosic acid, } \\
\text { carnosol, rosmarinic } \\
\text { acid, rosmanol }\end{array}$ & $\begin{array}{l}\text { colorectal cancer, } \\
\text { leukemia }\end{array}$ & Allegra et al., 2020 \\
\hline 278. & Rubia akane & Root & Anthraquinones & liver cancer & Moon et al., 2010 \\
\hline 279. & Rubia cordifolia & $\begin{array}{l}\text { Root, aerial } \\
\text { parts }\end{array}$ & $\begin{array}{l}\text { Rubidianin, purpurin, } \\
\text { Xanthopurpurin }\end{array}$ & $\begin{array}{l}\text { breast cancer, } \\
\text { cervical cancer }\end{array}$ & Adwankar et al., 1980 \\
\hline 280. & Rubus idaeus & Leaves & $\begin{array}{l}\text { Flavonoid and tannin, } \\
\text { ellagic acid }\end{array}$ & colorectal cancer & Veljkovic et al., 2018 \\
\hline 281. & Ruscus aculeatus & Root & $\begin{array}{l}\text { Ruscogenin and } \\
\text { neoruscogenin }\end{array}$ & breast cancer & Cappelli et al., 1988 \\
\hline 282. & Ruscus hypophyllum & Root & $\begin{array}{l}\text { Ruscogenin, } \\
\text { furostanol. spirostanol }\end{array}$ & $\begin{array}{l}\text { promyelocytic } \\
\text { leukemia }\end{array}$ & Mimakia et al., 2008 \\
\hline 283. & Salicornia europaea & Leaves & Luteolin and quercetin & breast cancer & Samuel et al., 2017 \\
\hline 284. & Salvadora persica & $\begin{array}{l}\text { Leaves, } \\
\text { root, bark }\end{array}$ & $\begin{array}{l}\text { Ursolic and oleanolic } \\
\text { acids }\end{array}$ & $\begin{array}{l}\text { breast, ovary, colon } \\
\text { cancer }\end{array}$ & Al Bratty et al., 2020 \\
\hline 285. & Salvia chinesis & Aerial parts & $\begin{array}{l}\text { Protocatechuic acid, } \\
\text { salvianolic acid, } \\
\text { xeractinol, kaempferol } \\
\text { and apigenin }\end{array}$ & $\begin{array}{l}\text { breast, lung, colon } \\
\text { cancer }\end{array}$ & Zhao et al., 2015 \\
\hline 286. & Salvia hypargeia & Root & $\begin{array}{l}\text { Ferruginol, } \\
\text { saprorthoquinone, }\end{array}$ & $\begin{array}{l}\text { breast, lung, colon } \\
\text { epidermoidal, }\end{array}$ & Ulubelen et al., 1999 \\
\hline
\end{tabular}




\begin{tabular}{|c|c|c|c|c|c|}
\hline & & & $\begin{array}{l}\text { 11,12-dioxoabieta- } \\
\text { 8,13-diene, taxodione, } \\
\text { hypargenin }\end{array}$ & prostate cancer & \\
\hline 287. & Salvia officinalis & Essential oil & $\begin{array}{l}\alpha \text {-thujone, } 1,8 \text {-cineole } \\
\text { and camphor }\end{array}$ & $\begin{array}{l}\text { prostate, breast, } \\
\text { cervical cancer }\end{array}$ & Privitera et al., 2019 \\
\hline 288. & Salvia prionitis & Root & $\begin{array}{l}\text { 3-keto-4- } \\
\text { hydroxysaprortho- } \\
\text { quinone }\end{array}$ & $\begin{array}{l}\text { leukemia and } \\
\text { stomach cancer }\end{array}$ & Chen et al., 2002 \\
\hline 289. & $\begin{array}{l}\text { Sanguinaria } \\
\text { Canadensis }\end{array}$ & Root & Sanguinarine & breast cancer & Almeida et al., 2017 \\
\hline 290. & Saussurea lappa & Root & $\begin{array}{l}\text { Sesquiterpene, } \\
\text { costunolide }\end{array}$ & $\begin{array}{l}\text { colon, skin, breast, } \\
\text { lung cancer }\end{array}$ & Robinson et al., 2008 \\
\hline 291. & Saxifraga stolonifera & Leaves & $\begin{array}{l}\text { Bergenin, gallic acid, } \\
\beta \text {-sitosterol and } \\
\text { quercetin }\end{array}$ & $\begin{array}{l}\text { breast, gastric, } \\
\text { esophageal cancer }\end{array}$ & Nagata et al., 2016 \\
\hline 292. & $\begin{array}{l}\text { Schizophyllum } \\
\text { commune }\end{array}$ & All parts & Schizophyllan & $\begin{array}{l}\text { gastric and neck } \\
\text { cancer }\end{array}$ & $\begin{array}{l}\text { Lemieszek \& Rzeski, } \\
2012\end{array}$ \\
\hline 293. & Scrophularia nodosa & All parts & $\begin{array}{l}\text { Iridoid, flavonoid and } \\
\text { phenolic acid }\end{array}$ & astrocytoma & Lajimi et al., 2010 \\
\hline 294. & Scutellaria barbata & All parts & Pheophorbide A & lung, ovarian cancer & Chen et al., 2017b \\
\hline 295. & $\begin{array}{l}\text { Selaginella } \\
\text { tamariscina }\end{array}$ & Leaves & $\begin{array}{l}\text { Amentoflavone, } \\
\text { hinokiflavone, apogeni } \\
\mathrm{n}\end{array}$ & lung cancer & Yang et al., 2007 \\
\hline 296. & $\begin{array}{l}\text { Semecarpus } \\
\text { anacardium }\end{array}$ & Kernel & $\begin{array}{l}\text { 3-(8(Z), 11(Z)- } \\
\text { pentadecadienyl) } \\
\text { catechol }\end{array}$ & $\begin{array}{l}\text { human leukemia, } \\
\text { breast, colon cancer }\end{array}$ & Nair et al., 2009 \\
\hline 297. & Smilax china & Rhizomes & $\begin{array}{l}\text { Kaempferol-7-O-beta- } \\
\text { D-glucoside }\end{array}$ & breast, cervix cancer & Xu et al., 2008 \\
\hline 298. & Smilax glabra & Rhizomes & $\begin{array}{l}\text { Apigenin, astilbin, } \\
\text { taxifolin, neoastilbin, } \\
\text { isoastilbin, } \\
\text { neoisoastilbin and } \\
\text { engelitin }\end{array}$ & $\begin{array}{l}\text { gastric, lung, colon, } \\
\text { bladder, breast, } \\
\text { liver, prostate and } \\
\text { cervix cancer }\end{array}$ & She et al., 2015 \\
\hline 299. & Solanum aculeastrum & Fruit & $\begin{array}{l}\text { Tomatidine and } \\
\text { solasodine }\end{array}$ & $\begin{array}{l}\text { colon, cervical and } \\
\text { breast cancer }\end{array}$ & Koduru et al., 2007 \\
\hline 300. & Solanum incanum & Leaves & $\begin{array}{l}\begin{array}{l}\text { Solamargine, } \\
\text { solasodine and } \\
\text { solasonine }\end{array} \\
\end{array}$ & $\begin{array}{l}\text { lung, breast and } \\
\text { ovarian cancer }\end{array}$ & Yu et al., 2017b \\
\hline 301. & Solanum lycopersicum & Fruit & Lycopene & $\begin{array}{l}\text { prostate and colon } \\
\text { cancer }\end{array}$ & Hahm et al., 2011 \\
\hline 302. & solanum lyratum & All parts & Sesquiterpenoids & $\begin{array}{l}\text { breast, intestinal, } \\
\text { lung, gastric cancer } \\
\text { and } \\
\text { hepatocarcinoma }\end{array}$ & Chen et al., 2017c \\
\hline 303. & Solanum nigrum & Leaves & $\begin{array}{l}\text { Glycoalkaloids, } \\
\text { polyphenols, } \\
\text { polysaccharides, } \\
\text { glycoproteins }\end{array}$ & breast cancer & Ling et al., 2019 \\
\hline 304. & Sophora flavescens & Root & $\begin{array}{l}\text { Matrine,oxymatrine } \\
\text { and Kushen Injection }\end{array}$ & breast cancer & Cao \& He, 2020 \\
\hline
\end{tabular}

Boletín Latinoamericano y del Caribe de Plantas Medicinales y Aromáticas / 16 


\begin{tabular}{|c|c|c|c|c|c|}
\hline 305. & Sophora japonica & Root & $\begin{array}{l}\text { Matrine and } \\
\text { oxymatrine }\end{array}$ & $\begin{array}{l}\text { liver, colon, lung, } \\
\text { cervix, ovary and } \\
\text { breast cancers }\end{array}$ & Sun et al., 2012 \\
\hline 306. & Sophora subprostrata & Root & $\begin{array}{l}\text { Matrine and } \\
\text { oxymatrine }\end{array}$ & $\begin{array}{l}\text { liver, colon, lung, } \\
\text { cervix, ovary and } \\
\text { breast cancers }\end{array}$ & Sun et al., 2012 \\
\hline 307. & Stachys floridana & Rhizomes & $\begin{array}{l}\text { Rhamnose, glucuronic } \\
\text { acid and arabinose }\end{array}$ & colon cancer & Ma et al., 2013 \\
\hline 308. & Stachys pilifera & Leaves & $\begin{array}{l}\text { Aucubin, carvacrol } \\
\text { and harpagide }\end{array}$ & colon cancer & Kokhdan et al., 2018 \\
\hline 309. & Stevia rebaudiana & Leaves & Steviol & $\begin{array}{l}\text { gastrointestinal } \\
\text { cancer }\end{array}$ & Chen et al., 2018a \\
\hline 310. & swertia chirayita & All parts & $\begin{array}{l}\text { Amarogentin, } \\
\text { mangiferin and } \\
\text { antileishmanial, }\end{array}$ & $\begin{array}{l}\text { colon, brain, breast } \\
\text { cancer }\end{array}$ & $\begin{array}{l}\text { Kumar \& Van Staden, } \\
2016\end{array}$ \\
\hline 311. & Sylibum marianum & $\begin{array}{l}\text { Leaves, } \\
\text { flowers }\end{array}$ & Silymarin & gastric, colon cancer & Öztürk et al., 2015 \\
\hline 312. & Symphonia globulifera & Leaves & Garcinol, xanthone V1 & $\begin{array}{l}\text { breast, cervix and } \\
\text { leukemia }\end{array}$ & Lenta et al., 2007 \\
\hline 313. & $\begin{array}{l}\text { Symplocus } \\
\text { cochinchinensis }\end{array}$ & Bark & Phloretin-2-glucoside & $\begin{array}{l}\text { brain, liver, breast } \\
\text { cancer }\end{array}$ & Abida et al., 2016 \\
\hline 314. & Syzygium cumini & Fruit, seed & Bergenin, myricetin & $\begin{array}{l}\text { cervical, breast } \\
\text { cancer }\end{array}$ & $\begin{array}{l}\text { Barh \& Viswanathan, } \\
2008\end{array}$ \\
\hline 315. & Tabebuia avellanedae & Bark & Naphthofurandione & breast cancer & Telang et al., 2019 \\
\hline 316. & Tabebuia Impetiginosa & Bark & $\begin{array}{l}\text { Lapachol and } \beta- \\
\text { lapachone }\end{array}$ & $\begin{array}{l}\text { breast, lung, cervical } \\
\text { cancer }\end{array}$ & Pires et al., 2015 \\
\hline 317. & Tamarindus indica & Seed kernel & $\begin{array}{l}\text { Polysaccharide } \\
\text { PST001 }\end{array}$ & $\begin{array}{l}\text { lung, oral, breast } \\
\text { cancer }\end{array}$ & Aravind et al., 2012 \\
\hline 318. & $\begin{array}{l}\text { Taraxacum } \\
\text { mongolicum }\end{array}$ & Root & Dandelion & breast cancer & Li et al., 2007 \\
\hline 319. & Taraxacum officinale & $\begin{array}{l}\text { leaves, } \\
\text { flowers and } \\
\text { roots }\end{array}$ & $\begin{array}{l}\text { Lupeol, } \alpha \text {-Amyrin, } \\
\beta \text {-sitosterol, and } \\
\text { betulin }\end{array}$ & $\begin{array}{l}\text { breast and prostate } \\
\text { cancer }\end{array}$ & Sigstedt et al., 2008 \\
\hline 320. & Taxus baccata & Needle & Paclitaxel & $\begin{array}{l}\text { gastric and colon } \\
\text { cancer }\end{array}$ & Durak et al., 2014 \\
\hline 321. & Taxus brevifolia & Bark & Paclitaxel & $\begin{array}{l}\text { ovarian and breast } \\
\text { cancer }\end{array}$ & Wani et al., 1971 \\
\hline 322. & Taxus cuspidate & $\begin{array}{l}\text { Needles and } \\
\text { twigs }\end{array}$ & 5-Fluorouracil & $\begin{array}{l}\text { breast, lung, } \\
\text { prostate, gastric, } \\
\text { melanoma }\end{array}$ & Shang et al., 2011 \\
\hline 323. & Taxus wallichiana & $\begin{array}{l}\text { Leaves and } \\
\text { bark }\end{array}$ & Paclitaxel, taxiresinol & $\begin{array}{l}\text { liver, colon, ovarian } \\
\text { and breast cancer }\end{array}$ & Juyal et al., 2014 \\
\hline 324. & Terminalia arjuna & Bark & Doxorubicin & $\begin{array}{l}\text { lung and breast } \\
\text { cancer }\end{array}$ & $\begin{array}{l}\text { Sivalokanathan et al., } \\
2006\end{array}$ \\
\hline 325. & Thuja occidentalis & All parts & Thujone & skin cancer & Biswas et al., 2011 \\
\hline 326. & Thymus vulgaris & All parts & $\begin{array}{l}\text { Thymol, carvacrol, } \\
\text { borneol, and p- } \\
\text { cymene, }\end{array}$ & $\begin{array}{l}\text { breast cancer, head } \\
\text { and neck cancer }\end{array}$ & Kubatka et al., 2019 \\
\hline 327. & Tinospora cordifolia & Stem & Berberine & colon cancer & Palmieri et al., 2019 \\
\hline 328. & Trifolium pratense & Flower & Formononetin, & breast, colorectal & Ong et al., 2019 \\
\hline
\end{tabular}

Boletín Latinoamericano y del Caribe de Plantas Medicinales y Aromáticas / 17 


\begin{tabular}{|c|c|c|c|c|c|}
\hline & & & biochanin $\mathrm{A}$ & and prostate cancer & \\
\hline 329. & Trifolium repen & Seed & $\begin{array}{l}\text { Medicarpin, } \\
\text { Formononetin }\end{array}$ & $\begin{array}{l}\text { colon, breast and } \\
\text { lung cancer }\end{array}$ & Sarno et al., 2020 \\
\hline 330. & $\begin{array}{l}\text { Trigonella foenum } \\
\text { graceum }\end{array}$ & Root, seed & $\begin{array}{l}\text { Trigonelline, } \\
\text { diosgenin, } \\
\text { protodioscin and } \\
\text { dioscin }\end{array}$ & $\begin{array}{l}\text { lung, breast, colon } \\
\text { cancer }\end{array}$ & El Bairi et al., 2017 \\
\hline 331. & Tripterygium wilfordii & Root & $\begin{array}{l}\text { Triptolide and } \\
\text { celastrol }\end{array}$ & $\begin{array}{l}\text { melanoma, prostate } \\
\text { and pancreatic } \\
\text { cancers }\end{array}$ & Chen et al., 2018b \\
\hline 332. & Triticum aestivum & Shoot & $\begin{array}{l}\text { Apigenin, quercitin, } \\
\text { luteoline }\end{array}$ & $\begin{array}{l}\text { lung and colon } \\
\text { cancer }\end{array}$ & $\begin{array}{l}\text { Mathankumar et al., } \\
2015\end{array}$ \\
\hline 333. & Tulbaghia violaceae & Leaves & $\begin{array}{l}\text { Methyla-D- } \\
\text { glucopyranoside }\end{array}$ & $\begin{array}{l}\text { liver, breast. Lung } \\
\text { colon cancer }\end{array}$ & Saibu et al., 2015 \\
\hline 334. & Tylophora Indica & Leaves & Tylophorine & breast cancer & Dhiman et al., 2013 \\
\hline 335. & $\begin{array}{l}\text { Typhonium } \\
\text { flagelliforme }\end{array}$ & All parts & $\begin{array}{l}\text { Pheophorbide-a, } \\
\text { pyropheophorbide-a } \\
\text { and methyl } \\
\text { pyropheophorbide-a }\end{array}$ & $\begin{array}{l}\text { breast and lung } \\
\text { cancer }\end{array}$ & Lai et al., 2010 \\
\hline 336. & Umbilicaria esculenta & All parts & $\begin{array}{l}\text { Polysaccharides } \beta \text { - } \\
\text { glucans, } \alpha \text {-glucans }\end{array}$ & leukemia & Sun et al., 2018 \\
\hline 337. & Uncaria tormentosa & Bark & Mitraphylline & $\begin{array}{l}\text { breast, lung, colon } \\
\text { cancer }\end{array}$ & Pilarski et al., 2010 \\
\hline 338. & Vaccaria segetalis & All parts & Segetoside I & $\begin{array}{l}\text { hepatoma, breast, } \\
\text { gastric, colon cancer }\end{array}$ & Firempong et al., 2016 \\
\hline 339. & $\begin{array}{l}\text { Vaccinium } \\
\text { macrocarpon }\end{array}$ & Fruit & $\begin{array}{l}\text { Hydroxycinnamoyl, } \\
\text { ursolic acid }\end{array}$ & $\begin{array}{l}\text { cervical, prostate } \\
\text { cancer }\end{array}$ & Neto et al., 2008 \\
\hline 340. & Vaccinium stamineum & Fruit & $\begin{array}{l}\text { Resveratrol, quercetin, } \\
\text { kaempferol }\end{array}$ & $\begin{array}{l}\text { lung cancer, } \\
\text { leukemia }\end{array}$ & Wang et al., 2007b \\
\hline 341. & $\begin{array}{l}\text { Ventilago } \\
\text { madraspatana }\end{array}$ & Bark & Physcion and emodin & $\begin{array}{l}\text { skin melanoma, } \\
\text { laryngeal carcinoma } \\
\text { and lymphoma }\end{array}$ & Ghosh et al., 2010 \\
\hline 342. & Vernonia amygdalina & Leaves & Paclitaxel, tamoxifen & breast cancer & Wong et al., 2013 \\
\hline 343. & Vernonia cinerea & Leaves & Vernolide-A,B & melanoma & $\begin{array}{l}\text { Pratheeshkumar \& } \\
\text { Kuttan, } 2011\end{array}$ \\
\hline 344. & Vicia faba & Fruit peels & Quercetin, quercetrin & $\begin{array}{l}\text { breast and colon } \\
\text { cancer }\end{array}$ & El-Feky et al., 2018 \\
\hline 345. & Viscum album & Sprouts & $\begin{array}{l}\text { Viscumin, chlorogenic } \\
\text { acid, caffeic acid, } \\
\text { sakuranetin }\end{array}$ & $\begin{array}{l}\text { breast, cervsix, } \\
\text { colon, kidney, lung } \\
\text { cancer }\end{array}$ & Khwaja et al., 1986 \\
\hline 346. & Vismia laurentii & Seed & Laurenquinone A, B & $\begin{array}{l}\text { colon and cervical } \\
\text { cancer }\end{array}$ & Wabo et al., 2007 \\
\hline 347. & Vitis vinifera & $\begin{array}{l}\text { Seed, } \\
\text { Leaves and } \\
\text { fruits }\end{array}$ & $\begin{array}{l}\text { Cyanidin, gallic acid, } \\
\text { catechin, resveratrol }\end{array}$ & $\begin{array}{l}\text { kidney, breast and } \\
\text { colon cancer }\end{array}$ & Esfahanian et al., 2013 \\
\hline 348. & Vitex agnus- castu & Fruit & Luteolin & $\begin{array}{l}\text { ovarian, cervical and } \\
\text { breast cancer }\end{array}$ & Ohyama et al., 2003 \\
\hline 349. & Vitex negundo & $\begin{array}{l}\text { Fruit and } \\
\text { leaves }\end{array}$ & $\begin{array}{l}\text { Chrysoplenetin, } \\
\text { luteolin-7-glucoside, } \\
\text { casticin, iridoid }\end{array}$ & $\begin{array}{l}\text { liver and pancreatic } \\
\text { cancer }\end{array}$ & Kadir et al., 2013 \\
\hline
\end{tabular}

Boletín Latinoamericano y del Caribe de Plantas Medicinales y Aromáticas / 18 


\begin{tabular}{|c|c|c|c|c|c|}
\hline 350. & Vitex rotundifolia & All parts & $\begin{array}{l}\text { Camphene, pinene and } \\
\text { diterpene }\end{array}$ & $\begin{array}{l}\text { breast cancer, } \\
\text { colorectal cancer }\end{array}$ & Chaudhry et al., 2019 \\
\hline 351. & Vitex trifolia & Leaves & $\begin{array}{l}\text { Casticin, vitexin and } \\
\text { luteolin }\end{array}$ & monocytic cell line & Wee et al., 2020 \\
\hline 352. & Wikstroemia indica & Rhizome & $\begin{array}{l}\text { Daphnoretin, } \\
\text { chrysophanol, } \\
\text { myricitrime and rutin }\end{array}$ & $\begin{array}{l}\text { liver and human } \\
\text { epithelial cancer }\end{array}$ & Lu et al., 2012 \\
\hline 353. & Wikstroemia viridi & All parts & Wikstromol & $\begin{array}{l}\text { breast cancer, } \\
\text { prostate cancer }\end{array}$ & $\begin{array}{l}\text { Tandon \& Rastogi, } \\
1976\end{array}$ \\
\hline 354. & Withania aduensis & $\begin{array}{l}\text { Leaves and } \\
\text { fruit }\end{array}$ & Methanol extract & $\begin{array}{l}\text { lung, bladder and } \\
\text { breast cancer }\end{array}$ & Mothana et al., 2007 \\
\hline 355. & Withania riebeckii & $\begin{array}{l}\text { Leaves and } \\
\text { fruit }\end{array}$ & Methanol extract & $\begin{array}{l}\text { lung, bladder and } \\
\text { breast cancer }\end{array}$ & Mothana et al., 2007 \\
\hline 356. & Withania somnifera & $\begin{array}{l}\text { Root and } \\
\text { leaves }\end{array}$ & Adriamycin & $\begin{array}{l}\text { lung, colon, breast } \\
\text { cancer }\end{array}$ & Yadav et al., 2010 \\
\hline 357. & Xanthium strumarium & Fruit, seed & $\begin{array}{l}\text { Xanthatin, } \\
\text { xanthostrumarin }\end{array}$ & $\begin{array}{l}\text { hepatoma, lung, } \\
\text { liver cancer }\end{array}$ & $\begin{array}{l}\text { Al-Mekhlafi et al., } \\
2017\end{array}$ \\
\hline 358. & Yucca glauca & Flowers & Polysaccharide & melanoma & Ali et al., 1978 \\
\hline 359. & Zanthoxylum armatum & Leaves & $\begin{array}{l}\text { Cisplatin, mitomycin } \\
\mathrm{C} \text { and camptothecin }\end{array}$ & $\begin{array}{l}\text { prostate, lung, } \\
\text { cervical, bone } \\
\text { cancer }\end{array}$ & Singh et al., 2015 \\
\hline 360. & Zingiber officinale & Rhizomes & 6-Shogaol,gingerol & ovary cancer & Park et al., 2014 \\
\hline 361. & Ziziphus jujube & $\begin{array}{l}\text { Fruits, eeds, } \\
\text { leaves }\end{array}$ & $\begin{array}{l}\text { Triterpenoids, linoleic } \\
\text { acids }\end{array}$ & breast cancer & $\begin{array}{l}\text { Tahergorabi et al., } \\
2015\end{array}$ \\
\hline 362. & Ziziphus nummularia & $\begin{array}{l}\text { Root, bark, } \\
\text { fruit }\end{array}$ & Betulinic acid, betulin & $\begin{array}{l}\text { ovarian cancer, } \\
\text { breast cancer, } \\
\text { leukemia }\end{array}$ & $\begin{array}{l}\text { Ray \& Dewanjee, } \\
2015\end{array}$ \\
\hline 363. & Ziziphus rugosa & $\begin{array}{l}\text { Pericarp and } \\
\text { seed }\end{array}$ & Betulinic acid & $\begin{array}{l}\text { cytotoxicity against } \\
\text { melanoma cells }\end{array}$ & Prema et al., 2019 \\
\hline 364. & Ziziphus spina-christi & Leaves & $\begin{array}{l}\beta \text {-sitosterol, rutin and } \\
\text { quercetin }\end{array}$ & cervix,breast cancer & Jafarian et al., 2014 \\
\hline
\end{tabular}

Medicinal plant parts and in vitro anticancer agents Medicinal plants are the most commonly used in fold medicines throughout the world and contain different kind of phytochemicals, which act as an important source of anticancer agents. In our anticancer plant documentation, most of the anticancer agents are purified from the various part of the plant like Flower, flower stigmas, pericarp, sprouts, fruits, seeds, roots, rhizomes, stem, leaves, embryo and bark. Among the plant parts leaves consist of $23 \%$ of ethnomedicinal anticancer components. Leaves are the important parts of the plant is easily accessible and effective in cancer treatment followed by root (17\%), all parts (13\%), bark (11\%), fruit (9\%), seed (9\%), flowers (5\%), rhizomes (4\%) and $9 \%$ of ethnomedicines were made up of pods, gum, bulb, juice, resin, thorns, lichen, corms, sap, needle, pericarp, kernel, aerial parts, peel, latex, twings and oil (Figure No. 2). Leaves are the most focused plant part of anticancer agents of Indian, Chinese and African medicine because of easy harvesting process and less side effect (Bhat et al., 2013). Present review showed that the plant's leaves contain a variety of primary and secondary metabolites such as alkaloids, alkynes, terpenoids and phenolic compounds, roots and barks contain terpenoids and phenolic compounds.

In-vitro cancer methods are cancer cell lines are less expensive and less time consuming as compared to in-vivo assays. At the end of in-vitro cancer cell lines lead to the characterization of the action of specific cancer entities responding to drug or extract. That in vitro analysis data is used for selection of active components and concentration of extracts for in-vivo analysis can be carried out (Zips et al., 2005). In-vitro methods are used to test the 
plant phytochemicals against cancer cell lines in the form of extract or pure compound. There are various assays used for measuring the cancer reduction rate of anticancer medicinal plants like lactic dehydrogenase assay, Tryphan blue dye exclusion assay, MTT assay, Sulforhodamine B assay and XTT (Chanda \& Nagani, 2013). Breast cancer was the most studied cancer cell lines among others with a 159 plants having a anti breast cancer activity followed by colorectal cancer (94), lung cancer (76), leukemia (59), liver cancer (47), cervical cancer (39), prostate cancer (32), gastric cancer (32), skin cancer (27), ovarian cancer (25), pancreatic cancer (12), lymphoma (10), bladder cancer (10) and 81 other type of cancer. Figure No. 3 shows the in vitro anticancer activity of medicinal plants in cancer cell lines.

\section{CONCLUSION}

The use of chemical drugs for the cancer treatment can cause worst side effects to the body. And no drug is totally effective or safe for the human body. These problems can be solved by phytochemical drugs derived from various medicinal plants. The present review has studied about 364 different varieties of medicinal plant parts with anticancerous activity. And the above-mentioned plant compounds play crucial roles in inhibiting the cancers or activating the proteins. The same component present in various plant species shows effects on the same cancer type but at various percentages. However, they still have not been able to claim its position in herbal market. We hope this study can benefit the lives of millions of cancer patients.

\section{ACKNOWLEDGMENTS}

We acknowledge the support of the Department of Biotechnology, Adhiyamaan College of Engineering (Autonomous), Hosur, Tamil Nadu, India.

Figure No. 2

Medicinal plant part based anticancer activity in cancer cell lines

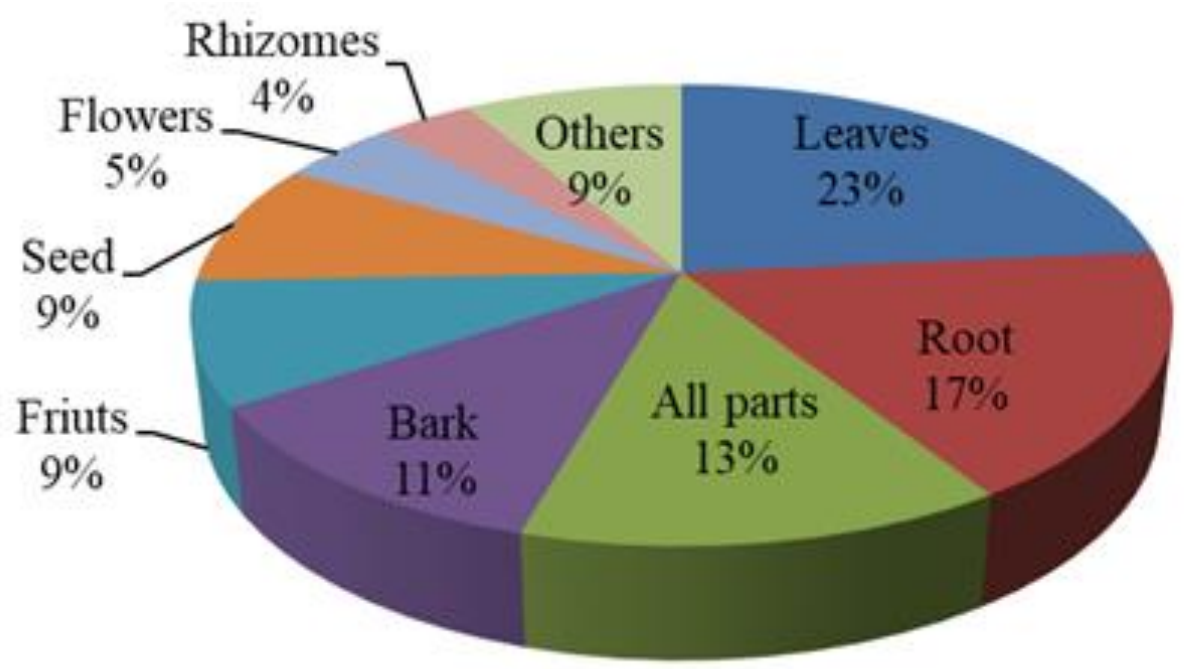

Boletín Latinoamericano y del Caribe de Plantas Medicinales y Aromáticas / 20 
Figure No. 3

In vitro anticancer activity of medicinal plants

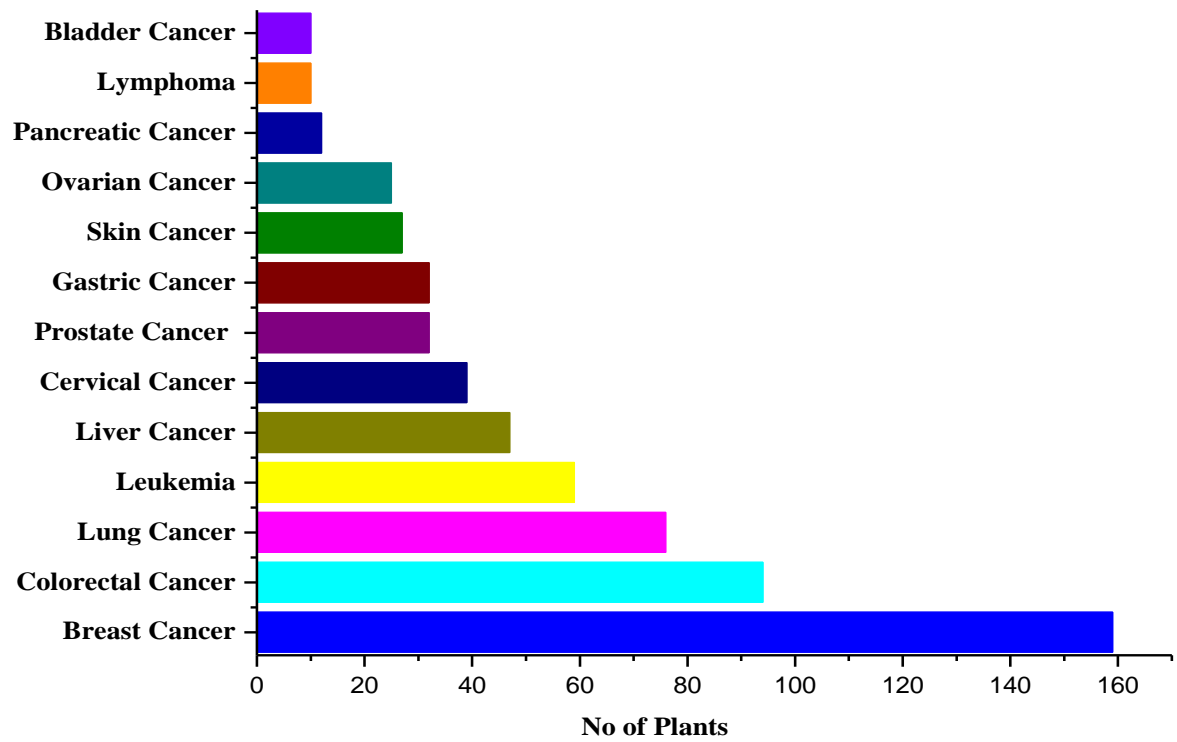

\section{REFERENCES}

Abida P, De Britto AJ, Antoney J, Raj TLS. 2016. Evaluation of in vitro anticancer activity of Symplocos cochinchinensis (Lour.) S. Moore bark. Int J Herb Med 4: 117 - 119.

Adebayo AH, Tan NH, Akindahunsi AA, Zeng GZ, Zhang YM. 2010. Anticancer and antiradical scavenging activity of Ageratum conyzoides L. (Asteraceae). Phcog Mag 6: 62 - 66.

https://doi.org/10.4103/0973-1296.59968

Adwankar MK, Chitnis MP, Khandalekar DD, Bhadsavale CG. 1980. Anti-cancer activity of the extracts of Rubia cordifolia Linn. (NSC b668893). Indian J Exp Biol 18: 102.

Aiyelaagbe OO, Hamid AA, Fattorusso E, Taglialatela-Scafati O, Schröder HC, Müller WE. 2011. Cytotoxic activity of crude extracts as well as of pure components from Jatropha species, plants used extensively in African Traditional Medicine. Evid Based Complement Alternat Med 134954. https://doi.org/10.1155\%2F2011\%2F134954

Akindele AJ, Wani Z, Mahajan G, Sharma S, Aigbe FR, Satti N, Adeyemi OO, Mondhe DM. 2014. Anticancer activity of Aristolochia ringens Vahl. (Aristolochiaceae). J Tradit Complement Med 5: 35 - 41. https://doi.org/10.1016\%2Fj.jtcme.2014.05.001

Al Bratty M, Makeen H, Alhazmi H, Syame S, Abdalla A, Homeida H, Sultana S, Ahsan W, Khalid A. 2020. Phytochemical, cytotoxic, and antimicrobial evaluation of the fruits of Miswak plant, Salvadora persica L. J Chem 2020: 4521951 https://doi.org/10.1155/2020/4521951

Al-Afifi NA, Alabsi AM, Bakri MM, Ramanathan A. 2018. Acute and sub-acute oral toxicity of Dracaena cinnabari resin methanol extract in rats. BMC Complement Altern Med 18: 50. https://doi.org/10.1186\%2Fs12906-018-2110-3

Al-Asmari AK, Albalawi SM, Athar MT, Khan AQ, Al-Shahrani H, Islam M. 2015. Moringa oleifera as an anticancer agent against breast and colorectal cancer cell lines. PLoS One 10: e0135814. https://doi.org/10.1371\%2Fjournal.pone.0135814

Al-Dabbagh B, Elhaty IA, Elhaw M, Murali C, Al Mansoori A, Awad B, Amin A. 2019. Antioxidant and anticancer activities of chamomile (Matricaria recutita L.). BMC Res Notes 12: 3. https://doi.org/10.1186/s13104-018-3960-y

Ali MA. 2014. Cassia fistula Linn: A review of phytochemical and pharmacological studies. Int J Pharm Sci Res 5: 2125 - 2130. http://doi.org/10.13040/IJPSR.0975-8232.5(6).2125-30

Ali MS, Sharma GC, Asplund RO, Nevins MP, Garb S. 1978. Isolation of antitumor polysaccharide fractions from 
Yucca glauca Nutt. (Lilliaceae). Growth 42: 213 - 223.

Allegra A, Tonacci A, Pioggia G, Musolino C, Gangemi S. 2020. Anticancer activity of Rosmarinus officinalis L.: mechanisms of action and therapeutic potentials. Nutrients 12: 1739.

https://doi.org/10.3390\%2Fnu12061739

Almagro L, Fernandez-Perez F, Pedreno MA. 2015. Indole alkaloids from Catharanthus roseus: bioproduction and their effect on human health. Molecules 20: 2973 - 3000. https://doi.org/10.3390/molecules20022973

Almeida IV, Fernandes LM, Biazi BI, Vicentini VEP. 2017. Evaluation of the anticancer activities of the plant alkaloids Sanguinarine and Chelerythrine in human breast adenocarcinoma cells. Anticancer Agents Med Chem 17: 1586 - 1592. https://doi.org/10.2174/1871520617666170213115132

Al-Mekhlafi FA, Abutaha N, Mashaly AMA, Nasr FA, Ibrahim KE, Wadaan MA. 2017. Biological activity of Xanthium strumarium seed extracts on different cancer cell lines and Aedes caspius, Culex pipiens (Diptera: Culicidae). Saudi J Biol Sci 24: 817 - 821. https://doi.org/10.1016\%2Fj.sjbs.2016.07.003

Al-Snafi A. 2014. Chemical constituents and pharmacological activities of Arachis hypogaea-a review. Int J Curr Pharm Res 3: 615 - 623.

Anajwala CC, Patel RM, Dakhara SL, Jariwala JK. 2010. In vitro cytotoxicity study of agave americana, strychnos nuxvomica and areca catechu extracts using mcf-7 cell line. J Adv Pharm Technol Res 1: 245 - 252.

Anderson LA, Harris A, Phillipson JD. 1983. Production of cytotoxic canthin-6-one alkaloids by Ailanthus altissima plant cell cultures. J Nat Prod 46: 374 - 378.

Antosiak A, Milowska K, Maczynska K, Rozalska S, Gabryelak T. 2017. Cytotoxic activity of genistein-8-Cglucoside form Lupinus luteus L. and genistein against human SK-OV-3 ovarian carcinoma cell line. Med Chem Res 26: 64 - 73. https://doi.org/10.1007\%2Fs00044-016-1725-5

Appendino G, Chianese G. Taglialatela-Scalfati O. 2011. Cannabinoids: occurrence and medicinal chemistry. Curr Med Chem 18: 1085 - 1099. https://doi.org/10.2174/092986711794940888

Aravind SR, Joseph MM, Varghese S, Balaram P, Sreelekha TT. 2012. Antitumor and immunopotentiating activity of polysaccharide PST001 isolated from the seed kernel of Tamarindus indica: an in vivo study in mice. Scientific World J:361382. https://doi.org/10.1100\%2F2012\%2F361382

Asl EA, Mehrabadi JF, Afshar D, Noorbazargan H, Tahmasebi H, Rahimi A. 2018. Apoptotic effects of Linum album extracts on AGS human gastric adenocarcinoma cells and ZNF703 oncogene expression. Asian Pac J Cancer Prev 19: 2911 - 2916. https://doi.org/10.22034\%2FAPJCP.2018.19.10.2911

Ayeka PA, Bian Y, Mwitari PG, Chu X, Zhang Y, Uzayisenga R, Otachi EO. 2016. Immunomodulatory and anticancer potential of Gan cao (Glycyrrhiza uralensis Fisch.) polysaccharides by CT-26 colon carcinoma cell growth inhibition and cytokine IL-7 upregulation in vitro. BMC Complement Altern Med 16: 206. https://doi.org/10.1186\%2Fs12906-016-1171-4

Ayoob I, Hazari YM, Lone SH, Shakeel-u-Rehman, Khuroo MA, Fazili KM, Bhat KA. 2017. Phytochemical and cytotoxic evaluation of peganum harmala: structure activity relationship studies of harmine. Chem Select 2: 2965 - 2968. https://doi.org/10.1002/slct.201700232

Baby TD, Kuttan G, Paddikkala. 1995. Cytotoxic and antitumour properties of certain taxa of Umbelliferae with special reference to Centella asiatica L. J Ethnopharmacol 48: 53 - 57. https://doi.org/10.1016/0378-8741(95)01284-K

Bakshi HA, Sam S, Anna F, Zeinab R, Ahmad SG, Sharma M. 2009. Crocin from Kashmiri saffron (Crocus sativus) induces in vitro and in vivo xenograft growth inhibition of Dalton's lymphoma (DLA) in mice. Asian Pac J Cancer Prev 10: 887 - 890.

Balkrishna A, Das SK, Pokhrel S, Joshi A; Laxmi, Verma S, Sharma VK, Sharma V, Sharma N, Joshi CS. 2019. Colchicine: isolation, LC-MS QT of screening, and anticancer activity study of Gloriosa superba Seeds. Molecules 24: 2772. https://doi.org/10.3390/molecules24152772

Barh D, Viswanathan G. 2008. Syzygium cumini inhibits growth and induces apoptosis in cervical cancer cell lines: a primary study. Ecancermedicalscience 2: 83. https://doi.org/10.3332\%2Fecancer.2008.83

Benarba B, Elmallah A, Pandiella A. 2019. Bryonia dioica aqueous extract induces apoptosis and G2/M cell cycle arrest in MDA-MB 231 breast cancer cells. Mol Med Rep 20: 73 - 80.

https://doi.org/10.3892/mmr.2019.10220

Bhandari J, Muhammad B, Thapa P, Shrestha BG. 2017. Study of phytochemical, anti-microbial, anti-oxidant, and anti-cancer properties of Allium wallichii. BMC Complement Altern Med 17: 102.

Boletín Latinoamericano y del Caribe de Plantas Medicinales y Aromáticas / 22 
https://doi.org/10.1186/s12906-017-1622-6

Bhat JA, Kumar M, Bussmann RW. 2013. Ecological status and traditional knowledge of medicinal plants in Kedarnath Wildlife Sanctuary of Garhwal Himalaya, India. J Ethnobiol Ethnomed 9: 1. https://doi.org/10.1186/1746-4269-9-1

Bhat KS, Sharma A and Venkatramana DK. 2014. Antiproliferative effect of Calotropis gigantean (L.) R. Br. on breast cancer cells MCF-7. Int J Pharm Sci Res 5: 3918 - 3923. https://doi.org/10.13040/IJPSR.0975-8232.5(9).3918-23

Biba VS, Jeba MPW, Remani P. 2013. Differential effects of Annona squamosa seed extracts: antioxidant, antibacterial, cytotoxic and apoptotic study. Int J Pharm Biol Sci 4: 899 - 907.

Biswas R, Mandal SK, Dutta S, Bhattacharyya SS, Boujedaini N, Khuda-Bukhsh AR. 2011. Thujone-rich fraction of Thuja occidentalis demonstrates major anti-cancer potentials: evidences from in vitro studies on A375 cells. Evid Based Complement Alternat Med 568148. https://doi.org/10.1093\%2Fecam\%2Fneq042

Boonsri S, Karalai C, Ponglimanont C, Kanjana-opas A, Chantrapromma K. 2006. Antibacterial and cytotoxic xanthones from the roots of Cratoxylum formosum. Phytochemistry 67: 723 - 727. https://doi.org/10.1016/j.phytochem.2006.01.007

Boueroy P, Saensa-Ard S, Siripong P, Kanthawong S, Hahnvajanawong C. 2018. Rhinacanthin-C extracted from Rhinacanthus nasutus (L.) inhibits cholangiocarcinoma cell migration and invasion by decreasing MMP-2, uPA, FAK and MAPK pathways. Asian Pac J Cancer Prev 19: 3605 - 3613. https://doi.org/10.31557\%2FAPJCP.2018.19.12.3605

Bousserouel S, Le Grandois J, Gossé F, Werner D, Barth SW, Marchioni E, Marescaux J, Raul F. 2013. Methanolic extract of white asparagus shoots activates TRAIL apoptotic death pathway in human cancer cells and inhibits colon carcinogenesis in a preclinical model. Int J Oncol 43: 394 - 404. https://doi.org/10.3892\%2Fijo.2013.1976

Brahmachari G, Gorai D, Roy R. 2013. Argemone mexicana: chemical and pharmacological aspects. Braz J Pharmacog 23: 559 - 575. https://doi.org/10.1590/S0102-695X2013005000021

Brown AC. 2012. Anticancer activity of Morinda citrifolia (Noni) fruit: a review. Phytother Res 26: 1427 - 1440. https://doi.org/10.1002/ptr.4595

Bruni R, Muzzoli M, Ballero M, Loi MC, Fantin G, Poli F, Sacchetti G. 2004. Tocopherols, fatty acids and sterols in seeds of four Sardinian wild Euphorbia species. Fitoterapia 75: 50 - 61. https://doi.org/10.1016/j.fitote.2003.07.009

Cao X, He Q. 2020. Anti-tumor activities of bioactive phytochemicals in Sophora flavescens for breast cancer. Cancer Manag Res 12: 1457 - 1467. https://doi.org/10.2147\%2FCMAR.S243127

Capistrano IR, Wouters A, Lardon F, Gravekamp C, Apers S, Pieters L. 2015. In vitro and in vivo investigations on the antitumour activity of Chelidonium majus. Phytomedicine 22: 1279 - 1287. https://doi.org/10.1016/j.phymed.2015.10.013

Cappelli R, Nicora M, Di Perri T. 1988. Use of extract of Ruscus aculeatus in venous disease in the lower limbs. Drugs Exp Clin Res 14: 277 - 283.

Cavallito CJ, Haskell TH. 1946. Alpha-methylene butyrolactone from Erythronium americanum. J Am Chem Soc 68: 2332 - 2334. https://doi.org/10.1021/ja01215a057

Chan LL, George S, Ahmad I, Gosangari SL, Abbasi A, Cunningham BT, Watkin KL. 2011. Cytotoxicity effects of Amoora rohituka and chittagonga on breast and pancreatic cancer cells. Evid base Compl Altern Med 2011: 860605. https://doi.org/10.1155/2011/860605

Chan YS, Yu H, Xia L, Ng TB. 2015. Lectin from green speckled lentil seeds (Lens culinaris) triggered apoptosis in nasopharyngeal carcinoma cell lines.Chin Med 10: 25. https://doi.org/10.1186\%2Fs13020-015-0057-6

Chanda S, Nagani K. 2013. In vitro and in vivo methods for anticancer activity evaluation and some Indian medicinal plants processing anticancer properties: An overview. J Pharmacog Phytochem 2: 140 - 152.

Chang TC, Wei PL, Makondi PT, Chen WT, Huang CY, Chang YJ. 2019. Bromelain inhibits the ability of colorectal cancer cells to proliferate via activation of ROS production and autophagy. Plos One 14: e0210274. https://doi.org/10.1371/journal.pone.0210274

Chatti IB, Limem I, Boubaker J, Skandrani I, Kilani S, Bhouri W, Ben Sghaier M, Nefatti A, Ben Mansour H, Ghedira K, Chekir-Ghedira L. 2009. Phytochemical, antibacterial, antiproliferative, and antioxidant potentials and DNA damage-protecting activity of Acacia salicina extracts. J Med Food 12: 675 - 683. 
https://doi.org/10.1089/jmf.2008.0120

Chaudhry GE, Jan R, Mohamad H, Tengku Muhammad TS. 2019. Vitex rotundifolia fractions induce apoptosis in human breast cancer cell line, MCF-7, via extrinsic and intrinsic pathways. Res Pharm Sci 14: 273 - 285. https://doi.org/10.4103\%2F1735-5362.258496

Chen X, Ding J, Ye Y, Zhang J. 2002. Bioactive abietane andseco-abietane diterpenoids from Salvia prionitis. J Nat Prod 65: 1016 - 1020. https://doi.org/10.1021/np010561j

Chen CA, Chang HH, Kao CY, Tsai TH, Chen YJ. 2009. Plumbagin, isolated from Plumbago zeylanica, induces cell death through apoptosis in human pancreatic cancer cells. Pancreatology 9: 797 - 809. https://doi.org/10.1159/000210028

Chen Y, Zhou C, Ge Z, Liu Y, Liu Y, Feng W, Li S, Chen G, Wei T. 2013. Composition and potential anticancer activities of essential oils obtained from myrrh and frankincense. Oncol Lett 6: 1140 - 1146. https://doi.org/10.3892\%2Fol.2013.1520

Chen AH, Liu QL, Ma YL, Jiang ZH, Tang JY, Liu YP, Chen GY, Fu YH, Xu W. 2017a. A new monoterpenoid indole alkaloid from Ochrosia elliptica. Nat Prod Res 31: 1490 - 1494. https://doi.org/10.1080/14786419.2016.1277349

Chen CC, Kao CP, Chiu MM, Wang SH. 2017b. The anti-cancer effects and mechanisms of Scutellaria barbata D. Don on CL1-5 lung cancer cells. Oncotarget 8: 109340 - 109357. https://doi.org/10.18632\%2Foncotarget.22677

Chen M, Wu J, Zhang XX, Wang Q, Yan SH, Wang HD, Liu SL, Zou X. 2017c. Anticancer activity of sesquiterpenoids extracted from Solanum lyratum via the induction of mitochondria-mediated apoptosis. Oncol Lett 13: 370 - 376. https://doi.org/10.3892\%2Fol.2016.5404

Chen J, Xia Y, Sui X, Peng Q, Zhang T, Li J, Zhang J. 2018a. Steviol, a natural product inhibits proliferation of the gastrointestinal cancer cells intensively. Oncotarget 9: 26299 - 26308. https://doi.org/10.18632\%2Foncotarget.25233

Chen SR, Dai Y, Zhao J, Lin L, Wang Y, Wang Y. 2018b. A mechanistic overview of triptolide and celastrol, natural products from Tripterygium wilfordii Hook F. Front Pharmacol 9: 104. https://doi.org/10.3389/fphar.2018.00104

Choedon T, Shukla SK, Kumar V. 2010. Chemopreventive and anticancer properties of the aqueous extract of flowers of Butea monosperma. J Ethnopharmacol 129: 208 - 213. https://doi.org/10.1016/j.jep.2010.03.011

Cirmi S, Maugeri A, Ferlazzo N, Gangemi S, Calapai G, Schumacher U, Navarra M. 2017. Anticancer potential of Citrus Juices and their extracts: A systematic review of both preclinical and clinical studies. Front Pharmacol 8: 420. https://doi.org/10.3389\%2Ffphar.2017.00420

Cragg GM, Newman DJ. 2005. Plants as a source of anti-cancer agents. J Ethnopharmacol 100: 72 - 79. https://doi.org/10.1016/j.jep.2005.05.011

Csupor-Löffler B, Hajdú Z, Zupkó I, Molnár J, Forgo P, Vasas A, Kele Z, Hohmann J. 2011. Antiproliferative constituents of the roots of Conyza canadensis. Planta Medica 77: 1183 - 1188. https://doi.org/10.1055/s-0030-1270714

Das B, Swamy A, Koti B, Gadad P. 2019. Experimental evidence for use of Acorus calamus (asarone) for cancer chemoprevention. Heliyon 5: e01585. https://doi.org/10.1016/j.heliyon.2019.e01585

Das I, Das S, Saha T. 2010. Saffron suppresses oxidative stress in DMBA-induced skin carcinoma: a histopathological study. Acta Histochem 112: 317 - 327. https://doi.org/10.1016/j.acthis.2009.02.003

De Marino S, Festa C, Zollo F, Nini A, Antenucci L, Raimo G, Iorizzi M. 2014. Antioxidant activity and chemical components as potential anticancer agents in the olive Leaves (Olea europaea L. cv leccino) decoction. Anticancer Agents Med Chem 14: 1376 - 1385. https://doi.org/10.2174/1871520614666140804153936

Deeg K, Eichhorn T, Alexie G, Kretschmer N, Andersch K, Bauer R, Efferth T. 2012. Growth inhibition of human acute lymphoblastic CCRF-CEM leukemia cells by medicinal plants of the West-Canadian Gwich'in Native Americans. Nat Prod Bioprospect 2: 35 - 40. https://doi.org/10.1007\%2Fs13659-012-0013-4

Dev LR, Anurag M, Rajiv G. 2010. Oroxylum indicum: A review. Phcog J 2: 304 - 310. https://doi.org/10.1016/S0975-3575(10)80121-X

Devi JR, Thangam EB. 2012. Mechanisms of anticancer activity of sulforaphane from Brassica oleracea in HEp-2 human epithelial carcinoma cell line. Asian Pac J Cancer Prev 13: 2095 - 2100.

Boletín Latinoamericano y del Caribe de Plantas Medicinales y Aromáticas / 24 
https://doi.org/10.7314/apjcp.2012.13.5.2095

Dhakar A, Chorotiya P, Meena M, Singh C, Purvia RP, Adlakha MK. 2019. Pharmacological properties and phytochemical of Limonia acidissima: a review. World J Pharm Res 8: 637 - 645.

https://doi.org/10.20959/wjpr201910-15730

Dhiman M, Khanna A, Manju SL. 2013. A new phenanthroindolizidine alkaloid from Tylophora indica. Chem Pap 67: 245 - 248. https://doi.org/10.2478/s11696-012-0265-9

Djakpo O, Yao W. 2010. Rhus chinensis and Galla Chinensis--folklore to modern evidence: review. Phytother Res 24: 1739 - 1747. https://doi.org/10.1002\%2Fptr.3215

Du GJ, Wang CZ, Qi LW, Zhang ZY, Calway T, He TC, Du W, Yuan CS. 2013. The synergistic apoptotic interaction of panaxadiol and epigallocatechin gallate in human colorectal cancer cells. Phytother Res 27: 272 - 277. https://doi.org/10.1002/ptr.4707

Du WJ, Yang XL, Song ZJ, Wang JY, Zhang WJ, He X, Zhang RQ, Zhang CF, Li F, Yu CH, Wang CZ, Yuan CS. 2016. Antitumor activity of total flavonoids from Daphne genkwa in colorectal cancer. Phytother Res 30: 323 - 330. https://doi.org/10.1002/ptr.5540

Durak ZE, Büber S, Devrim E, Kocaoğlu H, Durak I. 2014. Aqueous extract from Taxus baccata inhibits adenosine deaminase activity significantly in cancerous and noncancerous human gastric and colon tissues. Pharmacogn Mag 10: 214 - 216. https://doi.org/10.4103\%2F0973-1296.133232

Dushimemaria F, Preez CID, Mumbengegwi DR. 2017. Randomized anticancer and cytotoxicity activities of Guibourtia coleosperma and Diospyros chamaethamnus. Afr J Tradit Complement Altern Med 14: 1 - 7. https://doi.org/10.21010\%2Fajtcam.v14i4.1

Efferth T. 2017. From ancient herb to versatile, modern drug: Artemisia annua and artemisinin for cancer therapy. Semin Canc Biol 46: 65 - 83. https://doi.org/10.1016/j.semcancer.2017.02.009

El Bairi K, Ouzir M, Agnieszka N, Khalki L. 2017. Anticancer potential of Trigonella foenum graecum: cellular and molecular targets. Biomed Pharmacother 90: 479 - 491. https://doi.org/10.1016/j.biopha.2017.03.071

El-Feky A, Elbatanony M, Mounier M. 2018. Anti-cancer potential of the lipoidal and flavonoidal compounds from Pisum sativum and Vicia faba peels. Egypt J Basic Appl Sci 5: 258 - 264. https://doi.org/10.1016/j.ejbas.2018.11.001

Elshamy AI, Mohamed TA, Essa AF, Abd-ElGawad AM, Alqahtani AS, Shahat AA, Yoneyama T, Farrag ARH, Noji M, El-Seedi HR, Umeyama A, Paré PW, Hegazy MF. 2019. Recent advances in kaempferia phytochemistry and biological activity: A comprehensive review. Nutrients 11: 2396. https://doi.org/10.3390\%2Fnu11102396

Erwiyani AR, Martodihardjo S, Lukitaningsih E. 2016. Antioxidant activity of dried strawberry juices (fragaria vesca 1.) emulgel preparation using candlenut oil and it's diffusion. Indonesian J Pharm 27: 145 - 151. http://doi.org/10.14499/indonesianjpharm27iss3pp145

Esfahanian Z, Behbahani M, Shanehsaz M, Hessami MJ, Nejatian MA. 2013. Evaluation of anticancer activity of fruit and leave extracts from virus infected and healthy cultivars of Vitis vinifera. Cell J 15: 116 - 123.

Eyberger AL, Dondapati R, Porter JR. 2006. Endophyte fungal isolates from Podophyllum peltatum produce podophyllotoxin. J Nat Prod 69: 1121 - 1124. https://doi.org/10.1021/np060174f

Eyong KO, Krohn K, Hussain H, Folefoc GN, Nkengfack AE, Schulz B, Hu Q. 2005. Newbouldiaquinone and newbouldiamide: a new naphthoquinone-anthraquinone coupled pigment and a new ceramide from Newbouldia laevis. Chem Pharm Bull 53: 616 - 619. https://doi.org/10.1248/cpb.53.616

Fang EF, Froetscher L, Scheibye-Knudsen M, Bohr VA, Wong JH, Ng TB. 2019. Emerging antitumor activities of the bitter melon (Momordica charantia). Curr Protein Pept Sci 20: 296 - 301. https://doi.org/10.2174\%2F1389203719666180622095800

Feldman EJ, Seiter KP, Ahmed T, Baskind P, Arlin ZA. 1996. Homoharringtonine in patients with myelodysplastic syndrome (MDS) and MDS evolving to acute myeloid leukemia. Leukemia 10: 40 - 42.

Finimundy TC, Gambato G, Fontana R, Camassola M, Salvador M, Moura S, Hess J, Henriques JA, Dillon AJ, Roesch-Ely M. 2013. Aqueous extracts of Lentinula edodes and Pleurotus sajor-caju exhibit high antioxidant capability and promising in vitro antitumor activity. Nutr Res 33: 76 - 84.

https://doi.org/10.1016/j.nutres.2012.11.005

Firempong CK, Zhang HY, Wang Y, Chen J, Cao X, Deng W, Zhou J, Wang Q, Tong SS, Yu J, Xu X. 2016. 
Segetoside I, a plant-derived bisdesmosidic saponin, induces apoptosis in human hepatoma cells in vitro and inhibits tumor growth in vivo. Pharmacol Res 110: 101 - 110.

https://doi.org/10.1016/j.phrs.2016.04.032

Formagio ASN, Vieira MC, Volobuff CRF, Silva MS, Matos AI, Cardoso CAL, Foglio MA, Carvalho JE. 2015. In vitro biological screening of the anticholinesterase and antiproliferative activities of medicinal plants belonging to Annonaceae. Braz J Med Bio Res 48: 308 - 315.

https://doi.org/10.1590/1414-431x20144127

Galván IJ, Mir-Rashed N, Jessulat M, Atanya M, Golshani A, Durst T, Petit P, Amiguet VT, Boekhout T, Summerbell R, Cruz I, Arnason JT, Smith ML. 2008. Antifungal and antioxidant activities of the phytomedicine pipsissewa, Chimaphila umbellata. Phytochemistry 69: 738 - 746.

https://doi.org/10.1016/j.phytochem.2007.09.007

Gao X, Liu Y, Deeb D, Arbab AS, Gautam SC. 2014. Anticancer activity of pristimerin in ovarian carcinoma cells is mediated through the inhibition of prosurvival Akt/NF-kB/mTOR signaling. J Exp Ther Oncol 10: 275 283.

Gao Y, He C. 2017. Anti-proliferative and anti-metastasis effects of ten oligostilbenes from the seeds of Paeonia suffruticosa on human cancer cells. Oncol Lett 13: 4371 - 4377. https://doi.org/10.3892\%2Fol.2017.5982

Garg A, Darokar MP, Sundaresan V, Faridi U, Luqman S, Rajkumar S. 2007. Anticancer activity of some medicinal plants from high altitude evergreen elements of Indian Western Ghats. J Res Educ Indian Med 13: 1 - 6 .

Garg P, Deep A. 2015. Anti-cancer potential of boswellic acid: a mini review. Hygeia J Drug Med 7: 18 - 27. https://doi.org/10.15254/H.J.D.Med.7.2015.147

GBD 2016 Risk Factors Collaborators. 2016. Global, regional, and national comparative risk assessment of 79 behavioural, environmental and occupational, and metabolic risks or clusters of risks, 1990-2015: a systematic analysis for the Global Burden of Disease Study 2015. Lancet 388: 1659 - 1724. https://doi.org/10.1016/s0140-6736(16)31679-8

George SA, Bhadran S, Sudhakar M, Harini BP. 2017. Comprehensive in vitro evaluation of pharmacological activities of selected plant extracts and gc-ms profiling of Flacourtia jangomas flower extract. Asian J Pharm Clin Res 10: 237 - 244. https://doi.org/10.22159/ajpcr.2017.v10i5.17419

Ghafourian E, Sadeghifard N, Pakzad I, Valizadeh N, Maleki A, Jafari F, Ghiasvand N, Abdi J, Shokoohinia Y, Ghafourian S. 2017. Ethanolic extract of Berberis vulgaris fruits inhibits the proliferation of MCF-7 breast cancer cell line through induction of apoptosis. Infect Disord Drug Targets 17: 192 - 198.

https://doi.org/10.2174/1871526517666170531113759

Ghagane SC, Puranik SI, Kumbar VM, Nerli RB, Jalalpure SS, Hiremath MB. 2017. In-vitro antioxidant and anticancer activity of Leea indica leaves extracts on human prostate cancer cell lines. Integr Med Res 6: 79 - 87. https://doi.org/10.1016/j.imr.2017.01.004

Ghosh S, Das Sarma M, Patra A, Hazra B. 2010. Anti-inflammatory and anticancer compounds isolated from Ventilago madraspatana Gaertn. Rubia cordifolia Linn. and Lantana camara Linn. J Pharm Pharmacol 62: 1158 - 1166. https://doi.org/10.1111/j.2042-7158.2010.01151.x

Gordanian B, Behbahani M, Carapetian J, Fazilati M. 2014. In vitro evaluation of cytotoxic activity of flower, leaves, stem and root extracts of five Artemisia species. Res Pharm Sci 9: 91 - 96.

Grigore A, Neagu G, Dobre N, Albulescu A, Ionita L, Ionita C, Albulescu R. 2018. Evaluation of antiproliferative and protective effects of Eupatorium cannabinum L. extracts. Turk J Biol 42: 334 - 344. https://doi.org/10.3906\%2Fbiy-1803-72

Gupta M, Mazumder UK, Kumar RS, Kumar TS. 2004a. Antitumor activity and antioxidant role of Bauhinia racemosa against Ehrlich ascites carcinoma in Swiss albino mice. Acta Pharmacol Sin 25: 1070 - 1076.

Gupta S, Zhang D, Yi J, Shao J. 2004b. Anticancer activities of Oldenlandia diffusa. J Herb Pharmacother 4: 21 33.

Gupta S, Ved A. 2017. Operculina turpethum (Linn.) Silva Manso as a medicinal plant species: A review on bioactive components and pharmacological properties. Pharmacogn Rev 11: 158 - 166. https://doi.org/10.4103\%2Fphrev.phrev_6_17

Gupta VK, Singh R, Sharma B. 2017. Phytochemicals mediated signalling pathways and their implications in cancer chemotherapy: Challenges and opportunities in phytochemicals based drug development: A review.

Boletín Latinoamericano y del Caribe de Plantas Medicinales y Aromáticas / 26 
Bio Chem Comp 5: 2. http://doi.org/10.7243/2052-9341-5-2

Gurukumar D, Rathi MA, Meenakshi P, Thirumoorthi L, Sunitha M, Gopalakrishnan VK. 2010. Anticancer activity of Cassia senna (L) against prostate carcinogenesis. J Pharm Res 3: 3028 - 3031.

Habib MR, Karim MR. 2013. Effect of anhydrosophoradiol-3-acetate of Calotropis gigantea (Linn.) flower as antitumoric agent against Ehrlich's ascites carcinoma in mice. Pharmacol Rep 65: 761 - 767. https://doi.org/10.1016/s1734-1140(13)71057-0

Hahm ER, Moura MB, Kelley EE, Van Houten B, Shiva S, Singh SV. 2011. Withaferin A-induced apoptosis in human breast cancer cells is mediated by reactive oxygen species. Plos One 6: e23354. https://doi.org/10.1371/journal.pone.0023354

Han R. 1994. Highlight on the studies of anticancer drugs derived from plants in china. Stem cells 12: 53 - 63. https://doi.org/10.1002/stem.5530120110

Hanlon PR, Webber DM, Barnes DM. 2007. Aqueous extract from Spanish black radish (Raphanus sativus L. Var. niger) induces detoxification enzymes in the HepG2 human hepatoma cell line. J Agric Food Chem 55: 6439 - 6446. https://doi.org/10.1021/jf070530f

Hashim NM, Rahmani M, Ee GCL, Sukari M, Yahayu M, Oktima W, Ali A, Go R. 2012. Antiproliferative activity of xanthones isolated from Artocarpus obtusus. J Biomed Biotechnol 1 - 9. https://doi.org/10.1155/2012/130627

He X, Fang J, Chen X, Zhao Z, Li Y, Meng Y, Huang L. 2019. Actinidia chinensis Planch: A review of chemistry and pharmacology. Front Pharmacol 10: 1236. https://doi.org/10.3389/fphar.2019.01236

Heidari S, Akrami H, Gharaei R, Jalili A, Mahdiuni H, Golezar E. 2014. Anti-tumor activity of Ferulago angulata Boiss. extract in gastric cancer cell line via induction of apoptosis. Iran J Pharm Res 13: 1335 - 1345.

Hendra R, Ahmad S, Oskoueian E, Sukari A, Shukor MY. 2011. Antioxidant, anti-inflammatory and cytotoxicity of Phaleria macrocarpa (Boerl.) Scheff fruit. BMC Complement Altern Med 11: 110. https://doi.org/10.1186\%2F1472-6882-11-110

Hichri F, Znati M, Bouajila J, Ben Jannet H. 2018. New cytotoxic sesquiterpene lactones from Achillea cretica L. growing in Tunisia. J Asian Nat Prod Res 20: 344 - 351. https://doi.org/10.1080/10286020.2017.1355362

Hosseini Z, Lorigooini Z, Rafieian-Kopaei M, Shirmardi HA, Solati K. 2017. A review of botany and pharmacological effect and chemical composition of Echinophora species growing in Iran. Pharmacogn Res 9: 305 - 312. https://doi.org/10.4103\%2Fpr.pr_22_17

$\mathrm{Hu}$ K, Yao X. 2003. The cytotoxicity of methyl protodioscin against human cancer cell lines in vitro. Cancer Invest 21: 389 - 393. https://doi.org/10.1081/cnv-120018230

Hu S, Zhou Q, Wu WR, Duan YX, Gao ZY, Li YW, Lu Q. 2016. Anticancer effect of deoxypodophyllotoxin induces apoptosis of human prostate cancer cells. Oncol Lett 12: 2918 - 2923. https://doi.org/10.3892/ol.2016.4943

Huntimer ED, Halaweish FT, Chase CC. 2006. Proliferative activity of Echinacea angustifolia root extracts on cancer cells: Interference with doxorubicin cytotoxicity. Chem Biodivers 3: 695 - 703. https://doi.org/10.1002/cbdv.200690071

Hwang BY, Su BN, Chai H, Mi Q, Kardono LB, Afriastini JJ, Riswan S, Santarsiero BD, Mesecar AD, Wild R, Fairchild CR, Vite GD, Rose WC, Farnsworth NR, Cordell GA, Pezzuto JM, Swanson SM, Kinghorn AD. 2004. Silvestrol and episilvestrol, potential anticancer rocaglate derivatives from Aglaila silvestris. J Org Chem 69: 3350 - 3358.

Hwang YJ, Lee EJ, Kim HR, Hwang KA. 2013. In vitro antioxidant and anticancer effects of solvent fractions from Prunella vulgaris var. lilacina. BMC Complement Altern Med 13: 310. https://doi.org/10.1186\%2F1472-6882-13-310

Jafarian A, Zolfaghari B, Shirani K. 2014. Cytotoxicity of different extracts of arial parts of Ziziphus spina-christi on Hela and MDA-MB-468 tumor cells. Adv Biomed Res 3: 38. https://doi.org/10.4103\%2F2277-9175.125727

Jagetia GC, Venkatesha VA. 2012. Preclinical determination of the anticancer activity of Rohituka (Aphanamixis polystachya) in Ehrlich ascites tumor-bearing mice. Med Aromat Plant Sci Biotechnol 6: 42 - 51.

Jamshidi-Kia F, Lorigooini Z, Amini-Khoei H. 2018. Medicinal plants: past history and future perspective. J Herbmed Pharmacol 7: 1 - 7. https://doi.org/10.15171/jhp.2018.01

Boletín Latinoamericano y del Caribe de Plantas Medicinales y Aromáticas / 27 
Javidnia K, Miri R, Rezai H, Jafari A, Azarmehr A, Amirghofran Z. 2010. Cytotoxic activity and aryltetraline lignans of Linum persicum Kotschy ex Boiss. Iran J Pharm Res 3: 74 - 74. https://doi.org/10.22037/ijpr.2010.518

Jelassi A, Zardi-Bergaoui A, Ben Nejma A, Belaiba M, Bouajila J, Ben Jannet H. 2014. Two new unusual monoterpene acid glycosides from Acacia cyclops with potential cytotoxic activity. Bioorg Med Chem Lett 24: 3777 - 3781. https://doi.org/10.1016/j.bmcl.2014.06.075

Jeon D, Kim SW, Kim HS. 2019. Platycodin D, a bioactive component of Platycodon grandiflorum, induces cancer cell death associated with extreme vacuolation. Anim Cells Syst 23: 118 - 127.

https://doi.org/10.1080\%2F19768354.2019.1588163

Jeong GS, Kwon OK, Park BY, Oh SR, Ahn KS, Chang MJ, Oh WK, Kim JC, Min BS, Kim YC, Lee HK. 2007. Lignans and coumarins from the roots of Anthriscus sylvestris and their increase of caspase-3 activity in HL-60 cells. Biol Pharm Bull 30: 1340 - 1343. https://doi.org/10.1248/bpb.30.1340.

Ji L, Liu T, Liu J, Chen Y, Wang Z. 2007. Andrographolide inhibits human hepatoma-derived Hep3B cell growth through the activation of c-Jun N-terminal kinase. Planta Med 73: 1397 - 1401. https://doi.org/10.1055/s-2007-990230.

Jia Y, Zhao G, Jia J. 2008. The effects of Aloe ferox Miller and Aloe arborescens Milleron wound healing. J Ethnopharmacol 120: 181 - 189.

Jiang D, Rasul A, Batool R, Sarfraz I, Hussain G, Mateen Tahir M, Qin T, Selamoglu Z, Ali M, Li J, Li X. 2019. Potential anticancer properties and mechanisms of action of formononetin. Biomed Res Int: 5854315. https://doi.org/10.1155\%2F2019\%2F5854315

Jolad SD, Hoffmann JJ, Cole JR, Tempesta MS, Bates RB. 1980. Cytotoxic agent from Penstemon deustus (Scrophulariaceae): isolation and stereochemistry of liriodendrin, a symmetrically substituted furofuranoid lignan diglucoside. J Org Chem 45: 1327 - 1329. https://doi.org/10.1021/jo01295a038

Jose JK, Kuttan G, Kuttan R. 2001. Antitumour activity of Emblica officinalis. J Ethnopharmacol 75: 65 - 69. https://doi.org/10.1016/s0378-8741(00)00378-0

Jose J, Dhanya AT, Haridas KR, Sumesh Kumar TM, Jayaraman S, Variyar EJ, Sudhakaran S. 2016. Structural characterization of a novel derivative of myricetin from Mimosa pudica as an anti-proliferative agent for the treatment of cancer. Biomed Pharmacother 84: 1067 - 1077.

https://doi.org/10.1016/j.biopha.2016.10.020

Juyal D, Thawani V, Thaledi S, Joshi M. 2014. Ethnomedical properties of Taxus wallichiana Zucc. (Himalayan yew). J Tradit Complement Med 4: 159 - 161. https://doi.org/10.4103\%2F2225-4110.136544

Kadir FA, Kassim NM, Abdulla MA, Yehye WA. 2013. PASS-predicted Vitex negundo activity: antioxidant and antiproliferative properties on human hepatoma cells-an in vitro study. BMC Complement Altern Med 13: 343. https://doi.org/10.1186\%2F1472-6882-13-343

Kandil A, Abou-Elella F, El Shemy H. 2019. Cytotoxic profile activities of ethanolic and methanolic extracts of chicory plant (Cichorium intybus L.). J Radiat Res Appl Sci 12: 106 - 111. https://doi.org/10.1080/16878507.2019.1594136

Kang YF, Liu CM, Kao CL, Chen CY. 2014. Antioxidant and anticancer constituents from the leaves of Liriodendron tulipifera. Molecules 19: 4234 - 4245. https://doi.org/10.3390\%2Fmolecules19044234

Kanne H, Burte NP, Prasanna V, Gujjula R. 2015. Extraction and elemental analysis of Coleus forskohlii extract. Pharmacogn Res 7: 237 - 241. https://doi.org/10.4103\%2F0974-8490.157966

Karmakar SR, Biswas SJ, Khuda-Bukhsh AR. 2010. Anti-carcinogenic potentials of a plant extract (Hydrastis canadensis): I. Evidence from in vivo studies in mice (Mus musculus). Asian Pac J Cancer Prev 11: 545 551.

Karmakar S, Choudhury SR, Banik NL, Ray SK. 2011. Molecular mechanisms of anti-cancer action of garlic compounds in neuroblastoma. Anticancer Agents Med Chem 11: 398 - 407. https://doi.org/10.2174/187152011795677553

Karthikeyan K, Gunasekaran P, Ramamurthy N, Govindasamy S. 1999. Anticancer activity of Ocimum Sanctum, Pharm Biol 37: 285 - 290. https://doi.org/10.1076/phbi.37.4.285.5801

Khwaja TA, Dias CB, Pentecost S. 1986. Recent studies on the anticancer activities of mistletoe (Viscum album) and its alkaloids. Oncology 43: 42 - 50. https://doi.org/10.1159/000226419

Kim S, Hwang BY, Su BN, Chai H, Mi Q, Kinghorn AD, Wild R, Swanson SM. 2007a. Silvestrol, a potential 
anticancer rocaglate derivative from Aglaia foveolata, induces apoptosis in LNCaP cells through the mitochondrial/apoptosome pathway without activation of executioner caspase-3 or -7. Anticancer Res 27: $2175-2183$.

Kim SH, Cui CB, Kang IJ, Kim SY, Ham SS. 2007b. Cytotoxic effect of buckwheat (Fagopyrum esculentum Moench) hull against cancer cells. J Med Food 10: 232 - 238. https://doi.org/10.1089/jmf.2006.1089

Kim JW, Kim HP, Sung SH. 2017. Cytotoxic pterosins from Pteris multifida roots against HCT116 human colon cancer cells. Bioorg Med Chem Lett 27: 3144 - 3147. https://doi.org/10.1016/j.bmcl.2017.05.034

Ko JH, Lee SG, Yang WM, Um JY, Sethi G, Mishra S, Shanmugam MK, Ahn KS. 2018. The application of embelin for cancer prevention and therapy. Molecules 23: 621.

https://doi.org/10.3390\%2Fmolecules23030621

Koduru S, Grierson D, van de Venter M, Afolayan A. 2007. Anticancer activity of steroid alkaloids isolated from Solanum aculeastrum. Pharm Biol 45: 613 - 618. https://doi.org/10.1080/13880200701538690

Kokhdan EP, Sadeghi H, Ghafoori H, Sadeghi H, Danaei N, Javadian H, Aghamaali MR. 2018. Cytotoxic effect of methanolic extract, alkaloid and terpenoid fractions of Stachys pilifera against HT-29 cell line. Res Pharm Sci 13: 404 - 412. https://doi.org/10.4103\%2F1735-5362.236833

Koshiura R, Miyamoto K, Ikeya Y, Taguchi H. 1985. Antitumor activity of methanol extract from roots of Agrimonia pilosa Ledeb. Jpn J Pharmacol 38: 9 - 16. https://doi.org/10.1254/jjp.38.9

Król SK, Kiełbus M, Rivero-Mûller A, Stepulak A. 2015. Comprehensive review on betulin as a potent anticancer agent. Bio Med Res Int: 584189. https://doi.org/10.1155/2015/584189

Krishnamurthi K. 2000. Screening of natural products for anticancer and antidiabetic properties. Health Adm 20: $69-75$.

Krishnasamy L, Selvam MM, Ravikrishnan B. 2016. Anticancer property of colchicine isolated from Indigofera aspalathoids. Res J Pharm Technol 9: 386 - 390. https://doi.org/10.5958/0974-360X.2016.00069.X

Kubatka P, Uramova S, Kello M, Kajo K, Samec M, Jasek K, Vybohova D, Liskova A, Mojzis J, Adamkov M, Zubor P, Smejkal K, Svajdlenka E, Solar P, Samuel SM, Zulli A, Kassayova M, Lasabova Z, Kwon TK, Pec M, Danko J, Büsselberg D. 2019. Anticancer activities of Thymus vulgaris L. in experimental breast carcinoma in vivo and in vitro. Int J Mol Sci 20: 1749. https://doi.org/10.3390\%2Fijms20071749

Kumar P, Pal T, Sharma N, Kumar V, Sood H, Chauhan RS. 2015. Expression analysis of biosynthetic pathway genes vis-à-vis podophyllotoxin content in Podophyllum hexandrum Royle. Protoplasma 252: 1253 1262. https://doi.org/10.1007/s00709-015-0757-x

Kumar V, Van Staden J. 2016. A Review of Swertia chirayita (Gentianaceae) as a traditional medicinal plant. Front Pharmacol 6: 308. https://doi.org/10.3389/fphar.2015.00308

Kumar A, Sharma PR, Mondhe DM. 2017. Potential anticancer role of colchicine-based derivatives: an overview. Anticancer Drugs 28: 250 - 262. https://doi.org/10.1097/cad.0000000000000464

Kumaran S, Banu BN, Julie J, Abirami J, Kumareasan R, Muthukumaran T, Rajasree S, Jothi JK. 2014. Anticancer activity of Datura metel in MCF-7 cell line. Asian J Pharm Clin Res 7: 181 - 183.

KunduSen S, Gupta M, Mazumder U, Haldar P, Saha P, Bala A. 2011. Antitumor activity of Citrus maxima (Burm.) Merr. leaves in Ehrlich's ascites carcinoma cell-treated mice. ISRN Pharmacol 1 - 4. https://doi.org/10.5402/2011/138737

Kupchan SM, Baxter RL. 1975. Mezerein: antileukemic principle isolated from Daphne mezereum L. Science 187: 652 - 653. https://doi.org/10.1126/science.1114315

Kuper H, Adami HO, Boffetta P. 2002. Tobacco use, cancer causation and public health impact. J Intern Med 251: 455 - 466. https://doi.org/10.1046/j.1365-2796.2002.00993.x

Lai CS, Mas RH, Nair NK, Mansor SM, Navaratnam V. 2010. Chemical constituents and in vitro anticancer activity of Typhonium flagelliforme (Araceae). J Ethnopharmacol 127: 486 - 494. https://doi.org/10.1016/j.jep.2009.10.009

Lajimi AA, Rezaie-Tavirani M, Mortazavi SA, Barzegar M, Moghadamnia SH, Rezaee MB. 2010. Study of anti cancer property of Scrophularia striata extract on the human astrocytoma cell line (1321). Iran J Pharm Res 9: 403 - 410.

Lanza A, Tava A, Catalano M, Ragona L, Singuaroli I, Robustelli della Cuna FS, Robustelli della Cuna G. 2004. Effects of the Medicago scutellata trypsin inhibitor (MsTI) on cisplatin-induced cytotoxicity in human breast and cervical cancer cells. Anticancer Res 24: 227 - 233.

Boletín Latinoamericano y del Caribe de Plantas Medicinales y Aromáticas / 29 
Lauritano H, Andersen JH, Hansen E, Albrigtsen M, Escalera L, Esposit F, Helland K, Hanssen K, Romano G, Lanora A. 2016. Bioactivity screening of microalgae for antioxidant, anti-inflammatory, anticancer, antidiabetes, and antibacterial activities. Front Mar Sci 3: 68. https://doi.org/10.3389/fmars.2016.00068

Law BY, Mo JF, Wong VK. 2014. Autophagic effects of Chaihu (dried roots of Bupleurum chinense DC or Bupleurum scorzoneraefolium WILD). Chin Med 9: 21. https://doi.org/10.1186\%2F1749-8546-9-21

Lee J, Shon MY, Jang DS, Ha TJ, Hwang SW, Nam SH., Seo E, Park KH, Yang M. 2005. Cytotoxic isoquinoline alkaloids from Chelidonium majus var. asiaticum. Agric Chem Biotechnol 48: 198 - 201.

Lee WS, Yi SM, Yun JW, Jung JH, Kim DH, Kim HJ, Chang SH, Kim G, Ryu CH, Shin SC, Hong SC, Choi YH, Jung JM. 2014. Polyphenols isolated from Allium cepa L. induces apoptosis by induction of p53 and suppression of Bcl-2 through inhibiting PI3K/Akt signaling pathway in AGS human cancer cells. J Cancer Prev 19: 14 - 22. https://doi.org/10.15430/jcp.2014.19.1.14

Lemieszek M, Rzeski W. 2012. Anticancer properties of polysaccharides isolated from fungi of the Basidiomycetes class. Contemp Oncol 16: 285 - 289. https://doi.org/10.5114\%2Fwo.2012.30055

Lenta BN, Vonthron-Sénécheau C, Weniger B, Devkota KP, Ngoupayo J, Kaiser M, Naz Q, Choudhary MI, Tsamo E, Sewald N. 2007. Leishmanicidal and cholinesterase inhibiting activities of phenolic compounds from Allanblackia monticola and Symphonia globulifera. Molecules 12: 1548 - 1557. https://doi.org/10.3390\%2F12081548

León IE, Cadavid-Vargas JF, Tiscornia I, Porro V, Castelli S, Katkar P, Desideri A, Bollati-Fogolin M, Etcheverry SB. 2015. Oxidovanadium (IV) complexes with chrysin and silibinin: anticancer activity and mechanisms of action in a human colon adenocarcinoma model. J Biol Inorg Chem 20: 1175 - 1191. https://doi.org/10.1007/s00775-015-1298-7

Levitsky DO, Dembitsky VM. 2015. Anti-breast cancer agents derived from plants.Nat Prod Bioprospect 5: 1 16. https://doi.org/10.1007/s13659-014-0048-9

Leyva-Peralta MA, Robles-Zepeda RE, Garibay-Escobar A, Ruiz-Bustos E, Alvarez-Berber LP, Gálvez-Ruiz JC. 2015. In vitro anti-proliferative activity of Argemone gracilenta and identification of some active components. BMC Comp Alter Med 15: 13. https://doi.org/10.1186/s12906-015-0532-8

Li J, Li QC, Chen C, Hao X, Liu H. 2009. Cytotoxic activity of cardenolides and cardenolide glycosides from Asclepias curassavica. Biooorganic Med Chem Lett 19: 1956 - 1959. https://doi.org/10.1016/j.bmcl.2009.02.045

Li Y, Lin W, Huang J, Xie Y, Ma W. 2016. Anti-cancer effects of Gynostemma pentaphyllum (Thunb.) Makino (Jiaogulan). Chin Med 11: 43. https://doi.org/10.1186\%2Fs13020-016-0114-9

Li XH, He XR, Zhou YY, Zhao HY, Zheng WX, Jiang ST, Zhou Q, Li PP, Han SY. 2017. Taraxacum mongolicum extract induced endoplasmic reticulum stress associated-apoptosis in triple-negative breast cancer cells. J Ethnopharmacol 206: 55 - 64. https://doi.org/10.1016/j.jep.2017.04.025

Li H, Hung A, Li M, Yang AWH. 2019a. Fritillariae Thunbergii bulbus: Traditional uses, phytochemistry, pharmacodynamics, pharmacokinetics and toxicity. Int J Mol Sci 20: 1667. https://doi.org/10.3390\%2Fijms20071667

Li M, Li B, Xia ZM, Tian Y, Zhang D, Rui WJ, Dong JX, Xiao FJ. 2019b. Anticancer effects of five biflavonoids from Ginkgo Biloba L. male flowers in vitro. Molecules 24: 1496. https://doi.org/10.3390\%2Fmolecules24081496

Li Y, Dong C, Xu MJ, Lin WH. 2020. New alkylated benzoquinones from mangrove plant Aegiceras corniculatum with anticancer activity. J Asian Nat Prod Res 22: 121 - 130. https://doi.org/10.1080/10286020.2018.1540604

Liang Z, Zhang J, Zhang X, Li J, Zhang X, Zhao C. 2016. Endophytic fungus from Sinopodophyllum emodi (Wall.) Ying that produces podophyllotoxin. J Chromatogr Sci 54: 175 - 178.

https://doi.org/10.1093/chromsci/bmv124

Liao KF, Chiu TL, Huang SY, Hsieh TF, Chang SF, Ruan JW, Chen SP, Pang CY, Chiu SC. 2018. Anti-cancer effects of radix Angelica Sinensis (Danggui) and N-Butylidenephthalide on gastric cancer: Implications for REDD1 activation and mTOR inhibition. Cell Physiol Biochem 48: 2231 - 2246. https://doi.org/10.1159/000492641

Lima A, Oliveira J, Saúde F, Mota J, Ferreira RB. 2017. Proteins in soy might have a higher role in cancer prevention than previously expected: Soybean protein fractions are more effective MMP-9 inhibitors than

Boletín Latinoamericano y del Caribe de Plantas Medicinales y Aromáticas / 30 
non-protein fractions, even in cooked seeds. Nutrients 9: 201. https://doi.org/10.3390\%2Fnu9030201

Lin X, Peng Z, Su C. 2015. Potential anticancer activities and mechanisms of costunolide and dehydrocostuslactone. Int J Mol Sci 16: 10888 - 10906. https://doi.org/10.3390/ijms160510888

Lin J, Cai QY, Xu W, Lin JM, Peng J. 2018. Chemical composition, anticancer, anti-neuroinflammatory, and antioxidant activities of the essential oil of Patrinia scabiosaefolia. Chin J Integr Med 24: 207 - 212. https://doi.org/10.1007/s11655-016-2459-4

Ling B, Xiao S, Yang J, Wei Y, Sakharkar MK, Yang J. 2019. Probing the antitumor mechanism of Solanum nigrum L. aqueous extract against human breast cancer MCF7 cells. Bioengineering 6: 112. https://doi.org/10.3390\%2Fbioengineering6040112

Liu B, Yang Y, Liu H, Xie Z, Li Q, Deng M, Li F, Peng J, Wu H. 2018a. Screening for cytotoxic chemical constituents from Justicia procumbens by HPLC-DAD-ESI-MS and NMR. Chem Cent J 12: 6. https://doi.org/10.1186\%2Fs13065-018-0371-z

Liu Y, Wang Q, Yang J, Guo X, Liu W, Ma S, Li S. 2018b. Polygonum multiflorum Thunb.: A review on chemical analysis, processing mechanism, quality evaluation, and hepatotoxicity. Front Pharmacol 9: 364. https://doi.org/10.3389\%2Ffphar.2018.00364

López-Meyer M, Nessler CL, McKnight TD. 1994. Sites of accumulation of the antitumor alkaloid camptothecin in Camptotheca acuminata. Planta Med 60: 558 - 560. https://doi.org/10.1055/s-2006-959571

Lu C, Zhu L, Piao J, Jiang J. 2012. Chemical compositions extracted from Wikstroemia indica and their multiple activities. Pharmaceut Biol 50: 225 - 231. https://doi.org/10.3109/13880209.2011.596207

Ma L, Qin C, Wang M, Gan D, Cao L, Ye H, Zeng X. 2013. Preparation, preliminary characterization and inhibitory effect on human colon cancer HT-29 cells of an acidic polysaccharide fraction from Stachys floridana Schuttl. ex Benth. Food Chem Toxicol 60: 269 - 276. https://doi.org/10.1016/j.fct.2013.07.060

Magee PJ, Owusu-Apenten R, McCann MJ, Gill CI, Rowland IR. 2012. Chickpea (Cicer arietinum) and other plant-derived protease inhibitor concentrates inhibit breast and prostate cancer cell proliferation in vitro. Nutr Cancer 64: 741 - 748. https://doi.org/10.1080/01635581.2012.688914

Mahata S, Maru S, Shukla S, Pandey A, Mugesh G, Das BC, Bharti AC. 2012. Anticancer property of Bryophyllum pinnata (Lam) Oken.Leaves on human cervical cancer cells. BMC Complement Altern Med 12: 15. https://doi.org/10.1186\%2F1472-6882-12-15

Mahmood U, Kaul VK, Jirovetz L. 2002. Alkylated benzoquinones from Iris kumaonensis. Phytochemistry 61: 923 - 926. https://doi.org/10.1016/s0031-9422(02)00474-0

Majdalawieh AF, Fayyad MW. 2016. Recent advances on the anti-cancer properties of Nigella sativa, a widely used food additive. J Ayurveda Integr Med 7: 173 - 180. https://doi.org/10.1016\%2Fj.jaim.2016.07.004

Mallick MN, Akhtar MS, Najm MZ, Tamboli ET, Ahmad S, Husain SA. 2015a. Evaluation of anticancer potential of Bacopa monnieri L. against MCF-7 and MDA-MB 231 cell line. J Pharm Bioallied Sci 7: 325 - 328. https://doi.org/10.4103\%2F0975-7406.168038

Mallick MN, Singh M, Parveen R, Khan W, Ahmad S, Zeeshan Najm M, Husain SA. 2015b. HPTLC Analysis of bioactivity guided anticancer enriched fraction of hydroalcoholic extract of Picrorhiza kurroa. Biomed Res Int 513875. https://doi.org/10.1155/2015/513875

Maneerat W, Thain S, Cheenpracha S, Prawat U, Laphookhieo S. 2011. New amides from the seeds of Clausana lansium. J Med Plants Res 5: 2812 - 2815.

Manosroi A, Sainakham M, Chankhampan C, Manosroi W, Manosroi J. 2016. In vitro anti-cancer activities of Job's tears (Coix lachryma-jobi Linn.) extracts on human colon adenocarcinoma. Saudi J Biol Sci 23: 248 - 256. https://doi.org/10.1016\%2Fj.sjbs.2015.03.008

Marcotullio MC, Curini M, Becerra JX. 2018. An ethnopharmacological, phytochemical and pharmacological review on lignans from Mexican Bursera spp. Molecules 23: 1976.

https://doi.org/10.3390\%2Fmolecules23081976

Mathankumar M, Tamizhselvi R, Manickam V, Purohit G. 2015. Assessment of anticarcinogenic potential of Vitex trifolia and Triticum aestivum Linn by in vitro rat liver microsomal degranulation. Toxicol Int 22: 114 118. https://doi.org/10.4103\%2F0971-6580.172269

Mathibe LJ, Botha J, Naidoo S. 2016. Z-venusol, from Gunnera perpensa, induces apoptotic cell death in breast cancer cells in vitro. South Afr J Bot 102: 228 - 233. https://doi.org/10.1016/j.sajb.2015.07.010

McGovern PE, Christofidou-Solomidou M, Wang W, Dukes F, Davidson T, El-Deiry WS. 2010. Anticancer 
activity of botanical compounds in ancient fermented beverages (review). Int J Oncol 37: 5 - 14. https://doi.org/10.3892/ijo_00000647

Meena V, Baruah H, Parveen R. 2019. Cassia auriculata: A healing herb for all remedy. J Pharmacogn Phytochem 8: 4093 - 4097.

Merina N, Chandra KJ, Jibon K. 2012. Medicinal plants with potential anticancer activity: A review. Int Res J Pharm 3: 26 - 30.

Mimakia Y, Aokia T, Jitsunoa M, Yokosukaa A, Kiliçb CS, Coşkunb M. 2008. Steroidal saponins from the rhizomes of Ruscus hypophyllum. Nat Prod Commun 3: 1671 - 1678.

Min BS, Gao JJ, Nakamura N, Kim YH, Hattori M. 2001. Cytotoxic alkaloids and a flavan from the bulbs of Crinum asiaticum var. japonicum. Chem Pharm Bull 49: 1217 - 1219.

https://doi.org/10.1248/cpb.49.1217

Mirmalek SA, Azizi MA, Jangholi E, Yadollah-Damavandi S, Javidi MA, Parsa Y, Parsa T, Salimi-Tabatabaee SA, Ghasemzadeh Kolagar H, Alizadeh-Navaei R. 2016. Cytotoxic and apoptogenic effect of hypericin, the bioactive component of Hypericum perforatum on the MCF-7 human breast cancer cell line. Cancer Cell Int 16: 3. https://doi.org/10.1186\%2Fs12935-016-0279-4

Mishra S, Aeri V, Gaur PK, Jachak SM. 2014. Phytochemical, therapeutic, and ethnopharmacological overview for a traditionally important herb: Boerhavia diffusa Linn. BioMed Res Int 808302. https://doi.org/10.1155/2014/808302

Mithun PR, Xavier J, Reddy J, Praveen N. 2017. Production of camptothecin from Nothapodytes nimmoniana: An overview. Int J Life Sci Scientif Res 3: 1476 - 1483. http://doi.org/10.21276/ijlssr.2017.3.6.9

Mitra SK, Prakash NS, Sundaram R. 2012. Shatavarins (containing Shatavarin IV) with anticancer activity from the roots of Asparagus racemosus. Ind J Pharmacol 44: 732 - 736. https://doi.org/10.4103\%2F0253-7613.103273

Moga MA, Balan A, Anastasiu CV, Dimienescu OG, Neculoiu CD, Gavriș C. 2018. An overview on the anticancer activity of Azadirachta indica (Neem) in gynecological cancers. Int J Mol Sci 19: 3898. https://doi.org/10.3390\%2Fijms19123898

Monika, Singh J. 2015. Plants and phytochemicals as potential source of anticancer agents. Inte J Adv Res 3: 307 317.

Montopoli M, Bertin R, Chen Z, Bolcato J, Caparrotta L, Froldi G. 2012. Croton lechleri sap and isolated alkaloid taspine exhibit inhibition against human melanoma SK23 and colon cancer HT29 cell lines. J Ethnopharmacol 144:747 - 753. http://doi.org/10.1016/j.jep.2012.10.032

Moon MK, Han YM, Lee YJ, Lee LH, Yang JH, Kwon BM, Kim DK. 2010. Inhibitory activities of anthraquinones from Rubia akane on phosphatase regenerating liver-3. Arch Pharm Res 33: 1747 - 1751. https://doi.org/10.1007/s12272-010-1106-4

Morán-Santibañez K, Vasquez AH, Varela-Ramirez A, Henderson V, Sweeney J, Odero-Marah V, Fenelon K, Skouta R. 2019. Larrea tridentata extract mitigates oxidative stress-induced cytotoxicity in human neuroblastoma SH-SY5Y cells. Antioxidants 8: 427. https://doi.org/10.3390\%2Fantiox8100427

Mothana RA, Grünert R, Lindequist U, Bednarski PJ. 2007. Study of the anticancer potential of Yemeni plants used in folk medicine. Pharmazie 62: 305 - 307. https://doi.org/10.1691/ph.2007.4.6696

Motta L, Furlan C, Santos D, Salatino M, Duarte-Almeida J, Negri G, Carvalho J, Ruiz A, Cordeiro I, Salatino A. 2011. Constituents and antiproliferative activity of extracts from leaves of Croton macrobothrys. Rev Bras Farmacogn 21: 972 - 977. https://doi.org/10.1590/S0102-695X2011005000174

Mousa AM, El-Sammad NM, Abdel-Halim AH, Anwar N, Khalil WKB, Nawwar M, Hashim AN, Elsayed EA, Hassan SK. 2019. Lagerstroemia speciosa (L.) Pers leaves extract attenuates lung tumorigenesis via alleviating oxidative stress, inflammation and apoptosis. Biomolecules 9: 871.

https://doi.org/10.3390/biom9120871

Mukhija M, Singh MP, Dhar KL, Kalia AN. 2015. Cytotoxic and antioxidant activity of Zanthoxylum alatum stem bark and its flavonoid constituents. J Pharm Phytochem 4: 86.

Nagata T, Win N, Xiao Long L, Miwa T, Okumura T, Fushimi H, Morita H, Shimada Y. 2016. Anti-cancer effect of Saxifraga stolonifera Meerb. Clin Exp Pharmacol 6: 211. https://doi.org/10.4172/2161-1459.1000211

Nair PK, Melnick SJ, Wnuk SF, Rapp M, Escalon E, Ramachandran C. 2009. Isolation and characterization of an anticancer catechol compound from Semecarpus anacardium. J Ethnopharmacol 122: 450 - 456.

Boletín Latinoamericano y del Caribe de Plantas Medicinales y Aromáticas / 32 
https://doi.org/10.1016/j.jep.2009.02.001

Nakahata AM, Mayer B, Rie C, de Paula CA, Karow M, Neth P, Sampaio MU, Jochum M, Oliva MLV. 2011. The effects of a plant proteinase inhibitor from Enterolobium contortisiliquum on human tumor cell lines. Biol Chem 392: 327 - 336. https://doi.org/10.1515/bc.2011.031

Nazmi SA, Nourazarian A, Bahhaj R, Khakikhatibi F. 2018. The anticancer effect of Arctium lappa and Glycyrrhiza glabra on HT-29 colon cancer and MCF-7 breast cancer cell lines. Crescent J Medical Biol Sci 5: 133 - 137.

Ncube B, Ndhlala AR, Okem A, Van Staden J. 2013. Hypoxis (Hypoxidaceae) in African traditional medicine. J Ethnopharmacol 150: 818 - 827. https://doi.org/10.1016/j.jep.2013.10.032

Neto CC, Amoroso JW, Liberty AM. 2008. Anticancer activities of cranberry phytochemicals: an update. Mol Nutr Food Res 52: 18 - 27. https://doi.org/10.1002/mnfr.200700433

Ng TB, Lam YW, Wang H. 2003. Calcaelin, a new protein with translation-inhibiting, antiproliferative and antimitogenic activities from the mosaic puffball mushroom Calvatia caelata. Planta Med 69: 212 - 217. https://doi.org/10.1055/s-2003-38492

Nho KJ, Chun JM, Lee AY, Kim HK. 2015. Anti-metastatic effects of Rheum palmatum L. extract in human MDAMB-231 breast cancer cells. Environ Toxicol Pharmacol 40: 30 - 38. https://doi.org/10.1016/j.etap.2015.05.006

Nono EC, Mkounga P, Kuete V, Marat K, Hultin PG, Nkengfack AE. 2010. Pycnanthulignenes A-D, antimicrobial cyclolignene derivatives from the roots of Pycnanthus angolensis. J Nat Prod 73: 213 - 216. https://doi.org/10.1021/np9007393

Norikura T, Kojima-Yuasa A, Shimizu M, Huang X, Xu S, Kametani S, Rho S, Kennedy D, Matsui-Yuasa I. 2008. Anticancer activities and mechanisms of Blumea balsamifera extract in hepatocellular carcinoma cells. Am J Chin Med 36: 411 - 424. https://doi.org/10.1142/S0192415X08005862

Ogbourne SM, Suhrbier A, Jones B, Cozzi SJ, Boyle GM, Morris M, McAlpine D, Johns J, Scott TM, Sutherland KP, Gardner JM, Le TT, Lenarczyk A, Aylward JH, Parsons PG. 2004. Antitumor activity of 3 -ingenyl angelate: plasma membrane and mitochondrial disruption and necrotic cell death. Cancer Res 64: 2833 2839. https://doi.org/10.1158/0008-5472.can-03-2837

Ogunwande IA, Walker TM, Bansal A, Setzer WN, Essien EE. 2010. Essential oil constituents and biological activities of Peristrophe bicalyculata and Borreria verticillata. Nat Prod Commun 5: 1815 - 1828.

Oh J, Rho HS, Yang Y, Yoon JY, Lee J, Hong YD, Kim HC, Choi SS, Kim TW, Shin SS, Cho JY. 2013. Extracellular signal-regulated kinase is a direct target of the anti-inflammatory compound amentoflavone derived from Torreya nucifera. Mediators Inflamm 761506. https://doi.org/10.1155/2013/761506

Ohyama K, Akaike T, Hirobe C, Yamakawa T. 2003. Cytotoxicity and apoptotic inducibility of Vitex agnus-castus fruit extract in cultured human normal and cancer cells and effect on growth. Biol Pharm Bull 26: 10 - 18. https://doi.org/10.1248/bpb.26.10

Ombra MN, d'Acierno A, Nazzaro F, Riccardi R, Spigno P, Zaccardelli M, Pane C, Maione M, Fratianni F. 2016. Phenolic composition and antioxidant and antiproliferative activities of the extracts of twelve common bean (Phaseolus vulgaris L.) endemic ecotypes of Southern Italy before and after Cooking. Oxid Med Cell Longev 1398298. https://doi.org/10.1155\%2F2016\%2F1398298

Ong SKL, Shanmugam MK, Fan L, Fraser SE, Arfuso F, Ahn KS, Sethi G, Bishayee A. 2019. Focus on formononetin: Anticancer potential and molecular targets. Cancers 11: 611. https://doi.org/10.3390\%2F cancers11050611

Ooko E, Kadioglu O, Greten HJ, Efferth T. 2017. Pharmacogenomic characterization and isobologram analysis of the combination of ascorbic acid and curcumin-two main metabolites of Curcuma longa-in cancer cells. Front Pharmacol 8: 38. https://doi.org/10.3389/fphar.2017.00038

Osman NHA, Said UZ, El-Waseef AM, Ahmed ESA. 2015. Luteolin supplementation adjacent to aspirin treatment reduced dimethyl hydrazine-induced experimental colon carcinogenesis in rats. Tumour Biol 36: 1179 1190. https://doi.org/10.1007/s13277-014-2678-2

Öztürk B, Kocaoğlu EH, Durak ZE. 2015. Effects of aqueous extract from Silybum marianum on adenosine deaminase activity in cancerous and noncancerous human gastric and colon tissues. Pharmacogn Mag 11: 143 - 146. https://doi.org/10.4103\%2F0973-1296.149729

Pal D, Mishra P, Sachan N, Ghosh AK. 2011. Biological activities and medicinal properties of Cajanus cajan (L) 
Millsp. J Adv Pharm Technol Res 2: 207 - 214. https://doi.org/10.4103\%2F2231-4040.90874

Palmieri A, Scapoli L, Iapichino A, Mercolini L, Mandrone M, Poli F, Giannì AB, Baserga C, Martinelli M. 2019. Berberine and Tinospora cordifolia exert a potential anticancer effect on colon cancer cells by acting on specific pathways. Int J Immunopathol Pharmacol 33: 1 - 10.

https://doi.org/10.1177\%2F2058738419855567

Panda SK, Padhi L, Leyssen P, Liu M, Neyts J, Luyten W. 2017. Antimicrobial, anthelmintic, and antiviral activity of plants traditionally used for treating infectious disease in the Similipal Biosphere Reserve, Odisha, India. Front Pharmacol 8: 658. https://doi.org/10.3389\%2Ffphar.2017.00658

Pang SQ, Wang GQ, Lin JS, Diao Y, Xu RA. 2014a. Cytotoxic activity of the alkaloids from Broussonetia papyrifera fruits. Pharm Biol 52: 1315 - 1319. https://doi.org/10.3109/13880209.2014.891139

Pang Y, Wang D, Fan Z, Chen X, Yu F, Hu X, Wang K, Yuan L. 2014b. Blumea balsamifera-A phytochemical and pharmacological review. Molecules 19: 9453 - 9477. https://doi.org/10.3390/molecules19079453

Park M, Cheon MS, Kim SH, Chun JM, Lee AY, Moon BC, Yoon T, Choo BK, Kim HK. 2011. Anticancer activity of Asparagus cochinchinensis extract and fractions in HepG2 cells. J Korean Soc Appl Biol Chem 54: 188 - 193. https://doi.org/10.3839/jksabc.2011.031

Park GH, Park JH, Song HM, Eo HJ, Kim MK, Lee JW, Lee MH, Cho KH, Lee JR, Cho HJ, Jeong JB. 2014. Anticancer activity of Ginger (Zingiber officinale) leaves through the expression of activating transcription factor 3 in human colorectal cancer cells. BMC Complement Altern Med 14: 408. https://doi.org/10.1186\%2F1472-6882-14-408

Park KI, Park H, Nagappan A, Hong GE, Yumnam S, Lee HJ, Kim EH, Lee WS, Shin SC, Kim JA, Lee SJ, Ma JY, Min T, Heo JD, Kim GS. 2017. Polyphenolic compounds from Korean Lonicera japonica Thunb. induces apoptosis via AKT and caspase cascade activation in A549 cells. Oncol Lett 13: 2521 - 2530. https://doi.org/10.3892\%2Fol.2017.5771

Peng B, Hu Q, Liu X, Wang L, Chang Q, Li J, Tang J, Wang N, Wang Y. 2009. Duchesnea phenolic fraction inhibits in vitro and in vivo growth of cervical cancer through induction of apoptosis and cell cycle arrest. Exp Biol Med 234: 74 - 83. https://doi.org/10.3181/0806-rm-204

Pilarski R, Filip B, Wietrzyk J, Kuraś M, Gulewicz K. 2010. Anticancer activity of the Uncaria tomentosa (Willd.) DC. preparations with different oxindole alkaloid composition. Phytomedicine 17: 1133 - 1139. https://doi.org/10.1016/j.phymed.2010.04.013

Pintha K, Yodkeeree S, Pitchakarn P, Limtrakul P. 2014. Anti-invasive activity against cancer cells of phytochemicals in red jasmine rice (Oryza sativa L.). Asian Pac J Cancer Prev 15: 4601 - 4607. https://doi.org/10.7314/apjcp.2014.15.11.4601

Pires TC, Dias MI, Calhelha RC, Carvalho AM, Queiroz MJ, Barros L, Ferreira IC. 2015. Bioactive properties of Tabebuia impetiginosa-based phytopreparations and phytoformulations: A comparison between extracts and dietary supplements. Molecules 20: 22863 - 22871. https://doi.org/10.3390\%2Fmolecules201219885

Powrie AH. 1975. The chemical constituents of Knowltonia capensis. Thesis, University of Cape Town, South Africa. http://hdl.handle.net/11427/12326

Pradheepkumar CP, Shanmugam G. 1999. Anticancer potential of cleistanthin A isolated from the tropical plant Cleistanthus collinus. Oncol Res 11: 225 - 232.

Prakash O, Kumar A, Kumar P, Ajeet. 2013. Anticancer potential of plants and natural products: A review. Am J Pharmacol Sci 1: 104 - 115. https://doi.org/10.12691/AJPS-1-6-1

Prasad SK, Singh MK. 2015. Horse gram- an underutilized nutraceutical pulse crop: a review. J Food Sci Technol 52: 2489 - 2499. https://doi.org/10.1007\%2Fs13197-014-1312-z

Pratama F, Rizki M, Suratno S, Mulyani E. 2018. Antibacterial activity of akar kuning (arcangelisia flava) secondary metabolites: molecular docking approach. Asian J Pharm Clin Res 11: 447 - 451. https://doi.org/10.22159/ajpcr.2018.v11i11.29189

Pratheeshkumar P, Kuttan G. 2011. Vernolide-A, a sesquiterpene lactone from Vernonia cinerea, induces apoptosis in B16F-10 melanoma cells by modulating p53 and caspase-3 gene expressions and regulating NF- $\kappa \mathrm{B}-$ mediated bcl-2 activation. Drug Chem Toxicol 34: 261 - 270.

https://doi.org/10.3109/01480545.2010.520017

Prema G, Chitra M, Kanagasabai R. 2019. Studies on antimicrobial activity of Ziziphus rugosa Lam. pericarp. Int J Pharm Sci Res 10: 4942 - 4948. https://doi.org/10.13040/IJPSR.0975-8232.10(11).4942-48

Boletín Latinoamericano y del Caribe de Plantas Medicinales y Aromáticas / 34 
Privitera G, Luca T, Castorina S, Passanisi R, Ruberto G, Napoli E. 2019. Anticancer activity of Salvia officinalis essential oil and its principal constituents against hormone-dependent tumour cells. Asian Pac J Trop Biomed 9: 24 - 28. https://doi.org/10.4103/2221-1691.250266

Qadir M, Dangroo NA, Shah SWA. 2019. Bioactivity-guided phytochemical investigations of Artemisia maritima: isolation and characterization of chemical constituents. Asian J Pharm Clin Res 12: 269 - 274. https://doi.org/10.22159/ajpcr.2019.v12i1.28600

Radhika M, Ghoshal N, Chatterjee A. 2012. Comparison of effectiveness in antitumor activity between flavonoids and polyphenols of the methanolic extract of roots of Potentilla fulgens in breast cancer cells. $\mathbf{J}$ Complement Integr Med 9: 24. https://doi.org/10.1515/1553-3840.1644

Ray SD, Dewanjee S. 2015. Isolation of a new triterpene derivative and in vitro and in vivo anticancer activity of ethanolic extract from root bark of Zizyphus nummularia Aubrev. Nat Prod Res 29: 1529 - 1536. https://doi.org/10.1080/14786419.2014.983921

Renukadevi KP, Sultana SS. 2011. Determination of antibacterial, antioxidant and cytotoxicity effect of Indigofera tinctoria on lung cancer cell line NCI-h69. Int J Pharmacol 7: 356 - 362.

http://doi.org/10.3923/ijp.2011.356.362

Restrepo DA, Saenz E, Jara-Muñoz OA, Calixto-Botía IF, Rodríguez-Suárez S, Zuleta P, Chavez BG, Sanchez JA, D'Auria JC. 2019. Erythroxylum in focus: An interdisciplinary review of an overlooked genus. Molecules 24: 3788. https://doi.org/10.3390\%2Fmolecules24203788

Rice S, Amon A, Whitehead SA. 2007. Ethanolic extracts of black cohosh (Actaea racemosa) inhibit growth and oestradiol synthesis from oestrone sulphate in breast cancer cells. Maturitas 56: 359 - 367. https://doi.org/10.1016/j.maturitas.2006.10.002

Robinson A, Kumar TV, Sreedhar E, Naidu VG, Krishna SR, Babu KS, Srinivas PV, Rao JM. 2008. A new sesquiterpene lactone from the roots of Saussurea lappa: structure-anticancer activity study. Bioorg Med Chem Lett 18: 4015 - 4017. https://doi.org/10.1016/j.bmcl.2008.06.008

Rosangkima G, Prasad SB. 2004. Antitumour activity of some plants from Meghalaya and Mizoram against murine ascites Dalton's lymphoma. Ind J Exp Biol 42: 981 - 988.

Rungruangmaitree R, Jiraungkoorskul W. 2017. Pea, Pisum sativum, and its anticancer activity. Pharmacogn Rev 11: 39 - 42. https:/doi.org/10.4103\%2Fphrev.phrev_57_16

Rzeski W, Stepulak A, Szymański M, Sifringer M, Kaczor J, Wejksza K, Zdzisińska B, Kandefer-Szerszeń M. 2006. Betulinic acid decreases expression of bcl-2 and cyclin D1, inhibits proliferation, migration and induces apoptosis in cancer cells. Naunyn Schmiedebergs Arch Pharmacol 374: 11 - 20.

https://doi.org/10.1007/s00210-006-0090-1

Safia, Kamil M, Jadiya P, Sheikh S, Haque E, Nazir A, Lakshmi V, Mir SS. 2015. The chromone alkaloid, rohitukine, affords anti-cancer activity via modulating apoptosis pathways in A549 cell line and yeast mitogen activated protein kinase (MAPK) pathway. Plos One 10: e0137991.

https://doi.org/10.1371\%2Fjournal.pone.0137991

Sahreen S, Khan MR, Khan RA, Shah NA. 2013. Estimation of flavonoids, antimicrobial, antitumor and anticancer activity of Carissa opaca fruits. BMC Compl Alter Med 13: 372.

https://doi.org/10.1186/1472-6882-13-372

Saibu GM, Katerere DR, Rees DJ, Meyer M. 2015. In vitro cytotoxic and pro-apoptotic effects of water extracts of Tulbaghia violacea leaves and bulbs. J Ethnopharmacol 164: 203 - 209. https://doi.org/10.1016/j.jep.2015.01.040

Sakarkar DM, Deshmukh VN. 2011. Ethnopharmacological review of traditional medicinal plants for anti-cancer activity. Int J Pharm Technol Res 3: 298 - 308.

Samarghandian S, Hadjzadeh MA, Afshari JT, Hosseini M. 2014. Antiproliferative activity and induction of apoptotic by ethanolic extract of Alpinia galanga rhizhome in human breast carcinoma cell line. BMC Complement Altern Med 14: 192. https://doi.org/10.1186/1472-6882-14-192

Samuel P, Kumar VJ, Dhayalan DR, Amirtharaj K, Sudarmani DNP. 2017. Bioprospecting of Salicornia europaea L. a marine halophyte and evaluation of its biological potential with special reference to anticancer activity. J Pharma Pharma Sci 2: 138. http://doi.org/10.29011/2574-7711/100038

Sandoval TA, Urueña CP, Llano M, Gómez-Cadena A, Hernández JF, Sequeda LG, Loaiza AE, Barreto A, Li S, Fiorentino S. 2016. Standardized extract from Caesalpinia spinosa is cytotoxic over cancer stem cells and 
enhance anticancer activity of doxorubicin. Am J Chin Med 44: 1693 - 1717.

https://doi.org/10.1142/s0192415x16500956

Sarno F, Pepe G, Termolino P, Carafa V, Massaro C, Merciai F, Campiglia P, Nebbioso A, Altucci L. 2020. Trifolium repens blocks proliferation in chronic myelogenous leukemia via the BCR-ABL/STAT5 pathway. Cells 9: 379. https://doi.org/10.3390\%2Fcells9020379

Satheesh LS, Murugan K. 2011.Antimicrobial activity of protease inhibitor from leaves of Coccinia grandis (L.) Voigt. Indian J Exp Biol 49: 366 - 374.

Shaikh R, Pund M, Dawane A, Iliyas S. 2014. Evaluation of anticancer, antioxidant, and possible anti-inflammatory properties of selected medicinal plants used in indian traditional medication. J Tradit Complement Med 4: 253 - 257. https://doi.org/10.4103\%2F2225-4110.128904

Shalabi M, Khilo K, Zakaria M, Elsebaei M, Abdo W, Awadin W. 2015. Anticancer activity of Aloe vera and Calligonum comosum extracts separetely on hepatocellular carcinoma cells. Asia Pac J Trop Biomed 5: 375 - 381. https://doi.org/10.1016/S2221-1691(15)30372-5

Shang W, Qiao J, Gu C, Yin W, Du J, Wang W, Zhu M, Han M, Lu W. 2011. Anticancer activity of an extract from needles and twigs of Taxus cuspidata and its synergistic effect as a cocktail with 5-fluorouracil. BMC Complement Altern Med 11: 123. https://doi.org/10.1186/1472-6882-11-123

Sharma H, Parihar L, Parihar P. 2011. Review on cancer and anticancerous properties of some medicinal plants. J Med Plant Res 5: 1818 - 1835.

Sharma N, Sharma A, Bhatia G, Landi M, Brestic M, Singh B, Singh J, Kaur S, Bhardwaj R. 2019. Isolation of phytochemicals from Bauhinia variegate L. bark and their in vitro antioxidant and cytotoxic potential. Antioxidants 8: 492. https://doi.org/10.3390/antiox8100492

She T, Qu L, Wang L, Yang X, Xu S, Feng J, Gao Y, Zhao C, Han Y, Cai S, Shou C. 2015. Sarsaparilla (Smilax Glabra Rhizome) extract inhibits cancer cell growth by S phase arrest, apoptosis, and autophagy via redoxdependent ERK1/2 pathway. Cancer Prev Res 8: 464 - 474.

https://doi.org/10.1158/1940-6207.capr-14-0372

Shebaby WN, Mroueh M, Bodman-Smith K, Mansour A, Taleb RI, Daher CF, El-Sibai M. 2014. Daucus carota pentane-based fractions arrest the cell cycle and increase apoptosis in MDA-MB-231 breast cancer cells. BMC Complement Altern Med 14: 387. https://doi.org/10.1186\%2F1472-6882-14-387

Shendge AK, Basu T, Chaudhuri D, Panja S, Mandal N. 2017. In vitro antioxidant and antiproliferative activities of various solvent fractions from Clerodendrum viscosum leaves. Pharmacogn Mag 13: 344 - 353. https://doi.org/10.4103\%2Fpm.pm_395_16

Sheng L, Yang Y, Zhang Y, Li N. 2019. Chemical constituents of Patrinia heterophylla Bunge and selective cytotoxicity against six human tumor cells. J Ethnopharmacol 236: 129 - 135. https://doi.org/10.1016/j.jep.2019.03.005

Shenouda NS, Sakla MS, Newton LG, Besch-Williford C, Greenberg NM, MacDonald RS, Lubahn DB. 2007. Phytosterol Pygeum africanum regulates prostate cancer in vitro and in vivo. Endocrine 31: 72 - 81. https://doi.org/10.1007/s12020-007-0014-y

Shi G, Liu J, Zhao W, Liu Y, Tian X. 2016. Separation and purification and in vitro anti-proliferative activity of leukemia cell K562 of Galium aparine L. petroleum ether phase. Saudi Pharm J 24: 241 - 244. https://doi.org/10.1016\%2Fj.jsps.2016.04.005

Shibata S, Nishikawa Y, Takeda T, Tanaka M, Fukuoka F. 1968. Studies on the chemical structures of the new glucans isolated from Gyrophora esculenta Miyoshi and Lasallia papulosa (Ach.) Llano and their inhibiting effect on implanted sarcoma 180 in mice. Chem Pharm Bull 16: 1639 - 1641. https://doi.org/10.1248/cpb.16.1639

Shin Y, Lee Y. 2013. Cytotoxic activity from Curcuma zedoaria through mitochondrial activation on ovarian cancer cells. Toxicol Res 29: 257 - 261. https://doi.org/10.5487\%2FTR.2013.29.4.257

Shoeb M, Celik S, Jaspars M, Kumarasamy Y, MacManus S, Nahar L, Thoo-Lin P, Sarker S. 2005. Isolation, structure elucidation and bioactivity of schischkiniin, a unique indole alkaloid from the seeds of Centaurea schischkinii. Tetrahedron 61: 9001 - 9006. https://doi.org/10.1016/j.tet.2005.07.047

Shoeb M, MacManus, S, Jaspars, M, Trevidu, J, Nahar, L, Kong-Thoo-Lin, P, Sarker, S. 2006. Montamine, a unique dimeric indole alkaloid, from the seeds of Centaurea montana (Asteraceae), and its in vitro cytotoxic activity against the $\mathrm{CaCo} 2$ colon cancer cells. Tetrahedron 62: 11172 - 11177.

Boletín Latinoamericano y del Caribe de Plantas Medicinales y Aromáticas / 36 
https://doi.org/10.1016/j.tet.2006.09.020

Shoemaker M, Hamilton B, Dairkee SH, Cohen I, Campbell MJ. 2005. In vitro anticancer activity of twelve Chinese medicinal herbs. Phytother Res 19: 649 - 651. https://doi.org/10.1002/ptr.1702

Siegel RL, Miller KD, Jemal A. 2018. Cancer statistics, 2018. CA Cancer J Clin 68: 7 - 30. https://doi.org/10.3322/caac.21442

Sigstedt SC, Hooten CJ, Callewaert MC, Jenkins AR, Romero AE, Pullin MJ, Kornienko A, Lowrey TK, Slambrouck SV, Steelant WF. 2008. Evaluation of aqueous extracts of Taraxacum officinale on growth and invasion of breast and prostate cancer cells. Int J Oncol 32: 1085 - 1090.

Singh TD, Meitei HT, Sharma AL, Robinson A, Singh LS, Singh TR. 2015. Anticancer properties and enhancement of therapeutic potential of cisplatin by leaves extract of Zanthoxylum armatum DC. Biol Res 48: 46. https://doi.org/10.1186\%2Fs40659-015-0037-4

Sivalokanathan S, Vijayababu MR, Balasubramanian MP. 2006. Effects of Terminalia arjuna bark extract on apoptosis of human hepatoma cell line HepG2. World J Gastroenterol 12: 1018 - 1024. https://doi.org/10.3748\%2Fwjg.v12.i7.1018

Srikanth S, Chen Z. 2016. Plant protease inhibitors in therapeutics-focus on cancer therapy. Front Pharmacol https://doi.org/10.3389/fphar.2016.00470

Srinivas K, Afolayan, AJ. 2007. Ethnobotanical information of medicinal plants used for treatment of cancer in the Eastern Cape Province, South Africa. Curr Sci 92: 906 - 908.

Stapel J, Oppermann C, Richter DU, Ruth W, Briese V. 2015. Anti-carcinogenic effects of ethanolic extracts from root and shoot of Lupinus angustifolius on breast carcinoma cell lines MCF-7 and BT20. J Med Plant Res 9: 561 - 568. https://doi.org/10.5897/JMPR2014.5392

Stipanovic RD, Puckhaber LS, Liu J, Bell AA. 2009. Total and percent atropisomers of gossypol and gossypol-6methyl ether in seeds from pima cottons and accessions of Gossypium barbadense L. J Agric Food Chem 57: 566 - 571. https://doi.org/10.1021/jf802756e

Subhadradevi V, Khairunissa K, Asokkumar K, Sivashanmugam MUA, Jagannath P. 2011. Induction of apoptosis and cytotoxic activities of Apium graveolens Linn. using in vitro models. Middle East J Sci Res 9: 90 - 94.

Sugata M, Lin CY, Shih YC. 2015. Anti-inflammatory and anticancer activities of taiwanese purple-fleshed sweet potatoes (Ipomoea batatas L. Lam) extracts. Biomed Res Int https://doi.org/10.1155/2015/768093

Sun J, Wang H, Ng TB. 2010. Trypsin isoinhibitors with antiproliferative activity toward leukemia cells from Phaseolus vulgaris cv "White Cloud Bean". J Biomed Biotechnol 219793.

https://doi.org/10.1155/2010/219793

Sun M, Cao H, Sun L, Dong S, Bian Y, Han J, Zhang L, Ren S, Hu Y, Liu C, Xu L, Liu P. 2012. Antitumor activities of kushen: literature review. Evid Based Complement Alternat Med 373219. https://doi.org/10.1155\%2F2012\%2F373219

Sun Q, Liu K, Shen X, Jin W, Jiang L, Sheikh MS, Hu Y, Huang Y. 2014. Lappaol F, a novel anticancer agent isolated from plant arctium Lappa L. Mol Cancer Ther 13: 49 - 59. https://doi.org/10.1158/1535-7163

Sun Y, Li J, Zhang Y, Tu Y, Huang C, Tao J, Yang M, Yang L. 2018. The polysaccharide extracted from Umbilicaria esculenta inhibits proliferation of melanoma cells through ROS-activated mitochondrial apoptosis pathway. Biol Pharm Bull 41: 57 - 64. https://doi.org/10.1248/bpb.b17-00562

Suresh P, Xavier A. S, Karthik V. P, Punnagai K. 2019. Anticancer activity of Cissus quadrangularis L. methanolic extract against MG63 human osteosarcoma cells - an in-vitro evaluation using cytotoxicity assay. Biomed Pharmacol J 12 https://doi.org/10.13005/bpj/1724

Tahergorabi Z, Abedini MR, Mitra M, Fard MH, Beydokhti H. 2015. "Ziziphus jujuba": A red fruit with promising anticancer activities. Pharmacogn Rev 9: 99 - 106. https://doi.org/10.4103\%2F0973-7847.162108

Tandon SF, Rastogi RP. 1976. Wikstromol, a new lignan from Wikstroemia viridiflora. Phytochemistry 15: 1789 1791. https://doi.org/10.1016/S0031-9422(00)97493-4

Tang SW, Sukari MA, Neoh BK, Yeap YS, Abdul AB, Kifli N, Ee GC. 2014. Phytochemicals from Kaempferia angustifolia Rosc. and their cytotoxic and antimicrobial activities. Biomed Res Int 417674. https://doi.org/10.1155/2014/417674

Tariq A, Sadia S, Pan K, Ullah I, Mussarat S, Sun F, Abiodun OO, Batbaatar A, Li Z, Song D, Xiong Q, Ullah R, Khan S, Basnet BB, Kumar B, Islam R, Adnan M. 2017. A systematic review on ethnomedicines of anticancer plants. Phytother Res 31: 202 - 264. https://doi.org/10.1002/ptr.5751

Boletín Latinoamericano y del Caribe de Plantas Medicinales y Aromáticas / 37 
Tascilar M, de Jong FA, Verweij J, Mathijssen RH. 2006. Complementary and alternative medicine during cancer treatment: beyond innocence. Oncologist 11: 732 - 741. https://doi.org/10.1634/theoncologist.11-7-732

Telang N, Nair HB, Wong GYC. 2019. Growth inhibitory efficacy and anti-aromatase activity of Tabebuia avellanedae in a model for post-menopausal Luminal A breast cancer. Biomed Rep 11: 222 - 229. https://doi.org/10.3892\%2Fbr.2019.1244

Thi ND, Hwang ES. 2018. Anti-cancer and anti-inflammatory activities of aronia (Aronia melanocarpa) leaves. Asian Pac J Trop Biomed 8: 586 - 592.

Ukiya M, Akihisa T, Tokuda H, Suzuki H, Mukainaka T, Ichiishi E, Yasukawa K, Kasahara Y, Nishino H. 2002. Constituents of Compositae plants III. Anti-tumor promoting effects and cytotoxic activity against human cancer cell lines of triterpene diols and triols from edible chrysanthemum flowers. Cancer Lett 177: 7 - 12. https://doi.org/10.1016/s0304-3835(01)00769-8

Ulubelen A, Topçu G, Chai H, Pezzuto JM. 1999. Cytotoxic activity of diterpenoids isolated from Salvia hypargeia. Pharm Biol 37: 148 - 151. https://doi.org/10.1076/phbi.37.2.148.6082

Veljkovic B, Djordjevic N, Dolicanin Z, Licina B, Topuzovic M, Stankovic M, Zlatic N, Dajic-stevanovic Z. 2018. Antioxidant and anticancer properties of leaves and fruit extracts of the wild Raspberry (Rubus idaeus L.). Not Bot Horti Agrobot Cluj Napoca 47: 359 - 367. https://doi.org/10.15835/nbha47111274

Vetchinkina E, Shirokov A, Bucharskaya A, Navolokin N, Prilepskii A, Burov A, Maslyakova G, Nikitina VE. 2016. Antitumor activity of extracts from medicinal basidiomycetes mushrooms. Int J Med Mushrooms 18: 955 - 964. https://doi.org/10.1615/intjmedmushrooms.v18.i11.10

Wabo HK, Kouam SF, Krohn K, Hussain H, Tala MF, Tane P, Ree Tv, Hu Q, Schulz B. 2007. Prenylated anthraquinones and other constituents from the seeds of Vismia laurentii. Chem Pharm Bull 55: 1640 1642. https://doi.org/10.1248/cpb.55.1640

Wall ME, Wani MC. 1996. Camptothecin. Discovery to clinic. Ann New York Acad Sci 803: 1 - 12. https://doi.org/10.1111/j.1749-6632.1996.tb26371.x

Wan G, Tao JG, Wang GD, Liu SP, Zhao HX, Liang QD. 2016. In vitro antitumor activity of the ethyl acetate extract of Potentilla chinensis in osteosarcoma cancer cells. Mol Med Rep 14: 3634 - 3640. https://doi.org/10.3892\%2Fmmr.2016.5679

Wang CZ, Xie JT, Zhang B, Ni M, Fishbein A, Aung HH, Mehendale SR, Du W, He TC, Yuan CS. 2007a. Chemopreventive effects of Panax notoginseng and its major constituents on SW480 human colorectal cancer cells. Int J Oncol 31: 1149 - 1156. https://doi.org/10.3892/ijo.31.5.1149

Wang SY, Feng R, Bowman L, Lu Y, Ballington JR, Ding M. 2007b. Antioxidant activity of Vaccinium stamineum: exhibition of anticancer capability in human lung and leukemia cells. Planta Med 73: 451 460. https://doi.org/10.1055/s-2007-967164

Wang CZ, Aung HH, Zhang B, Sun S, Li XL, He H, Xie JT, He TC, Du W, Yuan CS. 2008. Chemopreventive effects of heat-processed Panax quinquefolius root on human breast cancer cells. Anticancer Res 28: 2545 $-2551$.

Wang Y, Hong C, Zhou C, Xu D, Qu H. 2011. Screening antitumor compounds psoralen and isopsoralen from Psoralea corylifolia L. Seeds. Evid Based Complement Alternat Med 363052. https://doi.org/10.1093/ecam/nen087

Wang CZ, Zhang Z, Wan JY, Zhang CF, Anderson S, He X, Yu C, He TC, Qi LW, Yuan CS. 2015. Protopanaxadiol, an active ginseng metabolite, significantly enhances the effects of fluorouracil on colon cancer. Nutrients 7: 799 - 814. https://doi.org/10.3390\%2Fnu7020799

Wang R, Xiao S, Niu Z. 2017. Anti-cancer activity of Aster tataricus on SCC-9 human oral squamous carcinoma. Afr J Tradit Complement Altern Med 4: 142 - 147. https://doi.org/10.21010\%2Fajtcam.v14i2.15

Wani MC, Taylor HL, Wall ME, Coggon P, McPhail AT. 1971. Plant antitumor agents. VI. The isolation and structure of taxol, a novel antileukemic and antitumor agent from Taxus brevifolia. J Am Chem Soc 93: 2325 - 2327. https://doi.org/10.1021/ja00738a045

Wee HN, Neo SY, Singh D, Yew HC, Qiu ZY, Tsai XC, How SY, Yip KC, Tan CH, Koh HL. 2020. Effects of Vitex trifolia L. leaves extracts and phytoconstituents on cytokine production in human U937 macrophages. BMC Complement Med Ther 20: 91. https://doi.org/10.1186\%2Fs12906-020-02884-w

William CSC, Kwok LN. 2007. In vitro and in vivo anti-tumor effects of Astragalus membranaceus. Cancer Lett 252: 43 - 54. https://doi.org/10.1016/j.canlet.2006.12.001

Boletín Latinoamericano y del Caribe de Plantas Medicinales y Aromáticas / 38 
Wong FC, Woo CC, Hsu A, Tan BK. 2013. The anti-cancer activities of Vernonia amygdalina extract in human breast cancer cell lines are mediated through caspase-dependent and p53-independent pathways. Plos One 8: e78021. https://doi.org/10.1371\%2Fjournal.pone.0078021

WHO. 2018. (World Health Organization). Cancer key factor. https://www.who.int/news-room/fact-sheets/detail/cancer

Wu PL, Lin SB, Huang CP, Chiou RY. 2002. Antioxidative and cytotoxic compounds extracted from the sap of Rhus succedanea. J Nat Prod 65: 1719 - 1721. https://doi.org/10.1021/np0201467

Wu CY, Ke Y, Zeng YF, Zhang YW, Yu HJ. 2017. Anticancer activity of Astragalus polysaccharide in human non-small cell lung cancer cells. Cancer Cell Int 17: 115. https://doi.org/10.1186\%2Fs12935-017-0487-6

Wu X, Li Q, Feng Y, Ji Q. 2018. Antitumor research of the active ingredients from Traditional Chinese Medical Plant Polygonum Cuspidatum. Evid Based Complement Alternat Med 2313021. https://doi.org/10.1155/2018/2313021

Xia EQ, Wang BW, Xu XR, Zhu L, Song Y, Li HB. 2011. Microwave-assisted extraction of oleanolic acid and ursolic acid from Ligustrum lucidum Ait. Int J Mol Sci 12: 5319 - 5329. https://doi.org/10.3390/ijms12085319

Xiang B, Yu X, Li B, Xiong Y, Long M, He Q. 2019. Characterization, antioxidant, and anticancer activities of a neutral polysaccharide from Duchesnea indica (Andr.) Focke. J Food Biochem 43: e12899. https://doi.org/10.1111/jfbc.12899

Xu W, Liu J, Li C, Wu HZ, Liu YW. 2008. Kaempferol-7-O-beta-D-glucoside (KG) isolated from Smilax china L. rhizome induces G2/M phase arrest and apoptosis on HeLa cells in a p53-independent manner. Cancer Lett 264: 229 - 240. https://doi.org/10.1016/j.canlet.2008.01.044

Yadav B, Bajaj A, Saxena M, Saxena AK. 2010. In vitro anticancer activity of the root, stem and leaves of Withania Somnifera against various human cancer cell lines. Ind J Pharm Sci 72: 659 - 663. https://doi.org/10.4103\%2F0250-474X.78543

Yang SF, Chu SC, Liu SJ, Chen YC, Chang YZ, Hsieh YS. 2007. Antimetastatic activities of Selaginella tamariscina (Beauv.) on lung cancer cells in vitro and in vivo. J Ethnopharmacol 110: 483 - 489. https://doi.org/10.1016/j.jep.2006.10.010

Yong YL, Tan LT, Ming LC, Chan KG, Lee LH, Goh BH, Khan TM. 2017. The effectiveness and safety of topical capsaicin in postherpetic neuralgia: a systematic review and meta-analysis. Front Pharm https://doi.org/10.3389/fphar.2016.00538

Yu PZ, Wang LP, Chen ZN. 1991. A new podophyllotoxin-type lignan from Dysosma versipellis var tomentosa. J Nat Prod 54: 1422 - 1424.

Yu J, Xian Y, Li G, Wang D, Zhou H, Wang X. 2017a. One new flavanocoumarin from the thorns of Gleditsia sinensis. Nat Prod Res 31: 275 - 280. https://doi.org/10.1080/14786419.2016.1233406

$\mathrm{Yu}$ S, Sheu HM, Lee CH. 2017b. Solanum incanum extract (SR-T100) induces melanoma cell apoptosis and inhibits established lung metastasis. Oncotarget 8: 103509 - 103517. https://doi.org/10.18632\%2Foncotarget.21508

Yuan XL, Mao XX, Du YM, Yan PZ, Hou XD, Zhang ZF. 2019. Anti-tumor activity of cembranoid-type diterpenes isolated from Nicotiana tabacum L. Biomolecules 9: 45. https://doi.org/10.3390\%2Fbiom9020045

Zalke AS, Kulkarni AV, Shirode DS, Duraiswamy B. 2010. In-vivo anticancer activity of Clerodendrum serratum (L) Moon. Res J Pharm Biol Chem Sci 1: 89 - 98.

Zhai X, Lenon G, Xue CCL, Li C. 2016. Euonymus alatus: A review on its phytochemistry and antidiabetic activity. Evid Based Complement Altern Med 1 - 12. https://doi.org/10.1155/2016/9425714

Zhang H, Wang X, Chen F, Androulakis XM, Wargovich MJ. 2007. Anticancer activity of limonoid from Khaya senegalensis. Phytother Res 21: 731 - 734. https://doi.org/10.1002/ptr.2148

Zhang D, Li K, Sun C, Cao G, Qi Y, Lin Z, Guo Y, Liu Z, Chen Y, Liu J, Cheng G, Wang P, Zhang L, Zhang J, Wen J, Xu D, Kong F, Zhao S. 2018. Anti-cancer effects of Paris polyphylla ethanol extract by inducing cancer cell apoptosis and cycle arrest in prostate cancer cells. Curr Urol 11: 144 - 150. https://doi.org/10.1159/000447209

Zhang XL, Wang BB, Mo JS. 2018. Puerarin 6"-O-xyloside possesses significant antitumor activities on colon cancer through inducing apoptosis. Oncol Lett 16: 5557 - 5564. https://doi.org/10.3892/ol.2018.9364 
Zhang Y, Zhang Y, Xu H. 2019. Effect of Codonopsis pilosula polysaccharides on the growth and motility of hepatocellular carcinoma HepG2 cells by regulating $\beta$-Catenin/TCF4 pathway. Int J Polym Sci 1 - 7. https://doi.org/10.1155/2019/7068437

Zhao Y, Wang CM, Wang BG, Zhang CX. 2005. Study on the anticancer activities of the Clematis manshrica saponins in vivo. China J Chin Mater Med 30: 1452 - 1453.

Zhao L, Li C, Zhang Y, Wen Q, Ren D. 2014. Phytochemical and biological activities of an anticancer plant medicine: Brucea javanica. Anticancer Agents Med Chem 14: 440 - 458. https://doi.org/10.2174/18715206113136660336

Zhao Q, Huo XC, Sun FD, Dong RQ. 2015. Polyphenol-rich extract of Salvia chinensis exhibits anticancer activity in different cancer cell lines, and induces cell cycle arrest at the $\mathrm{G}_{0} / \mathrm{G}_{1}$-phase, apoptosis and loss of mitochondrial membrane potential in pancreatic cancer cells. Mol Med Rep 12: 4843 - 4850. https://doi.org/10.3892\%2Fmmr.2015.4074

Zhao X, Feng X, Wang C, Peng D, Zhu K, Song JL. 2017. Anticancer activity of Nelumbo nucifera stamen extract in human colon cancer HCT-116 cells in vitro. Oncol Lett 13: 1470 - 1478. https://doi.org/10.3892\%2Fol.2016.5547

Zheng MS, Liu YS, Yuan T, Liu LY, Li ZY, Huang XL. 2020. Research progress on chemical constituents of Citrullus colocynthis and their pharmacological effects. Zhongguo Zhong Yao Za Zhi 45: 816 - 824. https://doi.org/10.19540/j.cnki.cjemm.20191104.201

Zi CT, Yang L, Xu FQ, Dong FW, Yang D, Li Y, Ding ZT, Zhou J, Jiang ZH, Hu JM. 2018. Synthesis and anticancer activity of dimeric podophyllotoxin derivatives. Drug Des Devel Ther 12: 3393 - 3406. https://doi.org/10.2147\%2FDDDT.S167382

Zips D, Thames HD, Baumann M. 2005. New anticancer agents: in vitro and in vivo evaluation. In vivo 19: 1 - 7. 